\title{
THE STRUCTURAL OPTIMIZATION OF [(2-R-QUINAZOLIN- 4-YLIDENE)HYDRAZONO]CARBOXYLIC ACIDS AND ESTERS - APPROACH FOR CREATING A NEW CLASS OF COMPOUNDS WITH THE ANTICANCER ACTIVITY
}

\author{
O.Yu.Voskoboynik ${ }^{\mathrm{a}}$, O.V.Karpenko ${ }^{\mathrm{b}}$, S.I.Kovalenko ${ }^{\mathrm{a}}$, G.G.Berest ${ }^{\mathrm{a}}$, V.V.Ivchuk ${ }^{\mathrm{c}}$, V.M.Shvets $^{\mathrm{a}}$
}

a Zaporizhzhia State Medical University

26, Mayakovsky ave., 69035, Zaporizhzhia, Ukraine. E-mail: kovalenkosergiy@gmail.com

${ }^{\mathrm{b}}$ Enamine Ltd (Ukraine)

${ }^{c}$ Kryvyi Rih Institute of Metallurgy of the Kryvyi Rih National University

Key words: quinazolines; structural optimization; anticancer; structure - activity relationship

\begin{abstract}
The strategies of the search of novel effective anticancer agents via optimization of [(2-R-quinazoline-4-ylydene) hydrazono]carboxylic acids and their esters are summarized in this article. To develop the most efficient synthetic approaches of initial substances the available information about chemical properties of [(2-R-quinazoline4-ylydene)hydrazono]carboxylic acids and their derivatives has been generalized and systematized. The basic approaches for optimization of the initial substances structure included variation of substituents in position 2 , creation and removal of conformational constraints and introduction of substituents into the cyclisation products. It has been shown that (3H-quinazoline-4-ylydene)hydrazine easily interacts with $\alpha, \beta, \gamma$-ketocarboxylic acids and their esters with formation of the corresponding hydrazonoderivatives. The given compounds are multicenter reagents, which are able to cyclize into the corresponding 3- $\mathrm{R}-2 \mathrm{H}-[1,2,4]$ triazino[2,3-c]quinazoline-2-ones. 3- $\mathrm{R}$ $2 \mathrm{H}-[1,2,4]$ triazino[2,3-c]quinazoline-2-ones are a class of electron-deficient heterocyclic systems and may be cleaved under the action of strong nuleophiles, in particular hydrazine, followed by formation of the corresponding 3-(2-aminophenyl)-6-R-1,2,4-triazine-5(2H)-ones or 3'-(2-aminophenyl)-3-R-spiro[pirazoline-5, 6' $\left(1^{\prime} H\right)-1,2,4-$ tiazine]-5'(4'H)-ones. A comparative description of spectral characteristics of the compounds synthesized has also been presented. The highest anticancer activities have been shown by compounds $2 c, 3 b$ and $3 c$ against leukemia cell lines CCRF-CEM (log $I_{50}=-6.10 ; 6.05 ; 5.81$, respectively), compound $3 \mathrm{~b}$ and $3 \mathrm{c}$ against breast cancer cell lines HS $578 T$ ( $\log \mathrm{GI}_{50}=-5.83 ;-6.43$, respectively). The results of SAR-analysis have been discussed and directions of further modification of the structures studied have been proposed.
\end{abstract}

СТРУКТУРНА ОПТИМІЗАЦІЯ [(2-R-ХІНАЗОЛІН-4-ІЛІДЕН)ГІДРАЗОНО]КАРБОНОВИХ КИСЛОТ ТА ЕСТЕРІВ - ПІДХІД ДО СТВОРЕННЯ НОВОГО КЛАСУ СПОЛУК З ПРОТИРАКОВОЮ ДІЄЮ

О.Ю.Воскобойнік, О.В.Карпенко, С.І.Коваленко, Г.Г.Берест, В.В.Івчук, В.М.Швець

Ключові слова: хіназоліни; структурна оптимізація; протираковий; взаємозв'язок структура - активність

Узагальнені стратегії пошуку нових ефективних протиракових агентів, засновані на структурній оптимізації [(2-R-хіназолін-4-іліден)гідразоно]карбонових кислот та їх естерів. Для розробки найбільш ефективних синтетичних напрямків модифрікації вихідних сполук проаналізовано та систематизовано наявний матеріал щодо хімічних властивостей [(2-R-хіназолін-4-іліден)гідразоно]карбонових кислот та їх похідних. Основні напрямки оптимізації структури вихідних сполук полягали у варіюванні замісників у положенні 2, накладанні та усуненні конорормаційних обмежень та введенні замісників у продукти їх циклізації. Показано, що ЗН-хіназолін-4-іліденгідразин легко взаємодіє з $\alpha, \beta, \gamma$-кетокарбоновими кислотами та їх естерами з утворенням відповідних гідразонопохідних. Зазначені сполуки являють собою мультицентрові реагенти та здатні до циклізацій у відповідні 3-R-2H-[1,2,4]триазино[2,3-с]хіназолін-2они. 3-R-2H-[1,2,4]триазино[2,3-с]хіназолін-2-они являють собою електронодефріцитну гетероциклічну систему та розщеплюються під дією сильних нуклеофілів, зокрема гідразину, з утворенням відповідних 3-(2-амінофеніл)-6-R-1, 2,4-триазин-5(2H)-онів або 3'-(2-амінофреніл)-3-R-спіро[піразолін-5, 6' (1'H)-1, 2, 4-mpuазин]-5'(4'H)-онів. Представлено порівняльний опис спектральних характеристик одержаних речовин. Найбільшу протиракову активність показали сполуки 2c, 3b та 3c по відношенню до клітин лейкемії лінії CCRF-CEM (log GI $50=-6.10 ; 6.05 ; 5.81$ відповідно), сполуки 3b та 3с-раку молочної залози HS 578T (log $I_{50}=-5.83 ;-6.43$ відповідно). Обговорені результати SAR-аналізу та запропоновані перспективні напрямки модифрікації описаних сполук з метою створення високоефективних протиракових агентів.

СТРУКТУРНАЯ ОПТИМИЗАЦИЯ [(2-R-ХИНАЗОЛИН-4-ИЛИДЕН)ГИДРАЗОНО]КАРБОНОВЫХ КИСЛОТ И ЭФИРОВ - ПОДХОД К СОЗДАНИЮ НОВОГО КЛАССА СОЕДИНЕНИЙ С ПРОТИВОРАКОВОЙ АКТИВНОСТЬЮ

А.Ю.Воскобойник, А.В.Карпенко, С.И.Коваленко, Г.Г.Берест, В.В.Ивчук, В.Н.Швец

Ключевые слова: хиназолины; структурная оптимизация; противораковый; взаимосвязь структура активность

Обобщены стратегии поиска новых эфрфективных противораковых агентов, которые основаны на структурной оптимизации [(2-R-хиназолин-4-илиден)гидразоно]карбоновых кислот и их эфиров. Для разработки наиболее эфрфективных синтетических направлений модификации исходных веществ проанализирован и систематизирован имеющийся материал относительно химических свойств [(2-R-хu- 
назолин-4-илиден)гидразоно]карбоновых кислот и их производных. Основные направления оптимизации структуры исходных веществ заключались в варьировании природы заместителя в положении 2, наложении и снятии конформационных ограничений и введении заместителей в продукты их циклизации. Показано, что ЗН-хиназолин-4-илиден)гидразин легко взаимодействует с $\alpha, \beta, \gamma$-кетокарбоновыми кислотами и их эфирами с образованием соответствующих гидразонопроизводных. Данные соединения представляют собой мультицентровые реагенты и способны циклизоваться в соответствующие 3-R-2H-[1, 2, 4]триазино[2, 3-с]хиназолин-2-оны. 3-R-2H-[1,2,4]триазино[2,3-c]хиназолин-2-оны представляют собой электронодефицитные системы и расщепляются под действием сильных нуклеофолов, в частности гидразина, с образованием соответствующих 3-(2-аминофенил)-6-R-1, 2, 4-mpuазин-5(2H)-онов или 3'-(2-аминофренил)-3-R-спиро[пиразолин-5, 6'(1'H)-1,2,4-триазин]-5'(4'H)-онов. Представлено сравнительное описание спектральных характеристик полученных веществ. Наибольшую противораковую активность показали соединения 2c, 3b та 3с по отношению к клеткам лейкемии CCRF-CEM (log GI ${ }_{50}=-6.10 ; 6.05 ; 5.81$ coответственно), соединения 3b и 3c-рака молочной железы HS $578 T$ ( $\log \mathrm{Gl}_{50}=-5.83 ;$-6.43 coответственно). Обобщены результаты SAR-анализа и предложены перспективные направления модифрикации описанных соединений с целью создания высокоэффрективных противораковых агентов.

Quinazoline derivatives have always attracted attention as a promising object of investigations aimed at designing novel effective medicines. This fact may be explained by a high biological activity of natural and synthetic quinazolines and wide possibilities of chemical modification of the given heterocyclic system. During last twenty years the interest to the class of compounds mentioned above has significantly increased as a result of revealing the anticancer activity among substituted 4-anilinoquinazolines $[5,6,15$, 18]. Now members of the series mentioned are well known as a reversible EGFR-mediated tyrosine kinase inhibitor and widely used in the treatment of non-small cell lung cancer, pancreatic cancer and some other oncology diseases. Obviously the medicines presented, as well as other anticancer drugs are far from perfect, there are a lot of side effects, contraindications and administration details that constrain their application in therapeutic regimens, therefore, the further design of quinazoline based anticancer agents with improved characteristics is of significant interest.

It is known that the search of novel bioactive agents among structural analogues of the existing drugs is a commonly used approach. Thus, we decided to search a new class of substances with the anticancer activity among 4-substituted quinazolines, namely [(2-Rquinazolin-4-ylidene)hydrazono]carboxylic acids and derived products. Our choice is based on the suppo- sition that combination of hydrazones of alkyl-(aryl-, heteryl-)carboxylic acids with the quinazoline fragment in one molecule, especially taken into account the broad antitumour potential of the latter, $[1,2,12$, 13 ] is a promising approach of finding new biologically active compounds.

Thus, the aim of this work is the purposeful search of anticancer agents in the range of [(2-R-quinazolin-4-ylidene)hydrazono]carboxylic acids based on the principles of the structural optimization of the molecule (Scheme 1) for detailed elaboration of the database and correlation of the "structure - antitumor activity".

\section{Results and Discussion}

\section{Chemistry}

At the first stage [(2-R-3H-quinazolin-4-ylidene) hydrazono]carboxylic acids and their esters $(\mathbf{2 a}-\mathbf{2} \mathbf{i}$, 3a-3g, Fig.) were synthesized by the interaction of ( $3 H$-quinazolin-4-ylidene)hydrazine (1.1) with $\alpha$-oxocarboxylic acids and their esters in propan-2-ol with short-term heating or at room temperature. Similarly, the reaction of compound $\mathbf{1 . 1}$ with $\gamma$-oxocarboxylic acids and their esters, namely the formation of hydrazones $\mathbf{2 j - 2} \mathbf{l}, \mathbf{3 h}-\mathbf{3 m}$, occurs (Scheme 2). Whereas, to obtain the corresponding acid, in case of the failure with $\beta$-ketoglutaric acid, regardless of the temperature conditions of the reaction (transient heating,

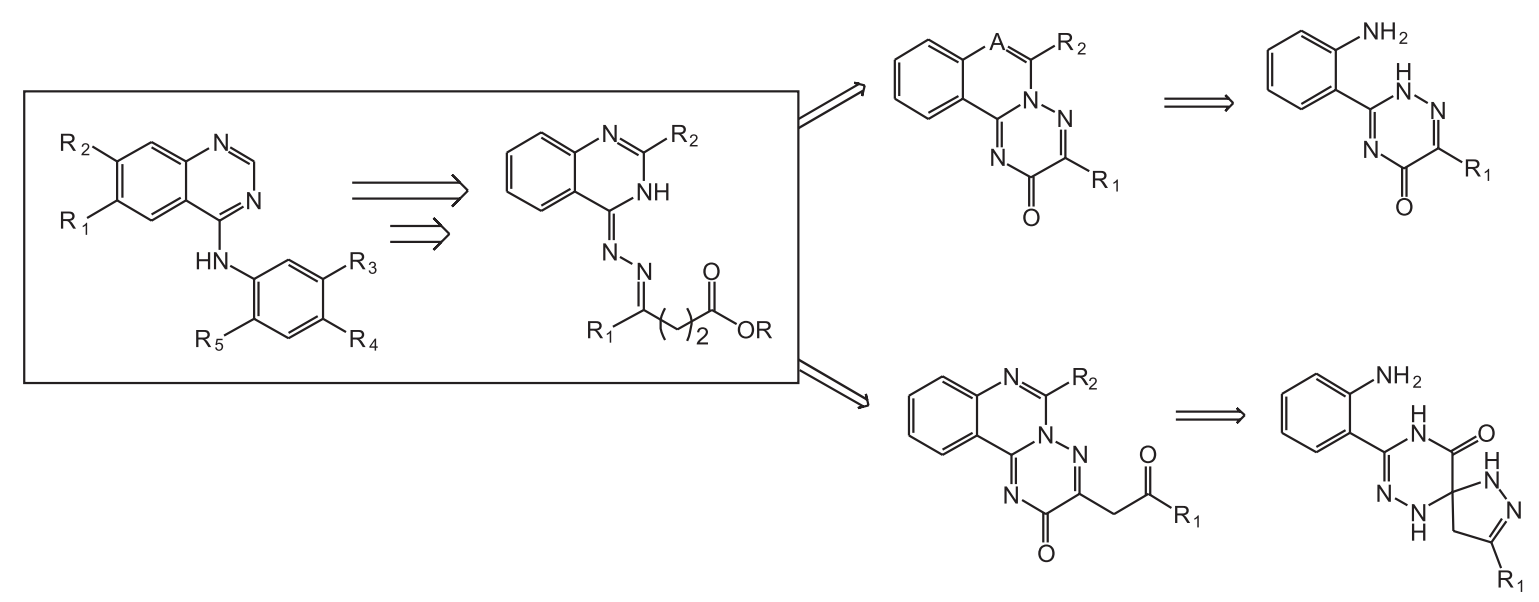

Scheme 1. Structures of quinazoline-based compounds and their medicinal chemistry optimization. 
2a R= $\mathrm{CH}_{3}, \mathrm{R}_{1}=\mathrm{H} ; 3 \mathrm{a} \mathrm{R}=\mathrm{CH}_{3}, \mathrm{R}_{1}=\mathrm{C}_{2} \mathrm{H}_{5}$;

2b R= $\mathrm{CH}_{2} \mathrm{CH}_{2} \mathrm{COOH}, \mathrm{R}_{1}=\mathrm{H}$

2c R=Bn, $\mathrm{R}_{1}=\mathrm{H} ; 3 \mathrm{bR}=\mathrm{Bn}, \mathrm{R}_{1}=\mathrm{C}_{2} \mathrm{H}_{5}$

2d R=4-NO $\mathrm{NO}_{2} \mathrm{Bn}, \mathrm{R}_{1}=\mathrm{H} ; 3 \mathrm{cR}=4-\mathrm{NO}_{2} \mathrm{Bn}, \mathrm{R}_{1}=\mathrm{C}_{2} \mathrm{H}_{5}$

2e R=Ph, $\mathrm{R}_{1}=\mathrm{H} ; \mathbf{3 d}=\mathrm{R}=\mathrm{Ph}, \mathrm{R}_{1}=\mathrm{C}_{2} \mathrm{H}_{5}$

2f R=4- $\mathrm{CH}_{3} \mathrm{Ph}, \mathrm{R}_{1}=\mathrm{H}$; 3eR=4- $\mathrm{CH}_{3} \mathrm{Ph}, \mathrm{R}_{1}=\mathrm{C}_{2} \mathrm{H}_{5}$

$2 \mathrm{~g} \mathrm{R}=4-\mathrm{CH}_{3} \mathrm{OPh}, \mathrm{R}_{1}=\mathrm{H} ; 3 \mathbf{e R}=4-\mathrm{CH}_{3} \mathrm{OPh}, \mathrm{R}_{1}=\mathrm{C}_{2} \mathrm{H}_{5}$

$\mathbf{2} \mathbf{h}=1,3,5$-trimethylpyrazol-4-yl, $\mathbf{R}_{\mathbf{1}}=\mathrm{H}$;

$2 \mathbf{i}=$ thiophen-2-yl, $\mathrm{R}_{1}=\mathrm{H} ; \mathbf{3 g}$ thiophen-2-yl, $\mathrm{R}_{1}=\mathrm{C}_{2} \mathrm{H}_{5}$

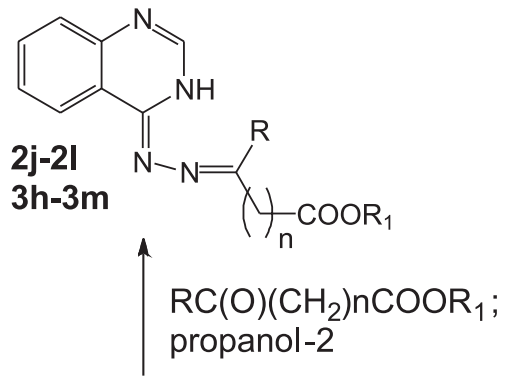

3h R $=\mathrm{CH}_{3}, \mathrm{R}_{1}=\mathrm{C}_{2} \mathrm{H}_{5}, \mathrm{n}=1$

3j R=furan-2-yl, $\mathrm{R}_{1}=\mathrm{C}_{2} \mathrm{H}_{5}, \mathrm{n}=1$

2j $\mathrm{R}=\mathrm{Ph}, \mathrm{R}_{1}=\mathrm{H}, \mathrm{n}=2$

3k R=Ph, $\mathrm{R}_{1}=\mathrm{C}_{2} \mathrm{H}_{5}, \mathrm{n}=2$

2k R=4- $\mathrm{CH}_{3} \mathrm{Ph}, \mathrm{R}_{1}=\mathrm{H}, \mathrm{n}=2$

3I $\mathrm{R}=4-\mathrm{CH}_{3} \mathrm{Ph}, \mathrm{R}_{1}=\mathrm{C}_{2} \mathrm{H}_{5}, \mathrm{n}=2$

2I $\mathrm{R}=4-\mathrm{CH}_{3} \mathrm{Ph}, \mathrm{R}_{1}=\mathrm{H}, \mathrm{n}=2$

$3 \mathrm{~m} \mathrm{R}=4-\mathrm{CH}_{3} \mathrm{OPh}, \mathrm{R}_{1}=\mathrm{C}_{2} \mathrm{H}_{5}, \mathrm{n}=2$<smiles>[R20]C(=O)/C([R])=N/N=c1\[nH]cnc2ccccc12</smiles>

\section{$\mathrm{RC}(\mathrm{O}) \mathrm{COOR}_{1}$ \\ propanol-2}
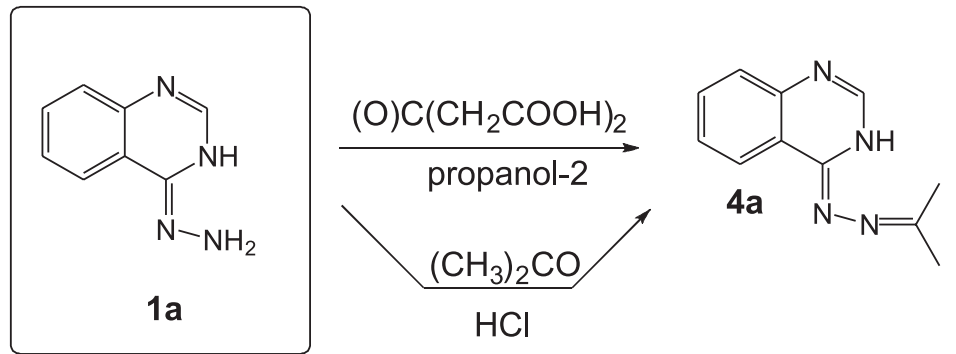

$2 m \mathrm{R}=4-\mathrm{CH}_{3} \mathrm{Ph}, \mathrm{R}_{1}=\mathrm{H}$

3n R=Ph, $\mathrm{R}_{1}=\mathrm{CH}_{3}$

3o $\mathrm{R}=4-\mathrm{CH}_{3} \mathrm{Ph}, \mathrm{R}_{1}=\mathrm{CH}_{3}$

$3 p \mathrm{R}=4-\mathrm{CH}_{3} \mathrm{OPh}, \mathrm{R}_{1}=\mathrm{CH}_{3}$

$3 q \mathrm{R}=$ thiophen-2-yl, $\mathrm{R}_{1}=\mathrm{CH}_{3}$

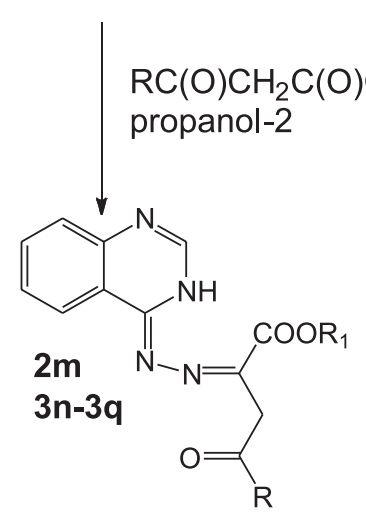

Scheme 2. Interaction of (3H-quinazolin-4-ylidene)hydrazine (1a) with oxocarboxylic and 2,4-diooxocarboxylic acids and their esters

room or $0-10^{\circ} \mathrm{C}$ temperature) and the reaction medium (ethanol, ethanol - water (1:1), propan-2-ol) $N$-Isopropylidene- $N$ '-(quinazolin-4(3H)-ylidene)hydrazine was the product of the reaction (4a, Scheme 2).

Under the given conditions hydrazine $1 \mathrm{a}$ reacts with 4-aryl-(heteryl-)-2,4-dioxobutanoic acids and their esters on the carbonyl group at $\mathrm{C}(2)$ atom, with the formation of the corresponding hydrazones $(2 \mathbf{m}$, $\mathbf{3 n}-\mathbf{3 q}$ ). It is important to note that these reactions should be carried out at room temperature because in more severe conditions a mixture of products is formed: the corresponding hydrazones $\mathbf{3 n - 3 q}$ and products of their heterocyclization - 3-[2-(het)aryl2-oxoethyl]-2H-[1,2,4] triazino[2,3-c]quinazolin-2ones (8a-8d).

The quinazoline moiety was replaced by the quinazoline-2-one cycle in order to enhance the antitumour activity of the compounds synthesized and guided by the principles of the molecule optimization. The abovementioned reconstruction of the molecule estimates involving all functional groups, which are contacting with the biological target, in the initial state, and at the same time it leads to a new polar molecule fragment that can participate in the formation of hydrogen with the active conformation of the protein.
It is important that the reactivity of 4-hydrazono- $1 H$-quinazolin-2-one (1b) with $\alpha$-, $\beta$ - and $\gamma$-oxocarboxylic acids and their esters in alcohols was slightly reduced and required acid catalysis. The low reactivity of compound $\mathbf{1 b}$ was apparently due to the decrease of nucleophilic properties of the hydrazine group caused by the electron-electron withdrawing effect of the carbonyl group at position 2. Appropriate 2-R-[(2-oxo-2,3-dihydro-1H-quinazolin-4-ylidene) hydrazono]carboxylic acids and their esters were the products of the reaction (5a-5h, $\mathbf{6 a - 6} \mathbf{j}$, Scheme 3). Interaction of compound $\mathbf{1 b}$ with 4 -aryl-(heteryl-)2,4-dioxobutanoic acids and their esters occurred in more severe conditions (DMF, acetic acid, 1,4-dioxane and the reaction time 1-2 $\mathrm{h}$ ) and regardless of the solvent used the corresponding hydrazones were formed (5i, 6k-6p, Scheme 3).

Conformational constraints were selected as the next step of the structural optimization implemented by one of the most common ways, namely cyclization, allowing to transform open side chains into cyclic fragments. The abovementioned modification explicitly led to significant changes in the spatial reorganization of the molecule. Therefore, it was logical to study cyclocondensation reactions of [(quinazo- 
5a R= $=\mathrm{CH}_{3}, \mathrm{R}_{1}=\mathrm{H} ; 6 \mathbf{a R}=\mathrm{CH}_{3}, \mathrm{R}_{1}=\mathrm{C}_{2} \mathrm{H}_{5}$; 5b R $=\mathrm{CH}_{2} \mathrm{CH}_{2} \mathrm{COOH}, \mathrm{R}_{1}=\mathrm{H}$ 6b R=Bn, $\mathrm{R}_{1}=\mathrm{C}_{2} \mathrm{H}_{5}$

5c $\mathrm{R}=4-\mathrm{NO}_{2} \mathrm{Bn}, \mathrm{R}_{1}=\mathrm{H} ; 6 \mathrm{c} \mathrm{R}=4-\mathrm{NO}_{2} \mathrm{Bn}, \mathrm{R}_{1}=\mathrm{C}_{2} \mathrm{H}_{5}$ 5d $\mathrm{R}=\mathrm{Ph}, \mathrm{R}_{1}=\mathrm{H} ; \mathbf{6 d}=\mathrm{R}=\mathrm{Ph}, \mathrm{R}_{1}=\mathrm{C}_{2} \mathrm{H}_{5}$

5e R=4- $\mathrm{CH}_{3} \mathrm{Ph}, \mathrm{R}_{1}=\mathrm{H} ; 6$ e R=4- $\mathrm{CH}_{3} \mathrm{Ph}, \mathrm{R}_{1}=\mathrm{C}_{2} \mathrm{H}_{5}$ 5f $\mathrm{R}=4-\mathrm{CH}_{3} \mathrm{OPh}, \mathrm{R}_{1}=\mathrm{H}$; $6 \mathrm{R}=4-\mathrm{CH}_{3} \mathrm{OPh}, \mathrm{R}_{1}=\mathrm{C}_{2} \mathrm{H}_{5}$ $\mathbf{5 g}=1,3,5$-trimethylpyrazol-4-yl, $\mathrm{R}_{1}=\mathrm{H}$;

$\mathbf{5 h}=$ thiophen-2-yl, $\mathrm{R}_{1}=\mathrm{H} ; \mathbf{6 g}$ thiophen-2-yl, $\mathrm{R}_{1}=\mathrm{C}_{2} \mathrm{H}_{5}$

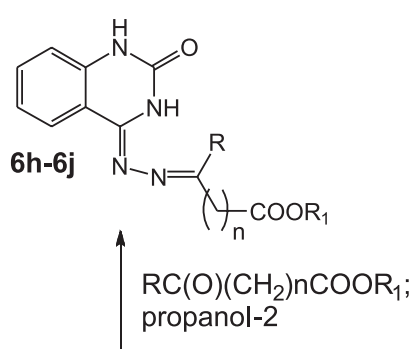

6h R $=\mathrm{CH}_{3} \mathrm{R}_{1}=\mathrm{C}_{2} \mathrm{H}_{5} \mathrm{n}=1$ 6i $\mathrm{R}=\mathrm{Ph}, \mathrm{R}_{1}=\mathrm{C}_{2} \mathrm{H}_{5}, \mathrm{n}=1$ 6j R=furan-2-yl, $\mathrm{R}_{1}=\mathrm{C}_{2} \mathrm{H}_{5}, \mathrm{n}=1$<smiles>[R20]C(=O)/C([R])=N/N=c1\[nH]c(=O)[nH]c2ccccc12</smiles><smiles>[R6]OCCOC(=O)O[R]</smiles><smiles>N/N=c1\[nH]c(=O)[nH]c2ccccc12</smiles>

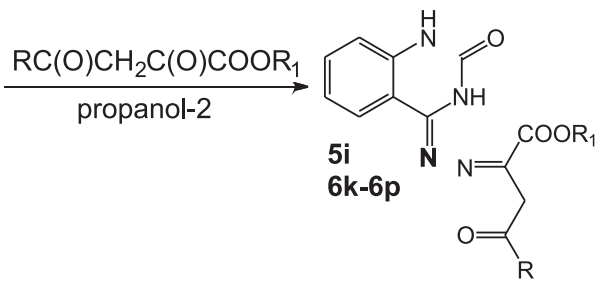

5i R=4- $\mathrm{CH}_{3} \mathrm{Ph}, \mathrm{R}_{1}=\mathrm{H}$

6k R=Ph, $\mathrm{R}_{1}=\mathrm{CH}_{3}$ 6I R=4- $\mathrm{CH}_{3} \mathrm{Ph}, \mathrm{R}_{1}=\mathrm{CH}_{3}$ $6 \mathrm{~m} \mathrm{R}=4-\mathrm{CH}_{3} \mathrm{OPh}, \mathrm{R}_{1}=\mathrm{CH}_{3}$ 6n $\mathrm{R}=4-\mathrm{ClOPh}, \mathrm{R}_{1}=\mathrm{CH}_{3}$ 6o R=furan-2-yl, $\mathrm{R}_{1}=\mathrm{CH}_{3}$ 6p R=thiophen-2-yl, $\mathrm{R}_{1}=\mathrm{CH}_{3}$

Scheme 3. Interaction of 4-hydrazono-1H-quinazolin-2-one (1b) with oxocarboxylic and 2,4-dioxocarboxylic acids and their esters.

lin-4(3H)-ylidene)hydrazono]carboxylic acids (2a-2m), esters (3a-3q) and [(2-oxo-2,3-dihydroquinazolin$4(1 H)$-ylidene)hydrazono] carboxylic acids (5a-5i), esters $(\mathbf{6 a - 6 p})$ for their further study as potential anticancer agents.

Esters $\mathbf{3 a - 3 g}, \mathbf{3 n}-\mathbf{3 q}$ quite easily gave cyclocondensation in the medium of glacial acetic acid with formation of 3-R-2H-[1,2,4] triazino[2,3-c] quinazolin-2-ones (7a-7g) and 3-[2-(het)aryl-2-oxoethyl]$2 H$-[1,2,4] triazino[2,3-c]quinazolin-2-ones (8a-8d), respectively (Scheme 4) $[7,8]$. In the case of esters 6a-6p, cyclocondensation was impossible due to re- duction of nucleophilicity of the quinazoline $\mathrm{N}_{3}$-atom caused by the electron-electron withdrawing effect of the neighbouring carbonyl group. Thus, we used a different strategy, namely the cyclocondensation of acids $(\mathbf{5 a}, \mathbf{5 d} \mathbf{- 5 f}, \mathbf{5 h}, \mathbf{2 c}-\mathbf{2 g}, \mathbf{2 i})$ in the corresponding 3-R-2H-[1,2,4] triazino[2,3-c]quinazoline-2,6(7H)diones (9a-9e) and 3-R-2H-[1,2,4] triazino[2,3-c]quinazoline-2-ones (7a-7g), via activating the carboxyl group with CDI in anhydrous dioxane or DMF (Scheme 4) $[11,16]$.

Following the above strategy of purposeful search of anticancer agents, we made further changes in the

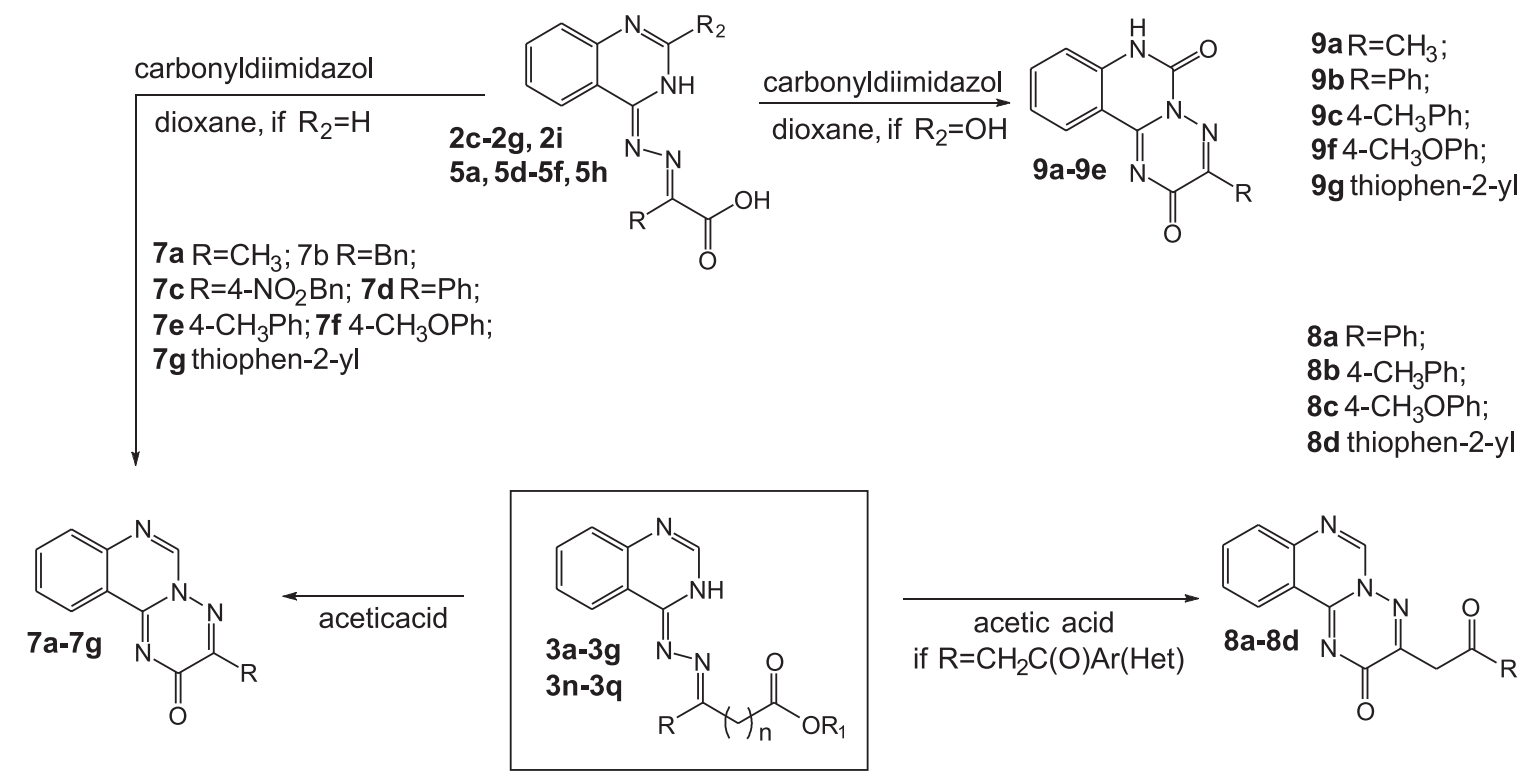

Scheme 4. Cyclocondensation of [(quinazolin-4(3H)-ylidene)hydrazono]carboxylic acids (2c-2g, 2i), esters (3a-3g, 3n-3q) and [(2-oxo-2,3-dihydroquinazolin-4(1H)-ylidene)hydrazono]carboxylic acids (5a, 5d-5f, 5h). 


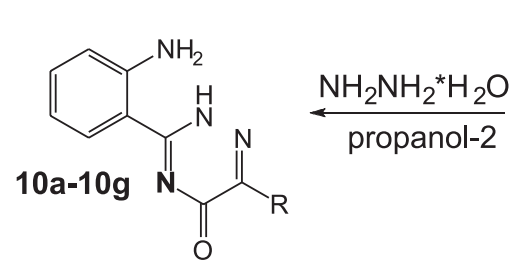

7a $\mathrm{R}=\mathrm{CH}_{3} ; 7 \mathbf{b} \mathrm{R}=\mathrm{Bn}$;

7c R=4- $\mathrm{NO}_{2} \mathrm{Bn} ; 7 \mathrm{~d} \mathrm{R}=\mathrm{Ph}$;

7e 4- $\mathrm{CH}_{3} \mathrm{Ph} ; 7 \mathrm{ff}$ 4- $\mathrm{CH}_{3} \mathrm{OPh}$;

$7 \mathrm{~g}$ thiophen-2-yl
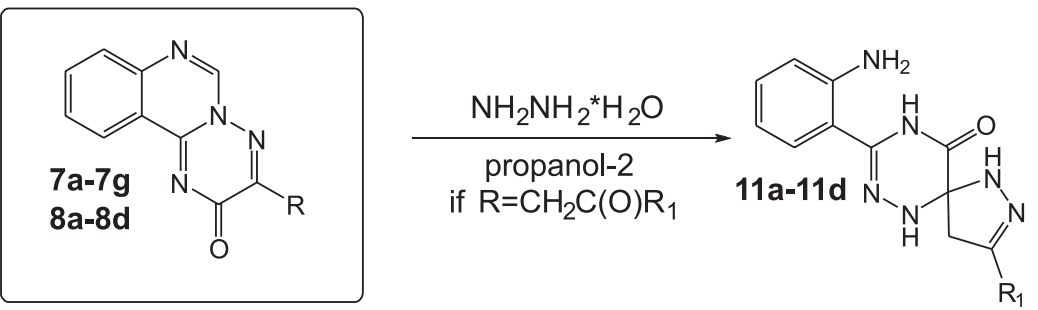

$8 \mathrm{a} \mathrm{R}=\mathrm{Ph}$;

8b 4- $\mathrm{CH}_{3} \mathrm{Ph}$;

8c 4- $\mathrm{CH}_{3} \mathrm{OPh}$;

8d thiophen-2-yl

Scheme 5. Nucleophilic degradation of 3-R-2H-[1,2,4]triazino[2,3-c]quinazoline-2-ones (7a-7g) and 3-[2-(het)aryl-2-oxoethyl]-2H-[1,2,4] triazino[2,3-c]quinazolin-2-ones (8a-8d).

molecule conformation of 3-R-2H-[1,2,4] triazino[2,3-c] quinazoline-2-ones (7a-7g) and 3-[2-(het)aryl-2-oxoethyl]-2H-[1,2,4] triazino[2,3-c]quinazolin-2-ones (8a8d). To solve this problem the well known methods [17], namely nucleophilic degradation of compounds $\mathbf{7 a - 7 g , ~ 8 a - 8 d ~ b y ~ h y d r a z i n e ~ h y d r a t e ~ i n ~ p r o p a n - 2 - o l ~}$ (Scheme 5), were used. The corresponding 3-(2-aminophenyl)-6-R-1,2,4-triazin-5(2H)-ones (10a-10e) were obtained as a result of interaction of compounds $7 \mathbf{a}-7 \mathbf{g}$ with the given nucleophile, while compounds 8a-8d formed 3'-(2-aminophenyl)-3-R-spiro[pyrazoline-5,6'(1'H)-1,2,4-triazin]-5'(4'H)-ones (11a-11d) [7]. It should be also noted that for the corresponding 3-R-2 $H$ - $[1,2,4]$ triazino [2,3-c] quinazoline-2,6(7H)diones $(\mathbf{9 a}-\mathbf{9 e})$ the reaction indicated failed.

The structure and purity of the compounds synthesized were confirmed by elemental analysis, ${ }^{1} \mathrm{H}$ and ${ }^{13} \mathrm{C}$ NMR, LS-MS and EI-MS data. Chromatography-mass spectrometry studies of compounds (2a2m, 3a-3q, 4a, 5a-5i, 6a-6p, 7a-7g, 8a-8d, 9a-9e, 10a-10g, 11a-11d) in the "soft' ionization (APCI) allowed to register in each case the peak of a quasimolecular ion $[\mathrm{M}+1]$, which had a high intensity and clearly demonstrated the individuality of the compounds synthesized.

According to the ${ }^{1} \mathrm{H}-\mathrm{NMR}$ spectra a broad singlet of NH-proton at low-field at 13.84-11.43 ppm and a set of signals of quinazoline protons were characteristic for compounds $\mathbf{2 a - 2 m}$ and $\mathbf{3 a - 3 q}$; it allowed to describe the substances studied as $3 \mathrm{H}$-tautomeric forms. It is important that enhydrazine-hydrazone tautomerism was characteristic for compounds 3a$\mathbf{3 c}, \mathbf{3 h}-\mathbf{3} \mathbf{j}$ in DMSO- $\mathrm{d}_{6}$. Thus, compound $\mathbf{3} \mathbf{i}$ had signals of $=\mathrm{NNH}$ - and $=\mathrm{C} H$-groups at 12.13 and $4.28 \mathrm{ppm}$, respectively, indicating its existence in the enhydrazine form. At the same time ${ }^{1} \mathrm{H}$ NMR spectra of com-

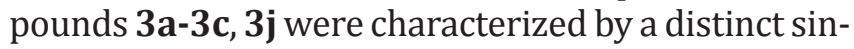
glet of $\mathrm{CH}_{2}$ signals at 3.96 and $3.94 \mathrm{ppm}$, respectively, suggesting the existence of the only hydrazone form of these compounds. Signals of enhydrazine and hydrazone forms in spectra of compound $\mathbf{3 h}$ in the ratio (1:1) were registered. Interestingly that compounds 3n-3q in DMSO- $\mathrm{d}_{6}$ existed as hydrazones, but with the characteristic different type of tautomerism keto-enol one. Thus, ${ }^{1} \mathrm{H}$ NMR spectra of compounds 3n-3q were characterized by a one-proton singlet of the $=\mathrm{CH}$-group for the enol form at 5.96-5.88 ppm and a two-proton singlet of $-\mathrm{CH}_{2}$-groups for the keto form at 4.56-4.55 ppm. In addition to these signals characterizing this tautomerism one could observed a one-proton singlet at low-field of the $=\mathrm{C}-\mathrm{OH}$ group at 13.72-13.44 ppm, doubled singlets of the imide proton (3-NH) and doubled singlets of aliphatic protons (the ratio of tautomers (1: 1).

Broad singlets in the low-field spectrum of two$\mathrm{NH}$ protons at 11.07-10.76 ppm ( $\mathrm{N}-1)$ and 10.729.49 ppm (N-3) were observed for compounds 5a5i, $6 \mathbf{a}-\mathbf{6} \mathbf{p}$ characterizing these compounds as- $1 H$, $3 \mathrm{H}$-tautomers. In addition, a diamagnetic shift of aromatic protons of the quinazoline cycle through the screening effect of the ureide moiety was observed for 2-oxoderivatives $\mathbf{5 a - 5 i}, \mathbf{6 a - 6}$. It is important that compounds $\mathbf{5 a - 5 i , ~} \mathbf{6 a}-\mathbf{6} \mathbf{p}$ exist as hydrazones, and only in case of compound $6 \mathrm{~h}$ doubled signals of $\mathrm{CH} / \mathrm{CH}_{2}-$ and $=\mathrm{N} / \mathrm{NH}$-groups have been recorded, indicating the enhydrazine-hydrazone tautomerism. It is interesting that introducing into the second position the acceptor group (oxygen) affects the keto-enol tautomerism of compounds $6 \mathbf{k}-\mathbf{6 p}$ in such a way that they exist only as keto derivatives.

${ }^{1} \mathrm{H}$ NMR spectra of compounds $\mathbf{7 a - 7} \mathbf{h}$ obtained by alternative methods had a characteristic singlet of $\mathrm{H}-6$ proton at $9.09-8.80 \mathrm{ppm}$ and a doublet of $\mathrm{H}-11$ at 8.67-8.52 ppm. It clearly confirms their structure and significantly differ them from compounds $\mathbf{3 a - 3 f}$. ${ }^{1} \mathrm{H}$ NMR spectra of compounds $\mathbf{8 a - 8 d}$ had a similar pattern and were characterized by a singlet of proton $\mathrm{H}-6$ in the region of 8.99-8.98 ppm and by a oneproton doublet of $\mathrm{H}-11$ at 8.55-8.59 ppm, whereas compounds 9a-9e had a one-proton doublet of H-11 due to the deshielding effect of the ureide fragment, which resonated in a weaker field at 8.29-8.27 ppm. Additionally, the compounds synthesized were characterized by a one-proton singlet of the phenacyl $\mathrm{CH}_{2}$ group at 4.58-4.52 ppm (compounds 8a-8d), by a broad singlet of the NH-group at 12.43-11.97 ppm 
(compounds 9a-9e). The ${ }^{13} \mathrm{C}$ NMR spectra were also in good agreement with the assigned structures of 7a-7h, 8a-8d and 9a-9e.

Comparing data of ${ }^{1} \mathrm{H}$ NMR-spectra of compounds

7a-7h and 8a-8d with compounds 10a-10f and 11a11d it should be noted the disappearance of a lowintensive singlet of proton $\mathrm{H}-6$ and the appearance of a two-proton signal of the $\mathrm{NH}_{2}$-group, which clearly indicated the pyrimidine ring degradation. The signals of the amino-group appeared as a broad twoproton singlet at 9.5-8.44 ppm (10a-10g) and 6.32$6.31 \mathrm{ppm}$ for compounds 11a-11d. The signal of NHproton of triazine and pyrazoline systems for compounds 11a-11d was detected in some cases as low intensive broad singlets. The diastereotopic hydrogens of the $\mathrm{CH}_{2}$-group of the pyrazoline ring (11a11d) appeared as two distinct doublets with ${ }^{3} J_{\mathrm{HH}}=$ 17.6 $\mathrm{Hz}$ in the range of 2.89-3.07 and 3.77-4.04 ppm.

Signals in ${ }^{13} \mathrm{C}$ NMR spectra correspond exactly to the proposed structure of the compounds synthesized 10a-10g. Characteristic signals caused by the C 5 atom of the triazine system were detected at 160.6$149.8 \mathrm{ppm}$. Signals of the spiro C-atom in ${ }^{13} \mathrm{C}$ NMR spectra of compounds 11a-11d were registered at 77.84-77.58 ppm serving as a reliable evidence of the spiro-heterocycles formation. The imine carbon $\mathrm{C}(3)$ of the pyrazoline ring was subjected to the influence of substituents in the het(aryl) ring and its signal was consequently predictably shifted in ${ }^{13} \mathrm{C}$ NMR spectra (148.26-147.58 ppm). The atom C(10) of the amide group was observed almost in the same region (163.45-164.08 ppm) as the corresponding one in the starting triazinoquinazolines.

The MS (EI) pattern is typical for this class of the heterocyclic system and is concerned mainly with the following processes. The basic direction of the molecular ions fragmentation of compounds $\mathbf{7 d - 7} \mathbf{i}$ was associated with the fragmentation of the $\mathrm{C}(2)$ $\mathrm{C}(3)$ and N(4)-N(5) and formation of fragments with $m / z$ 171. The aryl(heteryl)acyl moiety of compounds $\mathbf{8 c}$ and $\mathbf{8 d}$ was ruptured at the first stage, forming the characteristic $\mathrm{ArC} \equiv \mathrm{O}^{+}$ions. The second stage was concerned with C(2)-C(3) and N(4)-N(5) bond breaking of triazinoquinazoline, which gave the fragment ion with $\mathrm{m} / \mathrm{z} 171$ (8c) or $\mathrm{m} / \mathrm{z} 170$ (8d). The mass spectrum of compound $9 \mathrm{a}$ had a similar fragmentation of the molecular ion with compounds $7 \mathrm{~d}-7 \mathrm{~h}$ forming the ion $\mathrm{m} / \mathrm{z} 187$ due to the rupture of the $\mathrm{C}(2)-\mathrm{C}(3)$ and $\mathrm{N}(3)-\mathrm{N}(4)$.

Evaluation of the anticancer activity in vitro

Newly synthesized compounds were selected by the National Cancer Institute (NCI) Developmental Therapeutic Program (www.dtp.nci.nih.gov) for the in vitro cell line screening to investigate their anticancer activity. Anticancer assays were performed according to the US NCI protocol described elsewhere $[3,4,14]$. Compounds were firstly evaluated at one dose primary anticancer assay relative to approximately 60 cell lines (the concentration was $10 \mu \mathrm{M}$ ). The human tumour cell lines were derived from nine different cancer types: leukemia, melanoma, lung, colon, CNS, ovarian, renal, prostate and breast cancers. In the screening protocol, each cell line was inoculated and preincubated for 24-48 h on a microtiter plate. Test agents were then added at a single concentration, and the culture was incubated for further $48 \mathrm{~h}$. End point determinations were made with a protein binding dye, sulforhodamine B (SRB). Results for each agent tested were reported as the percent growth of the treated cells comparing to the untreated control cells. The preliminary screening results are shown in Tab. 1.

The screening of the compounds synthesized in the concentration of $10 \mu \mathrm{M}$ showed that individual cell lines had different sensitivity to the compounds synthesized. Thus, significant antitumour activity among the substances studied revealed compounds $\mathbf{2 c}, \mathbf{3 b}$ and 3c, which turned out to be active against most cancer cell lines (the mean growth, 62.92, 45.37, 47.94\%, respectively). Among these compounds, ethyl 3-phenyl-2-[quinazolin-4(3H)-ylidene-hydrazono]propanoate (3b) possessed a high cytotoxic effect against cell lines (CCRF-CEM, K-562, MOLT-4, RPMI -8226) of leukemia and a proliferative effect against cell lines (HL-60 (TB), SR) of leukemia (Fig.). In addition, these compound $\mathbf{3 b}$ had a wide spectrum of the antitumour activity in comparison with compounds $\mathbf{2 c}$ and $3 \mathrm{c}$ (Tab. 2).

According to the standard procedure the dose-dependent action in 5 concentrations of NCI at 59 cell lines of 9 types of cancer $(100 \mu \mathrm{M}-0.01 \mu \mathrm{M})$ was studied for compounds $\mathbf{2 c}$, $\mathbf{3 b}$ and $\mathbf{3 c}$. Three dose-dependent parameters were calculated during our study: 1) $\mathrm{GI}_{50}$ - the molar concentration of the compound that inhibited 50\% net cell growth; 2) TGI - the molar concentration of the compound leading to total inhibition of the cell growth; 3 ) $\mathrm{LC}_{50}$ - the molar concentration of the compound leading to $50 \%$ net cell death. If logarithmic data of the parameters studied $\left(\log \mathrm{GI}_{50}, \log \mathrm{TGI}\right.$ and $\log \mathrm{LC}_{50}$ ) were less than - 4.00, compounds were marked as active.

Parameters of the compound activity against the most sensitive cell lines are shown in Table $2\left(\log \mathrm{GI}_{50} \leq-5.60\right)$. It is necessary to mention the selective activity of compounds $2 \mathrm{c}, 3 \mathrm{~b}$ and $\mathbf{3} \mathrm{c}$ against cell lines of leukemia (CCRF-CEM), NSC lung cancer (NCI-H226). So, substances $\mathbf{2 c}, \mathbf{3 b}$ and $\mathbf{3 c}$ revealed the high level of inhibition against cell line CCRF-CEM of leukemia $\left(\log \mathrm{GI}_{50}=\right.$ $-6.10 ;-6.05 ;-5.81$, respectively). It is important that compounds $\mathbf{3 b}$ and $\mathbf{3} \mathbf{c}$ effectively inhibited the growth of cell lines HS 578T of breast cancer $\left(\log \mathrm{GI}_{50}=-5.83\right.$; -6.43 , respectively).

It is important that among the substances under research compound $\mathbf{3 . 2}$ has a high anticancer acti- 
Table 1

Anticancer screening data in the concentration of $10 \mu \mathrm{M}$

\begin{tabular}{|c|c|c|c|c|c|}
\hline \multirow[b]{2}{*}{ Compound } & \multicolumn{4}{|c|}{60 Cell lines assay in 1-dose $10 \mu \mathrm{M}$ conc. } & \multirow{2}{*}{$\begin{array}{c}\text { Active (selected } \\
\text { for } 5 \text {-dose } 60 \text { cell lines } \\
\text { assay) }\end{array}$} \\
\hline & $\begin{array}{c}\text { Mean } \\
\text { growth \% }\end{array}$ & $\begin{array}{l}\text { Range of } \\
\text { growth \% }\end{array}$ & $\begin{array}{c}\text { The most sensitive } \\
\text { cell line }\end{array}$ & $\begin{array}{c}\text { Growth \% of the most } \\
\text { sensitive cell line }\end{array}$ & \\
\hline $2 b$ & 111.15 & 82.86 to 149.71 & RPMI-8226/L & \begin{tabular}{|l|}
82.86 \\
\end{tabular} & Inactive \\
\hline $2 c$ & 62.92 & -24.95 to 123.65 & $\mathrm{SR} / \mathrm{L}$ & -24.95 & Active \\
\hline $2 e$ & 97.84 & -4.81 to 174.14 & HS 578T/BC & -4.81 & Inactive \\
\hline $2 \mathrm{~h}$ & 90.09 & 28.89 to 247.08 & OVCAR-3/OV & 28.89 & Inactive \\
\hline $2 \mathrm{i}$ & 100.48 & 53.43 to 154.20 & RXF 393/RC & 53.43 & Inactive \\
\hline $2 m$ & 105.64 & 79.30 to 140.70 & HOP-92/nscLC & 79.60 & Inactive \\
\hline $3 b$ & 45.37 & -30.08 to 85.34 & $\mathrm{SR} / \mathrm{L}$ & -30.08 & Active \\
\hline $3 c$ & 47.94 & -0.68 to 90.84 & BT-549/BC & -0.68 & Active \\
\hline $3 f$ & 102.05 & 66.50 to 135.41 & $786-0 / R C$ & 66.50 & Inactive \\
\hline $3 j$ & 94.90 & 23.66 to 130.35 & MDA-MB-468/BC & 23.66 & Inactive \\
\hline 30 & 99.47 & 60.99 to 159.34 & IGROV1/OV & 60.99 & Inactive \\
\hline $3 p$ & 105.67 & 48.38 to 208.57 & SNB-75/CNSC & 48.38 & Inactive \\
\hline $3 q$ & 109.96 & 25.14 to 140.72 & $\mathrm{SR} / \mathrm{L}$ & 25.14 & Inactive \\
\hline $5 \mathrm{~h}$ & 101.98 & 16.80 to 138.20 & UACC-257/M & 16.80 & Inactive \\
\hline $5 \mathrm{i}$ & 107.02 & 45.11 to 131.70 & HOP-62/nscLC & 45.11 & Inactive \\
\hline $6 j$ & 102.20 & 21.49 to 157.22 & MDA-MB-468/BC & 21.49 & Inactive \\
\hline 61 & 110.69 & -39.43 to 159.85 & 786-0/RC & -39.43 & Inactive \\
\hline $6 \mathrm{~m}$ & 107.26 & 78.70 to 143.99 & RPMI-8226/L & 78.70 & Inactive \\
\hline $6 n$ & 108.96 & 77.16 to 148.43 & RPMI-8226/L & 77.16 & Inactive \\
\hline $7 a$ & 99.23 & 69.07 to 170.33 & IGROV1/OV & 69.07 & Inactive \\
\hline $7 b$ & 95.04 & 10.25 to 16.54 & $\mathrm{NCl}-\mathrm{H} 522 / \mathrm{nscLC}$ & 10.25 & Inactive \\
\hline $7 c$ & 112.28 & 82.17 to 150.83 & HL-60(TB)/L & 82.17 & Inactive \\
\hline $7 d$ & 93.73 & -9.11 to 167.26 & HS 578T/BC & -9.11 & Inactive \\
\hline $7 f$ & 94.80 & $43.38-138.34$ & RXF 393/RC & 43.38 & Inactive \\
\hline $7 g$ & 92.99 & $41.66-134.16$ & IGROV1/OV & 41.66 & Inactive \\
\hline $8 a$ & 100.64 & $70.10-146.04$ & RXF 393/RC & 70.10 & Inactive \\
\hline $8 c$ & 102.44 & $68.90-163.27$ & IGROV1/OV & 68.90 & Inactive \\
\hline $9 a$ & 101.64 & $77.81-128.07$ & HOP-92/nscLC & 77.81 & Inactive \\
\hline $9 b$ & 105.44 & $85.91-137.18$ & SNB-75/CNSC & 85.91 & Inactive \\
\hline $9 c$ & 103.30 & $61.69-138.32$ & EKVX/nscLC) & 61.69 & Inactive \\
\hline $9 d$ & 105.10 & $64.32-183.56$ & $\mathrm{HL}-60(\mathrm{~TB}) / \mathrm{L}$ & 64.32 & Inactive \\
\hline $9 e$ & 106.53 & $73.83-298.40$ & HL-60(TB)/L & 73.83 & Inactive \\
\hline $10 a$ & 100.06 & $67.17-125.28$ & RPMI-8226/L & 67.17 & Inactive \\
\hline $10 \mathrm{~b}$ & 96.27 & $69.88-115.45$ & RPMI-8226/L & 69.88 & Inactive \\
\hline $10 c$ & 109.03 & $69.48-143.11$ & $\mathrm{HL}-60(\mathrm{~TB}) / \mathrm{L}$ & 69.48 & Inactive \\
\hline $10 \mathrm{e}$ & 102.36 & $23.98-129.53$ & UACC-257/M & 23.98 & Inactive \\
\hline $10 f$ & 100.91 & $27.48-133.38$ & UACC-257/M & 27.48 & Inactive \\
\hline $10 \mathrm{~g}$ & 103.34 & $63.19-146.15$ & CAKI-1/RC & 63.19 & Inactive \\
\hline $11 \mathrm{c}$ & 93.86 & $54.54-128.15$ & RPMI-8226/L & 54.54 & Inactive \\
\hline $11 d$ & 93.38 & $35.69-125.01$ & HCC-2998/ColC & 35.68 & Inactive \\
\hline
\end{tabular}

$\mathrm{a}-\mathrm{L}$ - leukemia, nscLC - non-small cell lung cancer, ColC - colon cancer, CNSC - CNS cancer, M - melanoma, OV- ovarian cancer, RC - renal cancer, PC - prostate cancer, $\mathrm{BC}$ - breast cancer. 
Table 2

The effect of compounds $2 \mathrm{c}, 3 \mathrm{~b}$ and $3 \mathrm{c}$ on the growth of individual tumour cell lines ( $\log \mathrm{Gl}_{50}<-5.60$ )

\begin{tabular}{|c|c|c|c|c|c|}
\hline Compd & Disease & Cell line & $\log \mathrm{Gl}_{50}$ & $\log \mathrm{TGl}$ & $\log L C_{50}$ \\
\hline \multirow{5}{*}{$2 c$} & \multirow{2}{*}{ Leukemia } & CCRF-CEM & -6.10 & -4.48 & $>-4.00$ \\
\hline & & HL-60(TB) & -5.64 & -5.11 & $>-4.00$ \\
\hline & NSC lung cancer & $\mathrm{NCl}-\mathrm{H} 226$ & -5.64 & -4.11 & $>-4.00$ \\
\hline & Ovarian Cancer & OVCAR-3 & -5.68 & -5.08 & $>-4.00$ \\
\hline & Prostate Cancer & DU-145 & -5.86 & $>-4.00$ & $>-4.00$ \\
\hline \multirow{8}{*}{$3 b$} & \multirow{3}{*}{ Leukemia } & CCRF-CEM & -6.05 & -5.06 & $>-4.00$ \\
\hline & & MOLT-4 & -5.66 & -4.15 & $>-4.00$ \\
\hline & & SR & -5.78 & -4.47 & $>-4.00$ \\
\hline & NSC lung cancer & $\mathrm{NCl}-\mathrm{H} 226$ & -5.61 & $>-4.00$ & $>-4.00$ \\
\hline & Colon Cancer & HCT-15 & -5.77 & $>-4.00$ & $>-4.00$ \\
\hline & Ovarian Cancer & IGROV1 & -5.70 & $>-4.00$ & $>-4.00$ \\
\hline & Renal cancer & UO-31 & -5.83 & $>-4.00$ & $>-4.00$ \\
\hline & Breast Cancer & HS 578T & -5.83 & -5.11 & $>-4.00$ \\
\hline \multirow{2}{*}{$3 c$} & Leukemia & CCRF-CEM & -5.81 & $>-4.00$ & $>-4.00$ \\
\hline & Breast Cancer & HS 578T & -6.43 & -5.29 & -4.26 \\
\hline
\end{tabular}

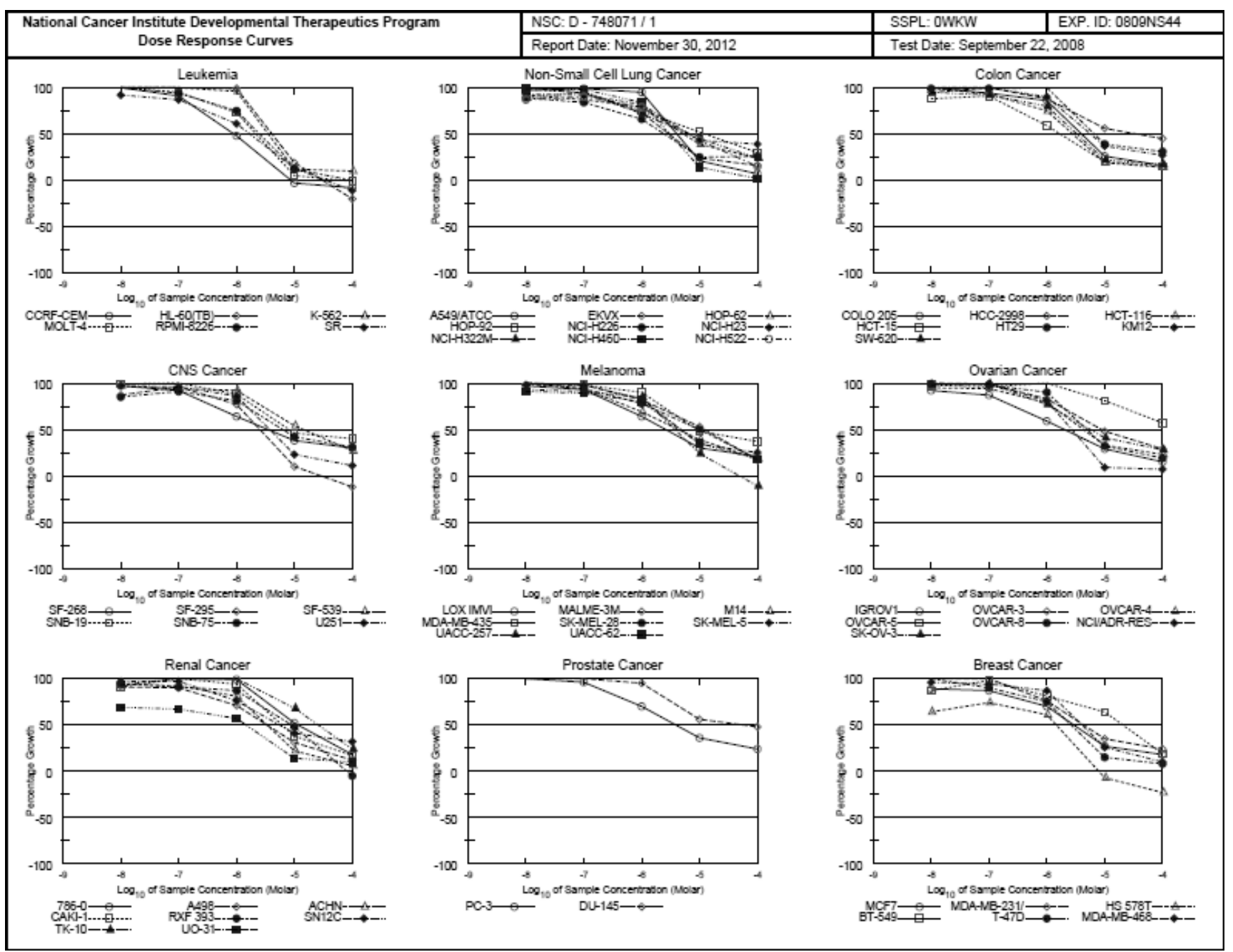

Fig. The effect of compound $\mathbf{3 . 2}$ on the growth of individual tumour cell lines. 
Table 3

The anticancer selectivity pattern

(the average value of $\operatorname{LogGl}_{50}$ ) of the most active compounds $2 \mathrm{c}, 3 \mathrm{~b}$ and $3 \mathrm{c}$

\begin{tabular}{|c|c|c|c|}
\hline \multirow{2}{*}{ Disease } & \multicolumn{3}{|c|}{ Compound } \\
\cline { 2 - 4 } & $2 \mathrm{c}$ & $3 \mathrm{~b}$ & $3 \mathrm{c}$ \\
\hline MGMID $(N)^{*}$ & $-5.14(59)$ & $-5.30(59)$ & $-5.13(59)$ \\
\hline $\mathrm{L}$ & $\mathbf{- 5 . 4 9}$ & $\mathbf{- 5 . 6 6}$ & -5.29 \\
\hline nscLC & -5.17 & $\mathbf{- 5 . 3 1}$ & -5.13 \\
\hline CoIC & -5.18 & $\mathbf{- 5 . 3 0}$ & -5.11 \\
\hline CNSC & -5.05 & -5.27 & -5.15 \\
\hline M & -5.06 & -5.25 & -4.99 \\
\hline OV & -5.23 & -5.18 & -5.04 \\
\hline RC & -5.03 & -5.23 & -5.05 \\
\hline PC & -4.26 & -4.81 & -4.97 \\
\hline BC & -5.27 & -5.40 & -5.36 \\
\hline
\end{tabular}

$*-N-$ is the number of sensitive cell lines against which the compound possessed a considerable growth inhibition according to the parameters $\log \mathrm{GI}_{50}$, $\log \mathrm{TGI}$ and $\log \mathrm{LC}_{50} \leq 4.00$.

vity against cell lines of leukemia (the average data $\operatorname{LogGI} I_{50}=-5.66$ ), NSC lung cancer (the average data $\operatorname{LogGI} I_{50}=-5.31$ ), colon cancer (the average data $\operatorname{LogGI} I_{50}=-5.30$ ) and breast cancer (the average data $\operatorname{LogGI}_{50}=-5.40$ ) (Tab. 3, Fig.).

\section{SAR Discussion}

The analysis of relationships between the chemical structure and the anticancer activity of the compounds synthesized showed that in most cases chemical modification aimed to the conformational constrains in molecules had a negative effect on the expression of the cytotoxic action. The transformation mentioned above allow changing significantly the sensitivity spectrum of compounds. However, the cyclization of [(2-R-3H-quinazolin-4-ylidene)hydrazono] carboxylic acids and their esters into the corresponding 3-R-2H-[1,2,4] triazino[2,3-c]quinazoline-2-ones in some cases had no effect on the antitumour action against HS 578T/BC (breast cancer) cell line. It may be explained by a determinative role of the presence of the quinazoline fragment for this type of action. Nucleophilic cleavage of the pyrimidine ring of 3-R$2 \mathrm{H}-[1,2,4]$ triazino[2,3-c]quinazoline-2-ones also cause the change of the activity spectrum. Thus, the most sensitive to 3-(2-aminophenyl)-6-R-1,2,4-triazin-5(2H)ones cell lines are RPMI-8226/L (Leukemia) and UACC-257/M (Melanoma).

\section{Experimental Protocols}

\section{Materials and Methods}

Melting points were determined in open capillary tubes and were uncorrected. The elemental analyses (C, H, N, S) were performed using an ELEMENTAR vario EL cube analyzer (USA). Analyses were indi- cated by the symbols of the elements or functions within $\pm 0.3 \%$ of the theoretical values. IR spectra (4000-600 $\mathrm{cm}^{-1}$ ) were recorded on a Bruker ALPHA FT-IR spectrometer (Bruker Bioscience, Germany) using a module for measuring attenuated total reflection (ATR). ${ }^{1} \mathrm{H}$ NMR spectra $(400 \mathrm{MHz})$ and ${ }^{13} \mathrm{C}$ NMR spectra (100 MHz): were recorded on VarianMercury 400 (Varian Inc., Palo Alto, CA, USA) spectrometers with TMS as an internal standard in DMSO- $d_{6}$ solution. LC-MS were recorded using chromatography/mass spectrometric system consisting of an "Agilent 1100 Series" high performance liquid chromatograph (Agilent, Palo Alto, CA, USA) equipped with a diode-matrix and an "Agilent LC/MSD SL" mass-selective detector (atmospheric pressure chemical ionization - APCI). Electron impact mass spectra (EI-MS) were recorded on a Varian $1200 \mathrm{~L}$ instrument at $70 \mathrm{eV}$ (Varian, USA). The purity of all the compounds obtained was checked by ${ }^{1} \mathrm{H}-\mathrm{NMR}$ and LC-MS.

Substances $\mathbf{1 a}$ and $\mathbf{1 b}$ were synthesized according to the reported procedures $[10,11]$. Other starting materials and solvents were obtained from commercially available sources and used without additional purification.

\section{Chemistry}

The general method of synthesis of [(quinazolin4(3H)-ylidene)hydrazono]carboxylic acids (2a-2m).

Add oxocarboxylic acid $(0.005 \mathrm{Mol})$ to the suspension of $0.8 \mathrm{~g}(0.005 \mathrm{Mol})$ of (quinazolin- $4(3 H)$-ylidene)hydrazine (1.1) in $15 \mathrm{ml}$ of propan-2-ol, boil the resulting mixture for 10-15 $\mathrm{min}$ (in case of $\gamma$-oxocarboxylic acid add 1 drop of hydrochloric acid and boil for 45-60 min; in case of 2,4-oxocarboxylic acids allow to stand at room temperature for $30 \mathrm{~min}$ ). Cool the mixture and dilute with water. Filter the precipitate formed and dry.

2-[Quinazolin-4(3H)-ylidenehydrazono]propanoic acid (2a). Yield - 82.6\%. M.p. - 206-208 ${ }^{\circ} \mathrm{C}$; ${ }^{1} \mathrm{H}-\mathrm{NMR}$, $\delta: 2.26\left(\mathrm{~s}, 3 \mathrm{H}, \mathrm{C}_{3}\right), 7.53(\mathrm{t}, 1 \mathrm{H}, \mathrm{H}-7), 7.62(\mathrm{~d}, 1 \mathrm{H}$, $\mathrm{H}-8), 7.78$ (t, 1H, H-6), 8.13 (s, 1H, H-2), 8.33 (d, 1H, $J=8.2 \mathrm{~Hz}, \mathrm{H}-5$ ), 12.00 (s, $1 \mathrm{H}, 3-\mathrm{N} H$ ); LC-MS, $m / z=230$ [M+1]; Anal. calcd. for $\mathrm{C}_{11} \mathrm{H}_{10} \mathrm{~N}_{4} \mathrm{O}_{2}$ : C, 57.39; $\mathrm{H}, 4.38$; $\mathrm{N}, 24.34$. Found: C, 57.38; H, 4.37; N, 24.38 .

2-[Quinazolin-4(3H)-ylidenehydrazono]pentanedioic acid (2b). Yield - 87.7\%. M.p. - 232-234 ${ }^{\circ} \mathrm{C} ;{ }^{1} \mathrm{H}$ NMR (400 MHz) $\delta: ~ 2.12$ (d, 4H, - $\left.\left(\mathrm{C}_{2}\right)_{2}-\right), 7.43(\mathrm{t}, 1 \mathrm{H}$, $\mathrm{H}-7$ ) , 7.55 (d, 1H, H-8), 7.68 (t, 1H, H-6), 7.93 (s, 1H, H-2), 8.03 (d, 1H, H-5), 12.34 (s, 1H, 3-N $\underline{H}$ ); LC-MS, $m / z=289$ [M+1]; Anal. calcd. for $\mathrm{C}_{13} \mathrm{H}_{12} \mathrm{~N}_{4} \mathrm{O}_{4}: \mathrm{C}, 57.17$; H, 4.20; N, 19.44; Found: C, 57.18; H, 4.17; N, 19.43 .

3-Phenyl-2-[quinazolin-4(3H)-ylidenehydrazono] propanoic acid (2c). Yield - 78.4\%. M.p. $-207-209^{\circ} \mathrm{C}$; ${ }^{1} \mathrm{H}-\mathrm{NMR}, \delta: 4.18\left(\mathrm{~s}, 2 \mathrm{H}, \mathrm{C}_{2}\right), 7.14(\mathrm{t}, 1 \mathrm{H}, J=7.0 \mathrm{~Hz}$, $\mathrm{H}-4 \mathrm{Ph}$ ), 7.23 (t, 2H, J=7.4 Hz, H-3, H-5 Ph), 7.29 (d, $2 \mathrm{H}, J=7.4 \mathrm{~Hz}, \mathrm{H}-2, \mathrm{H}-6 \mathrm{Ph}), 7.53$ (t, 1H, J=7.4 Hz, H-7), $7.61(\mathrm{~d}, 1 \mathrm{H}, J=8.2 \mathrm{~Hz}, \mathrm{H}-8), 7.77(\mathrm{t}, 1 \mathrm{H}, J=7.8 \mathrm{~Hz}, \mathrm{H}-6)$, 8.12 (s, 1H, H-2), 8.38 (d, 1H, J=8.0 Hz, H-5), 12.35 
(s, $1 \mathrm{H}, 3-\mathrm{N} \underline{H}$ ); LC-MS, $m / z=307$ [M+1]; Anal. calcd. for $\mathrm{C}_{17} \mathrm{H}_{14} \mathrm{~N}_{4} \mathrm{O}_{2}$ : C, 66.66; $\mathrm{H}, 4.61 ; \mathrm{N}, 18.29$. Found: $\mathrm{C}$, 66.68; H, 4.63; N, 18.31 .

3-(4-Nitrophenyl)-2-[quinazolin-4(3H)-ylidenehydrazono]propanoic acid (2d). Yield - 85.5\%. M.p. - 196-200 ${ }^{\circ} \mathrm{C} ;{ }^{1} \mathrm{H}-\mathrm{NMR}, \delta: 4.33$ (s, $2 \mathrm{H}, \mathrm{C}_{2}$ ), 7.56 (m, $3 \mathrm{H}, \mathrm{H}-7$ Quin, H-2, H-6 Ph), 7.64 (d, $1 \mathrm{H}, J=8.2 \mathrm{~Hz}$, $\mathrm{H}-8), 7.78(\mathrm{t}, 1 \mathrm{H}, J=8.0 \mathrm{~Hz}, \mathrm{H}-6), 8.10(\mathrm{~d}, 2 \mathrm{H}, J=7.6 \mathrm{~Hz}$, $\mathrm{H}-3, \mathrm{H}-5 \mathrm{Ph}$ ), 8.17 (s, $1 \mathrm{H}, \mathrm{H}-2$ ), 8.36 (d, $1 \mathrm{H}, J=7.8 \mathrm{~Hz}$, H-5); LC-MS, $m / z=352$ [M+1]; Anal. calcd. for $\mathrm{C}_{17} \mathrm{H}_{13} \mathrm{~N}_{5} \mathrm{O}_{4}$ : C, 58.12; H, 3.73; N, 19.93. Found: C, 58.14; H, 3.75; $\mathrm{N}, 19.91$.

Phenyl-[quinazolin-4(3H)-ylidenehydrazono]acetic acid (2e).Yield - 92.5\%. M.p. $-208-210^{\circ} \mathrm{C} ;{ }^{1} \mathrm{H}-\mathrm{NMR}$,

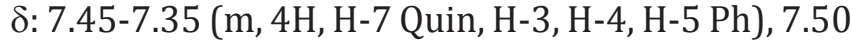
(d, 1H, J=8.2 Hz, H-8), 7.63 (t, 1H, J=6.8 Hz, H-6), 7.85 (s, 1H, H-2), 7.95-7.90 (m, 2H, H-2, H-6 Ph), 8.23 (d, $1 \mathrm{H}, J=7.6 \mathrm{~Hz}, \mathrm{H}-5$ ), 12.26 (s, 1H, 3-N $\underline{H}$ ); LC-MS, $m / z$ $=293$ [M+1]; Anal. calcd. for $\mathrm{C}_{16} \mathrm{H}_{12} \mathrm{~N}_{4} \mathrm{O}_{2}: \mathrm{C}, 65.75 ; \mathrm{H}$, 4.14; N, 19.17. Found: C, 65.74; H, 4.15; N, 19.19.

(4-Methylphenyl)-[quinazolin-4(3H)-ylidenehydrazono]acetic acid (2f). Yield $-88.1 \%$. M.p. $-194-196^{\circ} \mathrm{C}$; ${ }^{1} \mathrm{H}-\mathrm{NMR}, \delta: 2.38$ (s, 3H, $\underline{\mathrm{H}}_{3}$ ), 7.34 (d, $2 \mathrm{H}, J=7.9 \mathrm{~Hz}$, H-3, H-5 Ph), 7.47 (t, 1H, J=7.7 Hz, H-7), 7.55 (d, 1H, $J=7.7 \mathrm{~Hz}, \mathrm{H}-8), 7.71(\mathrm{t}, 1 \mathrm{H}, J=7.5 \mathrm{~Hz}, \mathrm{H}-6), 7.84(\mathrm{~d}, 2 \mathrm{H}$, $J=8.1 \mathrm{~Hz}, \mathrm{H}-2, \mathrm{H}-6 \mathrm{Ph}), 7.93$ (s, 1H, H-2), 8.13 (d, 1H, $J=7.7 \mathrm{~Hz}, \mathrm{H}-5$ ), 11.83 (s, 1H, 3-N $\underline{H}$ ); LC-MS, $m / z=307$ [M+1]; Anal. calcd. for $\mathrm{C}_{17} \mathrm{H}_{14} \mathrm{~N}_{4} \mathrm{O}_{2}$ : C, 66.66; $\mathrm{H}, 4.61$; $\mathrm{N}, 18.29$. Found: C, 66.67; H, 4.59; N, 18.27.

(4-Methoxyphenyl)-[quinazolin-4(3H)-ylidenehydrazono]acetic acid (2g). Yield - 86.8\%. M.p. - 184$186^{\circ} \mathrm{C} ;{ }^{1} \mathrm{H}-\mathrm{NMR}, \delta: 3.85$ (s, $3 \mathrm{H}, \mathrm{OC} \underline{H}_{3}$ ), 7.08 (d, $2 \mathrm{H}, \mathrm{J}=$ $8.9 \mathrm{~Hz}, \mathrm{H}-2, \mathrm{H}-6 \mathrm{Ph}), 7.46$ (t, 1H, J=7.7 Hz, H-7), 7.53 (d, 1H, J=8.3 Hz, H-8), 7.69 (t, 1H, J=7.9 Hz, H-6), 7.86 (d, 2H, J=8.9 Hz, H-3, H-5 Ph), 7.91 (s, 1H, H-2), 8.11 (d, $1 \mathrm{H}, J=7.5 \mathrm{~Hz}, \mathrm{H}-5$ ), 11.81 (s, $1 \mathrm{H}, 3-\mathrm{N} \underline{H}$ ); LC-MS, $m / z$ $=323[\mathrm{M}+1]$; Anal. calcd. for $\mathrm{C}_{17} \mathrm{H}_{14} \mathrm{~N}_{4} \mathrm{O}_{3}: \mathrm{C}, 63.35 ; \mathrm{H}$, 4.38; N, 17.38. Found: C, 63.34; H, 4.36; N, 17.35.

[Quinazolin-4(3H)-ylidenehydrazono] $(1,3,5-$ trimethyl-1H-pyrazol-4-yl)acetic acid (2h). Yield - 80.1\%. M.p. $-168-170{ }^{\circ} \mathrm{C} ;{ }^{1} \mathrm{H}-\mathrm{NMR}, \delta: 2.50$ (s, $6 \mathrm{H}, 3,5-\left(\mathrm{CH}_{3}\right)_{2}$, 3.72 (s, 3H, N-CH $\mathrm{CH}_{3}$, 7.75-7.35 (m, 3H, H-6, H-7, H-8), $8.08 / 7.99(\mathrm{~d}, 1 \mathrm{H}, J=7.5 \mathrm{~Hz}, \mathrm{H}-5), 8.47 / 8.28(\mathrm{~s}, 1 \mathrm{H}$, $\mathrm{H}-2$ ); LC-MS, $m / z=325$ [M+1]; Anal. calcd. for $\mathrm{C}_{16} \mathrm{H}_{16} \mathrm{~N}_{6} \mathrm{O}$ : C, 59.25; H, 4.97; N, 25.91. Found: C, 59.24; H, 4.96; $\mathrm{N}, 25.89$.

[Quinazolin-4(3H)-ylidenehydrazono](2-thienyl)acetic acid (2i). Yield $-80.5 \%$. M.p. $-166-168^{\circ} \mathrm{C} ;{ }^{1} \mathrm{H}-\mathrm{NMR}$, $\delta: 7.18(\mathrm{t}, 1 \mathrm{H}, J=4.4 \mathrm{~Hz}, \mathrm{H}-4 \mathrm{Th}$.), 7.60-7.48 (m, $2 \mathrm{H}$, H-6 Quin, H-5 Th.), 7.65 (d, 1H, J=2.5 Hz, H-8), 7.75 (d, 1H, H-3 Th.), 7.70 (t, 1H, J=7.1 Hz, H-6), 8.47/7.91 (d, 1H, J=8.9 Hz, H-5), 8.71/8.20 (s, 1H, H-2); LC-MS, $m / z=299$ [M+1]; Anal. calcd. for $\mathrm{C}_{14} \mathrm{H}_{10} \mathrm{~N}_{4} \mathrm{O}_{2} \mathrm{~S}$ : C, 56.37; H, 3.38; N, 18.78; S, 10.75. Found: C, 56.34; H, 3.36; N, 18.75; S, 10.74 .

4-Phenyl-4-[quinazolin-4(3H)-ylidenehydrazono]butanoic acid (2j). Yield - 62.5\%. M.p. - 196-198 C; LC-MS, $m / z=321$ [M+1]; Anal. calcd. for $\mathrm{C}_{18} \mathrm{H}_{16} \mathrm{~N}_{4} \mathrm{O}_{2}$ : $\mathrm{C}$, 67.49; H, 5.03; N, 17.49. Found: C, 67.51; H, 5.06; N, 17.52.

4-(4-Methylphenyl)-4-[quinazolin-4(3H)-ylidenehydrazono]butanoic acid (2k). Yield - 77.6\%. M.p. 208-210 ${ }^{\circ}$; ${ }^{1} \mathrm{H}-\mathrm{NMR}, \delta: 2.47$ (t, $2 \mathrm{H}, J=8.3 \mathrm{~Hz}, \mathrm{C}_{2} \mathrm{CH}_{2}-$ ), 2.35 (s, $3 \mathrm{H}, \mathrm{C}_{3}$ ), 3.29 (t, $2 \mathrm{H}, J=7.6 \mathrm{~Hz}, \mathrm{CH}_{2}-\mathrm{C}_{2}-$ ), 7.26 (d, 2H, J=8.3 Hz, H-3, H-5 Ph), 7.45 (t, $1 \mathrm{H}, J=8.1 \mathrm{~Hz}$, $\mathrm{H}-7), 7.52(\mathrm{~d}, 1 \mathrm{H}, J=7.8 \mathrm{~Hz}, \mathrm{H}-8), 7.66(\mathrm{t}, 1 \mathrm{H}, J=7.3 \mathrm{~Hz}$ H-6), 7.98 (m, 3H, H-2 Quin, H-2, H-6 Ph), 8.24 (d, 1H, $J=7.6 \mathrm{~Hz}, \mathrm{H}-5), 11.96(\mathrm{~s}, 1 \mathrm{H}, 3-\mathrm{N} \underline{H}), 12.06(\mathrm{~s}, 1 \mathrm{H}, \mathrm{COO} \underline{H})$; LC-MS, $m / z=335[\mathrm{M}+1]$; Anal. calcd. for $\mathrm{C}_{19} \mathrm{H}_{18} \mathrm{~N}_{4} \mathrm{O}_{2}$ : C, 68.25; H, 5.43; N, 16.76. Found: C, 68.27; H, 5.46; $\mathrm{N}, 16.78$.

4-(4-Methoxyphenyl)-4-[quinazolin-4(3H)-ylidenehydrazono]butanoic acid (21). Yield - 77.7\%. M.p. 228-230 ${ }^{\circ}$; LC-MS, $m / z=352$ [M+1]; Anal. calcd. for $\mathrm{C}_{19} \mathrm{H}_{18} \mathrm{~N}_{4} \mathrm{O}_{3}: \mathrm{C}, 65.13 ; \mathrm{H}, 5.18 ; \mathrm{N}, 15.99$. Found: C, 65.10; $\mathrm{H}, 5.16 ; \mathrm{N}, 15.93$.

4-Oxo-4-(methylphenyl)-2-[quinazolin-4(3H)-ylidenehydrazono]butanoic acid (2m). Yield - 91.9\%. M.p. - 222-224 ${ }^{\circ} \mathrm{C}$; LC-MS, m/z=349 [M+1]; Anal. calcd. for $\mathrm{C}_{19} \mathrm{H}_{16} \mathrm{NO}_{3}$ : C, 65.51; $\mathrm{H}, 4.63 ; \mathrm{N}, 16.08$. Found: $\mathrm{C}, 65.52$; $\mathrm{H}, 4.64 ; \mathrm{N}, 16.07$.

The general method of synthesis of methyl (ethyl)[(quinazolin-4(3H)-ylidenehydrazono]carboxilate (3a-3q).

Add ethyloxocarboxilate or methyl 2,4-dioxocarboxilate $(0.005 \mathrm{Mol})$ to the suspension of $0.8 \mathrm{~g}(0.005 \mathrm{Mol})$ of (3H-quinazolin-4-ylidene)hydrazine (1a) in $15 \mathrm{ml}$ of propan-2-ol, boil the resulting mixture for 45-60 min (in case of methyl 2,4-dioxocarboxilate keep at room temperature with stirring for 45-60 min). Cool the mixture dilute with water. Filter the precipitate formed and dry.

Ethyl 2-(quinazolin-4(3H)-ylidenehydrazono)propanoate (3a). Yield $-49.3 \%$. M.p. $-128-130^{\circ} \mathrm{C} ;{ }^{1} \mathrm{H}-\mathrm{NMR}$, $\delta: 1.38\left(\mathrm{t}, 3 \mathrm{H}, J=6.8 \mathrm{~Hz}, \mathrm{OCH}_{2} \mathrm{C}_{3}\right), 2.31\left(\mathrm{~s}, 3 \mathrm{H}, \mathrm{C}_{3}\right)$, $4.9\left(\mathrm{q}, 2 \mathrm{H}, J=7.0 \mathrm{~Hz}, \mathrm{OC} \underline{H}_{2} \mathrm{CH}_{3}\right), 7.36(\mathrm{t}, 1 \mathrm{H}, J=7.4 \mathrm{~Hz}$, $\mathrm{H}-7), 7.50(\mathrm{~d}, 1 \mathrm{H}, J=7.6 \mathrm{~Hz}, \mathrm{H}-8), 7.60(\mathrm{t}, 1 \mathrm{H}, J=8.4 \mathrm{~Hz}$, H-6), 7.86 (s, 1H, H-2), 8.32 (d, 1H, J=7.0 Hz, H-5), 11.43 (s, $1 \mathrm{H}, \mathrm{NH}$ ); LC-MS, $m / z=259$ [M+1]; Anal. calcd. for $\mathrm{C}_{13} \mathrm{H}_{14} \mathrm{~N}_{4} \mathrm{O}_{2}$ : C, 60.46; $\mathrm{H}, 5.46 ; \mathrm{N}, 21.69$. Found: $\mathrm{C}$, 60.43; H, 5.44; N, 21.65.

Ethyl 3-phenyl-2-[quinazolin-4(3H)-ylidenehydrazono]propanoate (3b). Yield - 64.3\%. M.p. $-118-120^{\circ} \mathrm{C}$; ${ }^{1} \mathrm{H}-\mathrm{NMR}, \delta: 1.25$ (t, 3H, J=6.8 Hz, OCH2C $\left.\underline{H}_{3}\right), 4.23(\mathrm{~m}$, $\left.4 \mathrm{H},-\underline{\mathrm{H}}_{2} \mathrm{Ph},-\mathrm{OC} \underline{\mathrm{H}}_{2} \mathrm{CH}_{3}\right), 7.51(\mathrm{~m}, 5 \mathrm{H}, \mathrm{H}-2, \mathrm{H}-3, \mathrm{H}-4$, $\mathrm{H}-5, \mathrm{H}-6 \mathrm{Ph}), 7.50(\mathrm{t}, 1 \mathrm{H}, J=7.0 \mathrm{~Hz}, \mathrm{H}-7), 7.57(\mathrm{~d}, 1 \mathrm{H}$, $J=7.4 \mathrm{~Hz}, \mathrm{H}-8), 7.73(\mathrm{t}, 1 \mathrm{H}, J=6.8 \mathrm{~Hz}, \mathrm{H}-6), 7.94(\mathrm{~s}, 1 \mathrm{H}$, $\mathrm{H}-2), 8.35$ (d, 1H, J=7.4 Hz, H-5), 11.53 (s, 1H, NH); LC-MS, $m / z=335[\mathrm{M}+1]$; Anal. calcd. for $\mathrm{C}_{19} \mathrm{H}_{18} \mathrm{~N}_{4} \mathrm{O}_{2}$ : C, 68.25; H, 5.43; N, 16.76. Found: C, 68.26; H, 5.46; $\mathrm{N}, 16.80$.

Ethyl 3-(4-nitrophenyl)-2-[quinazolin-4(3H)-ylidenehydrazono]propanoate (3c). Yield - 55.2\%. M.p. 108-110 ${ }^{\circ}$; ; ${ }^{1} \mathrm{H}-\mathrm{NMR}, \delta: 1.26\left(\mathrm{t}, 3 \mathrm{H}, J=7.4 \mathrm{~Hz}, \mathrm{OCH}_{2} \mathrm{CH}_{3}\right)$, $4.24\left(\mathrm{q}, 2 \mathrm{H}, J=6.0 \mathrm{~Hz}, \mathrm{OC} \underline{H}_{2} \mathrm{CH}_{3}\right), 4.37\left(\mathrm{~s}, 2 \mathrm{H}, \underline{\mathrm{C}}_{2} \mathrm{Ph}\right)$, 
7.53 (m, 3H, H-7 Quin, H-2, H-4 Ph), 7.60 (d, 1H, J= $7.8 \mathrm{~Hz}, \mathrm{H}-8), 7.76$ (t, 1H, J=6.4 Hz, H-6), 7.97 (s, 1H, H-2), 8.33 (d, 2H, J=8.0 Hz, H-3, H-5 Ph), 8.33 (d, 1H, $J=7.6 \mathrm{~Hz}, \mathrm{H}-5), 11.69$ (s, $1 \mathrm{H}, \mathrm{NH}$ ); LC-MS, $m / z=380$ $[\mathrm{M}+1]$; Anal. calcd. for $\mathrm{C}_{19} \mathrm{H}_{17} \mathrm{~N}_{5} \mathrm{O}_{4}$ : C, 60.15; $\mathrm{H}, 4.52$; N, 18.46. Found: C, 60.12; H, 4.51; N, 18.43.

Ethyl phenyl-[quinazolin-4(3H)-ylidenehydrazono] acetate (3d). Yield - 78.8\%. M.p. $-182-184^{\circ} \mathrm{C} ;{ }^{1} \mathrm{H}-\mathrm{NMR}$, $\delta: 1.45$ (s, 3H, OCH${ }_{2} \underline{\mathrm{H}}_{3}$ ), 4.29 (q, 2H, OC $\underline{H}_{2} \mathrm{CH}_{3}$ ), 7.527.44 (m, 5H, H-7, H-8 Quin, H-3, H-5 Ph), 7.71 (t, 1H, H-6), 7.92-7.85 (m, 2H, H-2, H-6 Ph), 7.94 (s, 1H, H-2), 8.12 (d, 1H, H-5), 11.86 (s, 1H, NH); LC-MS, $m / z=321$ $[\mathrm{M}+1]$; Anal. calcd. for $\mathrm{C}_{18} \mathrm{H}_{16} \mathrm{~N}_{4} \mathrm{O}_{2}$ : C, 67.49; $\mathrm{H}, 5.03$; N, 17.49. Found: C, 67.47; H, 5.01; N, 17.47 .

Ethyl (4-methylphenyl)-[quinazolin-4(3H)-ylidenehydrazono]acetate (3e). Yield - 86.1\%. M.p. - 146$148^{\circ} \mathrm{C} ;{ }^{1} \mathrm{H}-\mathrm{NMR}, \delta: 1.44\left(\mathrm{t}, 3 \mathrm{H}, \mathrm{J}=7.2 \mathrm{~Hz}, \mathrm{OCH}_{2} \mathrm{CH}_{3}\right)$, 3.42 (s, 3H, $\underline{\mathrm{H}}_{3}$ ), 4.45 (q, $2 \mathrm{H}, J=6.9 \mathrm{~Hz}, \mathrm{OC}_{2} \mathrm{CH}_{3}$ ), 7.22 (d, 2H, J=7.7 Hz, H-3, H-5 Ph), 7.33 (t, 1H, J=7.9 Hz $\mathrm{Hz}, \mathrm{H}-7$ ), 7.47 (d, 1H, J=8.5 Hz, H-8), 7.57 (t, 1H, J= $7.2 \mathrm{~Hz}, \mathrm{H}-6), 7.72$ (d, 2H, J=7.2 Hz, H-2, H-6 Ph), 7.89 (s, 1H, H-2), 8.12 (d, 1H, J=8.4 Hz, H-5), 11.80 (s, 1H, $\mathrm{NH}$ ); LC-MS, $m / z=335$ [M+1]; Anal. calcd. for $\mathrm{C}_{19} \mathrm{H}_{18} \mathrm{~N}_{4} \mathrm{O}_{2}$ : C, 68.25; H, 5.43; N, 16.76. Found: C, 68.27; H, 5.47; $\mathrm{N}, 16.74$.

Ethyl (4-methoxyphenyl)-[quinazolin-4(3H)-ylidenehydrazono]acetate (3f). Yield - 65.1\%. M.p. - 196$198^{\circ} \mathrm{C} ;{ }^{1} \mathrm{H}-\mathrm{NMR}, \delta: 1.35\left(\mathrm{t}, 3 \mathrm{H}, J=7.1 \mathrm{~Hz}, \mathrm{OCH}_{2} \mathrm{CH}_{3}\right)$, $3.83\left(\mathrm{~s}, 3 \mathrm{H}, \mathrm{OC} \underline{H}_{3}\right), 4.42\left(\mathrm{q}, 2 \mathrm{H}, \mathrm{J}=7.1 \mathrm{~Hz}, \mathrm{OC} \underline{H}_{2} \mathrm{CH}_{3}\right)$, $7.04(\mathrm{~d}, 2 \mathrm{H}, \mathrm{J}=8.4 \mathrm{~Hz}, \mathrm{H}-3, \mathrm{H}-5 \mathrm{Ph}), 7.43$ (t, 1H, J=6.8 Hz, H-7), 7.51 (d, 1H, J=8.1 Hz, H-8), 7.67 (t, 1H, J=7.6 Hz, H-6), 7.81 (d, 2H, J=8.8 Hz, H-2, H-6 Ph), 7.82 (s, 1H, H-2), 8.06 (d, 1H, J=7.8 Hz, H-5), 11.58 (s, 1H, NH); LC-MS, $m / z=351[\mathrm{M}+1]$; Anal. calcd. for $\mathrm{C}_{19} \mathrm{H}_{18} \mathrm{~N}_{4} \mathrm{O}_{3}$ : C, 65.13; H, 5.18; N, 15.99. Found: C, 65.12; H, 5.17; N, 15.94.

Ethyl [quinazolin-4(3H)-ylidenehydrazono](2-thienyl)acetate (3g). Yield - 75.5\%. M.p. - 100-102 ${ }^{\circ} \mathrm{C}$; ${ }^{1} \mathrm{H}-\mathrm{NMR}, \delta: 1.37$ (t, 3H, J=7.1 Hz, $\mathrm{OCH}_{2} \underline{\mathrm{H}}_{3}$ ), 4.41 (q, $2 \mathrm{H}, J=7.2 \mathrm{~Hz}, \mathrm{OC} \underline{H}_{2} \mathrm{CH}_{3}$ ), 7.19 (t, $\left.1 \mathrm{H}, J=4.0 \mathrm{~Hz}, \mathrm{H}-7\right)$, 7.59 (m, 3H, H-8 Quin., H-4, H-5 Th.), 7.77 (t, 1H, J=7.2 Hz, H-6), 7.94 (m, 2H, H-2 Quin, H-3 Th.), 8.49 (d, 1H, J=7.1 Hz, H-5), 11.88 (s, 1H, NH); LC-MS, $m / z$ $=327$ [M+1]; Anal. calcd. for $\mathrm{C}_{16} \mathrm{H}_{14} \mathrm{~N}_{4} \mathrm{O}_{2} \mathrm{~S}$ : C, 58.88; H, 4.32; N, 17.17, S, 9.82. Found: C, 58.85; H, 4.29; N, 17.14; S, 9.79.

Ethyl 3-[quinazolin-4(3H)-ylidenehydrazono]butanoate (3h). Yield - 91.8\%. M.p. $-168-170^{\circ} \mathrm{C} ;{ }^{1} \mathrm{H}-\mathrm{NMR}$, $\delta: 1.17\left(\mathrm{t}, 3 \mathrm{H}, \mathrm{CH}_{2}-\underline{\mathrm{C}}_{3}\right), 2.12\left(\mathrm{~s}, 3 \mathrm{H}, \mathrm{C}_{3}\right), 4.12 / 3.99$ (q, 2H, $\underline{\mathrm{C}}_{2}-\mathrm{CH}_{3}$ ), 4.42/4.12 (s, $1 \mathrm{H}, \mathrm{C} \underline{\mathrm{H}} / \mathrm{CH}_{2}$ ), 7.61/724 (t, 1H, H-7), 7.38/7.12 (d, 1H, H-8), 7.72/7.43 (t, 1H, H-6), 8.18/7.88 (s, 1H, H-2), 8.06/7.81 (d, 1H, H-5), 11.46/11.22 (s, 1H, 3-NH), 13.84 (s, 1H, =NN트); LC-MS, $m / z=272[\mathrm{M}+1]$; Anal. calcd. for $\mathrm{C}_{14} \mathrm{H}_{16} \mathrm{~N}_{4} \mathrm{O}_{2}$ : C, 61.75; H, 5.92; N, 20.57. Found: C, 61.78; H, 5.96; N, 20.59.

Ethyl 3-phenyl-3-[quinazolin-4(3H)-ylidenehydrazono]propanoate (3i). Yield - 83.3\%. M.p. - 192-194 ${ }^{\circ}$; ${ }^{1} \mathrm{H}-\mathrm{NMR}, \delta: 1.26$ (t, 3H, $\mathrm{CH}_{2}-\mathrm{C}_{3}$ ), $4.28\left(\mathrm{q}, 2 \mathrm{H}, \mathrm{C}_{2}-\mathrm{CH}_{3}\right)$, $4.38(\mathrm{~s}, 1 \mathrm{H},=\mathrm{C} \underline{H}), 7.50-7.30(\mathrm{~m}, 5 \mathrm{H}, \mathrm{H}-5, \mathrm{H}-6$ Quin, H-3, H-4, H-5 Ph), 7.58 (t, 1H, H-6); 7.98 (s, 2H, H-2, H-6 Ph), 7.82 (s, 1H, H-2), 8.21 (d, 1H, H-5), 11.43 (s, 1H, 3-NH), 12.13 (s, 1H, =NN $\underline{H}$ ); LC-MS, $m / z=335$ [M+1]; Anal. calcd. for $\mathrm{C}_{19} \mathrm{H}_{18} \mathrm{~N}_{4} \mathrm{O}_{2}$ : C, 68.25; $\mathrm{H}, 5.43$; N, 16.76. Found: C, 68.27; H, 5.46; N, 16.79.

Ethyl 3-(2-furyl)-3-[quinazolin-4(3H)-ylidenehydrazono]propanoate (3j). Yield - 55.5\%. M.p. - 158$160^{\circ} \mathrm{C}$; ${ }^{1} \mathrm{H}-\mathrm{NMR}, \delta: 1.10\left(\mathrm{t}, 3 \mathrm{H}, J=7.1 \mathrm{~Hz}, \mathrm{OCH}_{2} \mathrm{C}_{3}\right)$, $3.96\left(\mathrm{~s}, 2 \mathrm{H}, \mathrm{CH}_{2}\right), 4.03\left(\mathrm{q}, 2 \mathrm{H}, \mathrm{J}=7.1 \mathrm{~Hz}, \mathrm{OC}_{2} \mathrm{CH}_{3}\right), 6.67$ (t, 1H, J=1.7 Hz, H-4 Fur), 7.21 (d, 1H, J=3.2 Hz, H-3 Fur), 7.42 (t, 1H, J=8.0 Hz, H-7), 7.49 (d, 1H, J=8.1 Hz, H-8), 7.65 (t, 1H, J=8.1 Hz, H-6), 7.84 (s, 1H, H-5 Fur), 7.88 (s, 1H, H-2), 8.13 (d, 1H, J=8.1 Hz, H-5), 11.54 (s, 1H, 3-NH); LC-MS, $m / z=325[\mathrm{M}+1]$; Anal. calcd. for $\mathrm{C}_{17} \mathrm{H}_{16} \mathrm{~N}_{4} \mathrm{O}_{3}$ : C, 62.95; $\mathrm{H}, 4.97 ; \mathrm{N}, 17.27$. Found: $\mathrm{C}$, 62.93; H, 4.92; N, 17.24.

Ethyl 4-phenyl-4-[quinazolin-4(3H)-ylidenehydrazono]butanoate (3k). Yield - 52.3\%; oil; LC-MS, $m / z$ $=349[\mathrm{M}+1]$; Anal. calcd. for $\mathrm{C}_{20} \mathrm{H}_{20} \mathrm{~N}_{4} \mathrm{O}_{2}$ : C, 68.95; $\mathrm{H}$, 5.79; N, 16.08. Found: C, 68.97; H, 5.81; N, 16.11.

Ethyl 4-(4-methylphenyl)-4-[quinazolin-4(3H)-ylidenehydrazono]butanoate (31). Yield - 48.0\%. M.p. 166-168 ${ }^{\circ} \mathrm{C} ;{ }^{1} \mathrm{H}-\mathrm{NMR}, \delta: 1.11\left(\mathrm{t}, 3 \mathrm{H}, \mathrm{J}=7.1 \mathrm{~Hz}, \mathrm{OCH}_{2} \mathrm{C}_{3}\right)$, 2.49 (t, 2H, J=7.8 Hz, $\underline{\mathrm{H}}_{2} \mathrm{CH}_{2} \mathrm{CO}$ ), 2.54 (t, $2 \mathrm{H}, J=7.8 \mathrm{~Hz}$, $\mathrm{CH}_{2} \mathrm{CH}_{2} \mathrm{CO}$ ), $2.58\left(\mathrm{~s}, 3 \mathrm{H}, \mathrm{CH}_{3}\right), 4.00(\mathrm{q}, 2 \mathrm{H}, J=7.1 \mathrm{~Hz}$, $\mathrm{OCH}_{2} \mathrm{CH}_{3}$ ), 6.98 (d, 2H, J=8.8 Hz, H-3, H-5 Ph), 7.41 (t, $1 \mathrm{H}, J=7.6 \mathrm{~Hz}, \mathrm{H}-7), 7.47$ (d, 1H,J=7.6 Hz, H-8), 7.63 (t, 1H, $J=7.8 \mathrm{~Hz}, \mathrm{H}-6), 7.83$ (s, 1H, H-2), 8.00 (d, 2H, J=7.3 Hz, H-2, H-6 Ph), 8.20 (d, 1H, J=7.8 Hz, H-5), 11.40 (s, 1H, $\mathrm{NH}$ ); Anal. calcd. for $\mathrm{C}_{21} \mathrm{H}_{22} \mathrm{~N}_{4} \mathrm{O}_{2}: \mathrm{C}, 69.59 ; \mathrm{H}, 6.12 ; \mathrm{N}$, 15.46. Found: C, 69.57; H, 6.10; N, 15.43.

Ethyl 4-(4-methoxyphenyl)-4-[quinazolin-4(3H)ylidenehydrazono]butanoate (3m). Yield - 52.9\%. M.p. $-162-164^{\circ} \mathrm{C} ;{ }^{1} \mathrm{H}-\mathrm{NMR}, \delta: 1.12\left(\mathrm{t}, 3 \mathrm{H}_{3}, J=7.1 \mathrm{~Hz}\right.$, $\mathrm{OCH}_{2} \mathrm{C} \underline{\mathrm{H}}$ ), 2.49 (t, 2H, J=7.8 Hz, $\left.\mathrm{CH}_{2} \mathrm{CH}_{2}-\mathrm{CO}\right), 2.54$ (t, $2 \mathrm{H}, J=7.8 \mathrm{~Hz}, \mathrm{CH}_{2} \mathrm{C}_{2} \mathrm{CO}$ ), 3.53 (s, $3 \mathrm{H}, \underline{\mathrm{C}}_{3}$ ), 4.00 (q, $2 \mathrm{H}, J=7.1 \mathrm{~Hz}, \mathrm{OC} \underline{H}_{2} \mathrm{CH}_{3}$ ), 7.24 (d, $2 \mathrm{H}, J=7.6 \mathrm{~Hz}, \mathrm{H}-3$, H-5 Ph), 7.42 (t, 1H, J=7.6 Hz, H-7), 7.48 (d, 1H, J=7.6 Hz, H-8), 7.64 (t, 1H, J=7.8 Hz, H-6), 7.83 (s, 1H, H-2), 7.95 (d, 2H, J=8.8 Hz, H-2, H-6 Ph), 8.20 (d, 1H, J=7.8 Hz, H-5), 11.40 (s, 1H, NH); LC-MS, $m / z=379$ [M+1]; Anal. calcd. for $\mathrm{C}_{21} \mathrm{H}_{22} \mathrm{~N}_{4} \mathrm{O}_{3}$ : C, 66.65; $\mathrm{H}, 5.86 ; \mathrm{N}, 14.80$. Found: C, 66.61; H, 5.83; N, 14.78.

Methyl 4-oxo-4-phenyl-2-[quinazolin-4(3H)-ylidenehydrazono]butanoate (3n). Yield - 65.9\%. M.p. $120-122^{\circ} \mathrm{C} ;{ }^{1} \mathrm{H}-\mathrm{NMR}, \delta: 3.91 / 3.81$ (s, $\left.3 \mathrm{H},-\mathrm{OC} \underline{H}_{3}\right), 4.59$ (s, 2H, $\left.-\underline{\mathrm{H}}_{2}\right), 5.98(\mathrm{~s}, 1 \mathrm{H},=\mathrm{C} \underline{\mathrm{H}}-), 7.31 / 7.27(\mathrm{t}, 1 \mathrm{H}, \mathrm{J}=$ $7.6 \mathrm{~Hz}, \mathrm{H}-7$ ), 7.45/7.23 (d, 1H, J=8.3 Hz, H-8), 7.567.49 (m, 3H, H-3, H-4, H-5 Ph), 7.67 (t, 1H, J=7.3 Hz, H-6), 7.93/7.85 (d, 2H, , J=8.1 Hz H-2, H-6 Ph), 8.03 (d, 1H, J=8.1 Hz, H-5), 8.11 (s, 1H, H-2), 11.94/11.74 (s, 1H, 3-N $\underline{H}$ ), 13.72 (s, 1H, $\underline{H O}-\mathrm{C}=$ ); LC-MS, $m / z=349$ [M+1]; Anal. calcd. for $\mathrm{C}_{19} \mathrm{H}_{16} \mathrm{~N}_{4} \mathrm{O}_{3}$ : C, 65.51; $\mathrm{H}, 4.63$; N, 13.78. Found: C, 65.55; H, 4.65; N, 13.81.

Methyl 4-oxo-4-(4-methylphenyl)-2-[quinazolin4(3H)-ylidenehydrazono]butanoate (3o). Yield - 58.1\%. 
M.p. - 110-112 ${ }^{\circ} \mathrm{C} ;{ }^{1} \mathrm{H}-\mathrm{NMR}, \delta: 2.39 / 2.34\left(\mathrm{~s}, 3 \mathrm{H},-\underline{\mathrm{C}}_{3}\right)$, 3.91/3.81 (s, 3H, $\left.-\mathrm{OC} \underline{H}_{3}\right), 4.56\left(\mathrm{~s}, 2 \mathrm{H},-\mathrm{C}_{2}-\right)$, 5.95 (s, $1 \mathrm{H},=\mathrm{C} \underline{H}-)$, 7.93-7.20 (m, 8H, H-5, H-6, H-7, H-8 Quin, H-2, H-6, H-3, H-5 Ph ), 8.09 (s, 1H, H-2), 11.91/11.70 (s, 1H, 3-N $\underline{H}$ ), 13.66 (s, 1H, $\underline{H O}-\mathrm{C}=$ ); LC-MS, $m / z=363$ [M+1]; Anal. calcd. for $\mathrm{C}_{20} \mathrm{H}_{18} \mathrm{~N}_{4} \mathrm{O}_{3}$ : C, 66.26; $\mathrm{H}, 5.01$; $\mathrm{N}, 15.46$. Found: C, 66.23; H, 4.98; N, 15.42 .

Methyl 4-oxo-4-(4-methoxyphenyl)-2-[quinazolin4(3H)-ylidenehydrazono]butanoate (3p). Yield - 61.0\%. M.p. - $152-153^{\circ} \mathrm{C} ;{ }^{1} \mathrm{H}-\mathrm{NMR}, \delta: 3.81 / 3.80$ (s, 3H, Ph-OC $\left.\underline{H}_{3}\right)$, $3.90 / 3.85$ (s, $3 \mathrm{H},-\mathrm{OC} \underline{H}_{3}$ ), 4.55 (s, $\left.2 \mathrm{H},-\mathrm{C} \underline{H}_{2}-\right), 7.07$ (d, 2H, J=8.8 Hz, H-3, H-5 Ph), 5.93 (s, 1H, =C $\underline{H}-$ ), 7.21/6.99 (d, 1H, J=8.8 Hz, H-8), 7.30 (t, 1H, J=6.6 Hz, H-7), 7.51 (t, 1H, J=8.6 Hz, H-6), 7.93/7.73 (d, 1H, J=7.8 Hz, H-5), 8.00/7.90 (d, 2H, J=8.8 Hz, H-2, H-6, Ph), 8.07 (s, 1 H, H-2), 11.67 (s, 1H, 3-N프), 13.60 (s, 1H, $\underline{H O}-\mathrm{C}=$ ); LC-MS, $m / z=379[\mathrm{M}+1]$; Anal. calcd. for $\mathrm{C}_{20} \mathrm{H}_{18} \mathrm{~N}_{4} \mathrm{O}_{4}$ : C, 63.49; H, 4.79; N, 14.81. Found: C, 64.51; H, 4.81; N, 14.82.

Methyl 4-oxo-2-[quinazolin-4(3H)-ylidenehydrazono]-4-(2-thienyl)butanoate (3q). Yield - 48.6\%. M.p. - 181-183 ${ }^{\circ} \mathrm{C} ;{ }^{1} \mathrm{H}-\mathrm{NMR}, \delta: 3.91 / 3.82\left(\mathrm{~s}, 3 \mathrm{H},-\mathrm{OC} \underline{H}_{3}\right)$, $4.55\left(\mathrm{~s}, 2 \mathrm{H},-\underline{\mathrm{H}}_{2}=\right), 5.88(\mathrm{~s}, 1 \mathrm{H},=\mathrm{C} \underline{\mathrm{H}}-), 7.30 / 7.15(\mathrm{t}, 1 \mathrm{H}$, $J=5.1 \mathrm{~Hz}, \mathrm{H}-4$ Th.), 7.30/7.22 (d, 1H, J=7.6 Hz, H-6), $7.68 / 7.52$ (t, 1H, J=7.1 Hz, H-7), 7.79 (d, 1H, J=4.6 Hz, H-5 Th.), 8.03/7.84 (d, 1H, J=8.1 Hz, H-5), 7.94 (s, 1H, H-2), 8.12/8.07 (d, 1H, J=3.7 Hz, H-3 Th.), 11.91/11.74 (s, $1 \mathrm{H}, 3-\mathrm{N} \underline{H}$ ), 13.44 (s, $1 \mathrm{H}, \underline{H O} \mathrm{O}-\mathrm{C}=$ ); LC-MS, $m / z=355$ $[\mathrm{M}+1]$; Anal. calcd. for $\mathrm{C}_{17} \mathrm{H}_{14} \mathrm{~N}_{4} \mathrm{O}_{3} \mathrm{~S}$ : C, 57.62; $\mathrm{H}, 3.98$; N, 15.81; S, 9.05. Found: C, 57.59; H, 3.96; N, 15.79; $\mathrm{S}, 9.02$.

The general method of synthesis of $\mathrm{N}$-izopropylidene-N'-(quinazolin-4(3H)-ylidene)-hydrazine (4a).

Method A. Add 3-oxocarboxylic acid (0.01 Mol) to the solution of $1.6 \mathrm{~g}(0.01 \mathrm{Mol})$ of 4-hydrazinoquinazoline (2.3) in $15 \mathrm{ml}$ of propan-2-ol and allow to stand at room temperature. During the reaction carbon monoxide is released. At the end of the process ( $2 \mathrm{~h}$ ) filter the precipitate and dried.

Method B. To $2.3 \mathrm{~g}(0.014 \mathrm{Mol})$ of 4-hydrazinoquinazoline (2c) add $20 \mathrm{ml}$ of acetone and 2 drops of the concentrated hydrochloric acid and boil for $90 \mathrm{~min}$. Cool the solution, filter the precipitate and dry.

$N$-izopropylidene- $N$ '-(quinazolin-4(3H)-ylidene)hydrazine (4a). Yield - 50.4\%. M.p. - $166-168^{\circ} \mathrm{C} ;{ }^{1} \mathrm{H}-\mathrm{NMR}$,

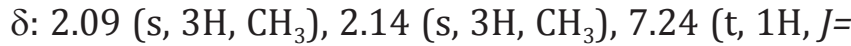
$7.6 \mathrm{~Hz}, \mathrm{H}-7$ ), 7.38 (d, 1H, J=8.1 Hz, H-8), 7.47 (t, 1H, $J=7.1 \mathrm{~Hz}, \mathrm{H}-6), 8.17$ (d, 1H,J=8.1 Hz, H-5), 7.65 (s, 1H, H-2), 10.7 (s, 1H, 3-N $\underline{H}$ ); LC-MS, $m / z=201$ [M+1]; Anal. calcd. for $\mathrm{C}_{11} \mathrm{H}_{12} \mathrm{~N}_{4}$ : C, 65.98; H, 6.04; N, 27.98. Found: C, 65.96; H, 6.02; N, 27.96.

The general method of synthesis of [(2-oxo-2,3dihydroquinazolin-4(1H)-ylidene)-hydrazono] carboxylic acids (5.1-5.9).

To the suspension of $0.88 \mathrm{~g}(0.005 \mathrm{Mol})$ of 4 -hydrazino- $1 H$-quinazolin-2-one $(\mathbf{1 b})$ in $10 \mathrm{ml}$ of methanol add $0.005 \mathrm{Mol}$ of the appropriate $\alpha$-oxocarboxy- lic acid and $1.03 \mathrm{~g}(0.005 \mathrm{Mol})$ of 4-(4'-methylphenyl)-2,4-dioxobutanoic acid, 1-2 drops of the concentrated hydrochloric acid and boil for $15 \mathrm{~min}$, cool, and filter the precipitate.

2-[(2-Oxo-2,3-dihydroquinazolin-4(1H)-ylidene) hydrazono]propanoic acid (5a). Yield - 77.2\%. M.p. - 252-254 ${ }^{\circ} \mathrm{C} ;{ }^{1} \mathrm{H}-\mathrm{NMR}, \delta: 2.26$ (s, $3 \mathrm{H}, \mathrm{C}_{3}$ ), 7.16 (m, $2 \mathrm{H}, \mathrm{H}-6, \mathrm{H}-8), 7.55$ (t, 1H, J=7.6 Hz, H-7), 8.18 (d, $1 \mathrm{H}, J=8.2 \mathrm{~Hz}, \mathrm{H}-5), 11.05$ (s, $1 \mathrm{H}, 3-\mathrm{N} \underline{H}), 11.40$ (s, $1 \mathrm{H}$, 1-N $\underline{H}), 12.37$ (s, $1 \mathrm{H}, \mathrm{COO} \underline{H}$ ); LC-MS, $m / z=247[\mathrm{M}+1]$; Anal. calcd. for $\mathrm{C}_{11} \mathrm{H}_{10} \mathrm{~N}_{4} \mathrm{O}_{3}: \mathrm{C}, 53.66 ; \mathrm{H}, 4.09 ; \mathrm{N}, 22.75$. Found: C, 55.63; H, 4.03; N, 22.73.

2-[2-Oxo-2,3-dihydroquinazolin-4(1H)-ylidene) hydrazono]pentanedioic acid (5b). Yield $-72.4 \%$. M.p. $-242-244{ }^{\circ} \mathrm{C} ;{ }^{1} \mathrm{H}-\mathrm{NMR}, \delta: 2.98$ (t, $2 \mathrm{H}, J=7.8 \mathrm{~Hz}$, $\left.-\mathrm{CH}_{2}-\mathrm{CH}_{2}-\mathrm{COOH}\right), 3.33\left(\mathrm{t}, 2 \mathrm{H},-\mathrm{C}_{2}-\mathrm{COOH}\right), 7.13(\mathrm{~d}, 1 \mathrm{H}$, $J=8.1 \mathrm{~Hz}, \mathrm{H}-8), 7.53(\mathrm{t}, 1 \mathrm{H}, J=7.8 \mathrm{~Hz}, \mathrm{H}-7), 7.58(\mathrm{t}, 1 \mathrm{H}$, $J=6.8 \mathrm{~Hz}, \mathrm{H}-6), 8.10(\mathrm{~d}, 1 \mathrm{H}, J=8.1 \mathrm{~Hz}, \mathrm{H}-5), 11.03(\mathrm{~s}$, $1 \mathrm{H}, 3-\mathrm{N} \underline{H}), 11.36(\mathrm{~s}, 1 \mathrm{H}, 1-\mathrm{N} \underline{H}), 12.28(\mathrm{~s}, 1 \mathrm{H}, \mathrm{COO} \underline{H})$; LC-MS, $m / z=305[\mathrm{M}+1]$; Anal. calcd. for $\mathrm{C}_{13} \mathrm{H}_{12} \mathrm{~N}_{4} \mathrm{O}_{5}$ : C, 51.32; H, 3.98; N, 18.41. Found: C, 51.36; H, 4.01; $\mathrm{N}, 18.43$.

3-(4-Nitrophenyl)-2-[(2-oxo-2,3-dihydroquinazolin-4(1H)-ylidene)hydrazono]propanoic acid (5c). Yield - 81.7\%. M.p. - 250-252 ${ }^{\circ}$; LC-MS, $m / z=368$ [M+1]; Anal. calcd. for $\mathrm{C}_{17} \mathrm{H}_{13} \mathrm{~N}_{5} \mathrm{O}_{5}$ : C, 55.59; $\mathrm{H}, 3.57 ; \mathrm{N}, 19.07$. Found: C, 55.54; H, 3.53; N, 19.03 .

Phenyl-[2-oxo-2,3-dihydroquinazolin-4(1H)-ylidene)hydrazono]acetic acid (5d). Yield - 77.6\%. M.p. - 280-282 ${ }^{\circ} \mathrm{C} ;{ }^{1} \mathrm{H}-\mathrm{NMR}, \delta: 7.13(\mathrm{~m}, 2 \mathrm{H}, \mathrm{H}-7, \mathrm{H}-8), 7.51$ (m, 5H, H-6 Quin, H-2, H-3, H-5, H-6 Ph), 8.04 (m, 2H, H-5 Quin, H-4 Ph), 11.06/10.62 (s, 1H, 3-N $\underline{H}$ ), 11.56/10.85 (s, 1H, 1-N $\underline{H}$ ), 12.63 (s, 1H, COO $\underline{H}$ ); LC-MS, $m / z=309$ (80:20) [M+1]; Anal. calcd. for $\mathrm{C}_{16} \mathrm{H}_{12} \mathrm{~N}_{4} \mathrm{O}_{3}$ : C, 62.31; H, 3.92; N, 18.17. Found: C, 62.35; H, 3.93; N, 18.21 .

(4-Methylphenyl)-[(2-oxo-2,3-dihydroquinazolin4(1H)-ylidene) hydrazono]acetic acid (5e). Yield - 87.0\%. M.p. $-266-268^{\circ} \mathrm{C} ;{ }^{1} \mathrm{H}-\mathrm{NMR}, \delta: 2.35$ (s, $\left.3 \mathrm{H}, \mathrm{C}_{3}\right), 7.10$ (m, 2H, H-7, H-8), 7.44 (d, 2H, J=8.0 Hz, H-3, H-5 Ph), $7.53(\mathrm{t}, 1 \mathrm{H}, J=7.0 \mathrm{~Hz}, \mathrm{H}-6), 7.91(\mathrm{~d}, 2 \mathrm{H}, \mathrm{H}-3, J=8.4 \mathrm{~Hz}$, H-5 Ph), 7.98 (d, 1H, J=7.6 Hz, H-5), 11.09/10.59 (s, $1 \mathrm{H}, 3-\mathrm{N} \underline{H}$ ), $11.60 / 10.82$ (s, $1 \mathrm{H}, 1-\mathrm{N} \underline{H}), 12.66$ (s, $1 \mathrm{H}$, $\mathrm{COO} \underline{H}$ ); LC-MS, $m / z=323$ (50:50) [M+1]; Anal. calcd. for $\mathrm{C}_{17} \mathrm{H}_{14} \mathrm{~N}_{4} \mathrm{O}_{3}$ : C, 63.35; $\mathrm{H}, 4.38 ; \mathrm{N}, 17.38$. Found: $\mathrm{C}$, 63.35; H, 4.39; N, 17.38.

(4-Methoxyphenyl)-[(2-oxo-2,3-dihydroquinazolin4(1H)-ylidene) hydrazono]acetic acid (5f). Yield $-82.8 \%$. M.p. $-280-282^{\circ} \mathrm{C} ;{ }^{1} \mathrm{H}-\mathrm{NMR}, \delta: 3.84$ (s, $\left.3 \mathrm{H}, \mathrm{OC} \underline{H}_{3}\right), 7.03$ (d, 2H, H-3, H-5 Ph), 7.15 (m, 2H, H-7, H-8), 7.53 (t, 1H, $J=7.5 \mathrm{~Hz}, \mathrm{H}-6), 7.98$ (m, 2H, H-5 Quin, H-3, H-5 Ph), $11.03 / 10.47$ (s, $1 \mathrm{H}, 3-\mathrm{N} \underline{H}), 11.42 / 10.77$ (s, $1 \mathrm{H}, 1-\mathrm{N} \underline{H})$, 11.49 (s, $1 \mathrm{H}, \mathrm{COO} \underline{H}$ ); LC-MS, $m / z=339$ (50:50) [M+1]; Anal. calcd. for $\mathrm{C}_{17} \mathrm{H}_{14} \mathrm{~N}_{4} \mathrm{O}_{4}$ : C, 60.35; $\mathrm{H}, 4.17 ; \mathrm{N}, 16.56$. Found: C, 60.39; H, 4.21; N, 16.58 .

[2-Oxo-2,3-dihydroquinazolin-4(1H)-ylidene)hydrazono]-(1,3,5-trimethyl-1H-pyrazol-4-yl)acetic acid (5g). Yield - 74.7\%. M.p. $-252-254^{\circ} \mathrm{C}$; ${ }^{1} \mathrm{H}-\mathrm{NMR}, \delta: 2.30$ (s, 
3H, 5-C $\left.\underline{H}_{3}\right), 2.42\left(\mathrm{~s}, 3 \mathrm{H}, 3-\mathrm{C}_{3}\right), 3.73\left(\mathrm{~s}, 3 \mathrm{H}, \mathrm{N}-\mathrm{CH}_{3}\right)$, 7.14 (m, 2H, H-6, H-8), 7.53 (t, 1H, J=6.8 Hz, H-7), $7.92 / 7.86$ (d, 1H, J=8.1 Hz, H-5), 9.22 (s, 1H, 3-N $\underline{H}$ ), 10.92 (s, 1H, 1-N $\underline{H}$ ), 12.55 (s, $1 \mathrm{H}, \mathrm{COO} \underline{H}$ ); LC-MS, $m / z$ =341 (50:50) [M+1]; Anal. calcd. for $\mathrm{C}_{16} \mathrm{H}_{16} \mathrm{~N}_{6} \mathrm{O}_{3}: \mathrm{C}, 56.47$; H, 4.74; N, 24.69. Found: C, 56.45; H, 4.73; N, 24.65.

[(2-oxo-2,3-dihydroquinazolin-4(1H)-ylidene)hydrazono](2-thienyl)acetic acid (5h). Yield - 85.9\%. M.p. - 206-208 ${ }^{\circ} \mathrm{C} ;{ }^{1} \mathrm{H}-\mathrm{NMR}, \delta:$ 7.31-7.11 (m, 3H, H-7, H-8 Quin, H-4 Th.), 7.65/7.56 (t, $1 \mathrm{H}, J=7.3 \mathrm{~Hz}, \mathrm{H}-6)$, 7.80/7.49 (t, 1H, H-5), 7.93 (d, 1H, J=5.2 Hz, H-3 Th.), 8.38 (d, 1H, J=4.4 Hz, H-5 Th.), 10.94 (s, 1H, 3-N $\underline{H}$ ), 11.20 (s, 1H, 1-N $\underline{H}$ ), 11.63 (s, 1H, COO $\underline{H}$ ); LC-MS, $m / z$ $=314$ (50:50) [M+1]; Anal. calcd. for $\mathrm{C}_{14} \mathrm{H}_{10} \mathrm{~N}_{4} \mathrm{O}_{3} \mathrm{~S}: \mathrm{C}$, 53.50; H, 3.21; N, 17.82;S, 10.20. Found: C, 53.45; H, 3.17; N, 17.79; S, 10.17 .

4-(4-Methylphenyl)-4-oxo-2-[(2Z)-(2-oxo-2,3-dihydroquinazolin-4(1H)-ylidene)hydrazono]butanoic acid (5i). Yield - 73.1\%. M.p. - 224-228 ${ }^{\circ} \mathrm{C} ;{ }^{1} \mathrm{H}-\mathrm{NMR}, \delta: 4.50$ (s, 2H, $\underline{\mathrm{H}}_{2}$ ) 6.97 (t, $\left.1 \mathrm{H}, J=7.6 \mathrm{~Hz}, \mathrm{H}-7\right), 7.09(\mathrm{~d}, 1 \mathrm{H}$, $J=8.3 \mathrm{~Hz}, \mathrm{H}-8$ ), 7.33 (d, 2H, J=8.1 Hz, H-3, H-5 Ph), 7.52 (t, 1H, J=7.1 Hz, H-6), 7.72 (d, 1H, J=7.3 Hz, H-5), 7.89 (d, 2H, J=8.1 Hz, H-2, H-6 Ph), 11.07 (s, 1H, 3-N $\underline{H}$ ), 11.45 (s, 1H, 1-N $\underline{H}$ ), 12.55 (s, 1H, COO $\underline{H}$ ); LC-MS, $m / z$ $=363[\mathrm{M}+1]$; Anal. calcd. for $\mathrm{C}_{19} \mathrm{H}_{16} \mathrm{~N}_{4} \mathrm{O}_{4}$ : C, 62.63; $\mathrm{H}$, 4.43; N, 15.38. Found: C, 62.59; H, 3.17; N, 17.79; S, 10.17 .

The general method of synthesis of methyl (ethyl) 2-R-2-\{[2-oxo-2,3-dihydroquinazolin-4(1H)ylidene]hydrazono\}carboxylic acids (6a-6p).

To the suspension of $0.88 \mathrm{~g}(0.005 \mathrm{Mol})$ of 4-hydrazino- $1 \mathrm{H}$-quinazolin-2-one (1.2) in $15 \mathrm{ml}$ of propan-2-ol add $0.005 \mathrm{Mol}$ of the corresponding oxocarboxylic ester or 2,4-dioxo-4-aryl(heteryl)butanoic acid, 1-2 drops of the concentrated hydrochloric acid and boil for $1 \mathrm{~h}$. Cool the suspension, filter the precipitate formed and dry.

Ethyl 2-[(2-oxo-2,3-dihydroquinazolin-4(1H)-ylidene)hydrazono]propanoate (6a). Yield - 65.7\%. M.p. - 248-250 ${ }^{\circ} \mathrm{C}$; LC-MS, $m / z=275[\mathrm{M}+1]$; Anal. calcd. for $\mathrm{C}_{13} \mathrm{H}_{14} \mathrm{~N}_{4} \mathrm{O}_{3}$ : C, 56.93; $\mathrm{H}, 5.14 ; \mathrm{N}, 20.43$. Found: $\mathrm{C}$, 56.90; H, 5.11; N, 20.39.

Ethyl 2-[(2-oxo-2,3-dihydroquinazolin-4(1H)-ylidene)hydrazono]-3-phenylpropanoate (6b). Yield 57.1\%. M.p. - $192-194^{\circ} \mathrm{C}$; LC-MS, $m / z=351$ [M+1]; Anal. calcd. for $\mathrm{C}_{19} \mathrm{H}_{18} \mathrm{~N}_{4} \mathrm{O}_{3}$ : C, 65.13; $\mathrm{H}, 5.18 ; \mathrm{N}, 15.99$. Found: C, 65.10; H, 5.15; N, 15.96.

Ethyl 3-(4-nitrophenyl)-2-[(2-oxo-2,3-dihydroquinazolin-4(1H)-ylidene)hydrazono]propanoate (6c). Yield - 79.9\%. M.p. - 242-244 ${ }^{\circ}$; LC-MS, $m / z=396$ [M+1]; Anal. calcd. for $\mathrm{C}_{19} \mathrm{H}_{17} \mathrm{~N}_{5} \mathrm{O}_{5}$ : C, 57.72; $\mathrm{H}, 4.33 ; \mathrm{N}, 17.71$. Found: C, 57.76; H, 4.38; N, 17.79.

Ethyl [(2-oxo-2,3-dihydroquinazolin-4(1H)-ylidene)hydrazono](phenyl)acetate (6d). Yield - 62.3\%. M.p. - 266-268 ${ }^{\circ} \mathrm{C} ;{ }^{1} \mathrm{H}-\mathrm{NMR}, \delta: 1.36$ (t, 3H, J=7.0 Hz, $-\mathrm{OCH}_{2} \mathrm{C}_{3}$ ), 4.44 (q, 2H, J=7.0 Hz, OC $\left.\underline{H}_{2} \mathrm{CH}_{3}\right), 7.12(\mathrm{~m}$, 2H, H-7, H-8 Quin), 7.51 (m, 4H, H-6 Quin, H-3, H-4,
H-5 Ph), 7.95 (d, 1H, J=7.8 Hz, H-5), 8.00 (d, 2H, J= $6.4 \mathrm{~Hz}, \mathrm{H}-3, \mathrm{H}-5 \mathrm{Ph}), 10.72$ (s, 1H, 3-NH), 10.89 (s, $1 \mathrm{H}, 1-\mathrm{NH})$; LC-MS, $m / z=337[\mathrm{M}+1]$; Anal. calcd. for $\mathrm{C}_{18} \mathrm{H}_{116} \mathrm{~N}_{4} \mathrm{O}_{3}$ : C, 64.28; $\mathrm{H}, 4.79 ; \mathrm{N}, 16.66$. Found: $\mathrm{C}$, 64.26; H, 4.81; N, 16.69.

Ethyl (4-methylphenyl)[(2-oxo-2,3-dihydroquinazolin-4(1H)-ylidene)hydrazono]acetate (6e). Yield - 40.0\%. M.p. - 257-259 ${ }^{\circ} \mathrm{C} ;{ }^{1} \mathrm{H}-\mathrm{NMR}, \delta: 1.33$ (t, $3 \mathrm{H}, J=7.0 \mathrm{~Hz}$, $-\mathrm{OCH}_{2} \mathrm{C}_{\underline{3}}$ ) 3.31 (s, 3H, $\left.\mathrm{C}_{3}\right) 4.43$ (q, 2H, J=7.0 Hz, OC $\underline{H}_{2} \mathrm{CH}_{3}$ ), 7.09 (m, 2H, H-7, H-8 Quin), 7.29 (d, 2H, $J=7.8 \mathrm{~Hz}, \mathrm{H}-2, \mathrm{H}-6 \mathrm{Ph}), 7.52$ (t, 1H, J=7.6 Hz, H-7), 7.89 (m, 3H, H-5 Quin, H-3, H-5 Ph), 10.65 (s, 1H, 3-NH), 10.84 (s, 1H, 1-NH); LC-MS, $m / z=351$ [M+1]; Anal. calcd. for $\mathrm{C}_{19} \mathrm{H}_{18} \mathrm{~N}_{4} \mathrm{O}_{3}$ : C, 65.13; H, 5.18; N, 15.99 . Found: C, 65.16; H, 5.20; N, 16.05.

Ethyl (4-methoxyphenyl)[(2-oxo-2,3-dihydroquinazolin-4(1H)-ylidene) hydrazono]acetate (6f). Yield 71.0\%. M.p. $-264-266^{\circ} \mathrm{C} ;{ }^{1} \mathrm{H}-\mathrm{NMR}, \delta: 1.43$ (t, 3H, J= $\left.7.0 \mathrm{~Hz}, \mathrm{OCH}_{2} \mathrm{C}_{3}\right), 3.85\left(\mathrm{~s}, 3 \mathrm{H}, \mathrm{OC} \underline{H}_{3}\right), 4.44(\mathrm{q}, 2 \mathrm{H}, J=$ $7.2 \mathrm{~Hz}, \mathrm{OC}_{2} \mathrm{CH}_{3}$ ), 6.97 (d, 2H, J=8.7 Hz, H-3, H-5 Ph), 7.03 (t, 1H, J=8.2 Hz, H-7), 7.10 (d, 1H, J=8.0 Hz, H-8), 7.40 (t, 1H, J=8.0 Hz, H-6), 7.80 (d, 2H, J=8.6 Hz, H-2, H-6 Ph), 7.96 (d, 1H, J=7.4 Hz, H-5), 9.83 (s, 1H, 3-NH), 10.76 (s, 1H, 1-NH); LC-MS, $m / z=367$ [M+1]; Anal. calcd. for $\mathrm{C}_{19} \mathrm{H}_{18} \mathrm{~N}_{4} \mathrm{O}_{4}$ : C, 62.29; $\mathrm{H}, 4.95 ; \mathrm{N}, 15.29$. Found: C, 62.32; H, 4.98; N, 15.32 .

Ethyl [(2-oxo-2,3-dihydroquinazolin-4(1H)-ylidene)hydrazono](2-thienyl)acetate (6g). Yield - 52.6\%. M.p. $-218-220^{\circ} \mathrm{C} ;{ }^{1} \mathrm{H}-\mathrm{NMR}, \delta: 1.36(\mathrm{t}, 3 \mathrm{H}, J=7.0 \mathrm{~Hz}$, $\left.\mathrm{OCH}_{2} \underline{\mathrm{C}}_{3}\right), 4.40\left(\mathrm{q}, 2 \mathrm{H}, \mathrm{J}=7.2 \mathrm{~Hz}, \mathrm{OC} \underline{H}_{2} \mathrm{CH}_{3}\right), 7.26-7.14$ (m, 3H, H-7, H-8 Quin, H-4 Th.), 7.60 (t, 1H, J=7.0 Hz, H-6 Quin), 7.70 (d, 1H, J=3.1 Hz, H-5 Th.), 7.95 (d, 1H, $J=4.9$ Hz, H-3 Th.), 8.30 (d, 1H, J=7.6 Hz, H-5), 10.00 (s, 1H, 3-NH), 11.07 (s, 1H, 1-NH); LC-MS, $m / z=343$ $[\mathrm{M}+1]$; EI-MS, $m / z\left(\mathrm{I}_{\mathrm{rel}}, \%\right)=344$ (3.5), 343 (12.7), 342 (53.8), 271 (5.9), 270 (14.9), 269 (100.0), 145 (6.7), 144 (5.6), 132 (9.1), 125 (13.9), 118 (6.8), 117 (5.4), 110 (6.4), 105 (8.6), 90 (15.3); Anal. calcd. for $\mathrm{C}_{16} \mathrm{H}_{14} \mathrm{~N}_{4} \mathrm{O}_{3} \mathrm{~S}$ : C, 51.13; H, 4.12; N, 16.36; S, 9.37. Found: C, 51.16; H, 4.15; N, 16.39; S, 9.40.

Ethyl 3-[(2-oxo-2,3-dihydroquinazolin-4(1H)-ylidene) hydrazono]butanoate (6h). Yield - 48.6\%. M.p. - 192-194 ${ }^{\circ} \mathrm{C}$; ${ }^{1} \mathrm{H}-\mathrm{NMR}, \delta: 1.22 / 1.14$ (t, 3H, J=7.1 Hz, $\mathrm{OCH}_{2} \mathrm{C}_{3}$ ), 2.10 (s, 3H, $\underline{\mathrm{H}}_{3}$ ), 3.60/3.49 (s, 2H, $\mathrm{C} \underline{\mathrm{H}} / \mathrm{C}_{2}$ ), 4.13/4.03 (q, 2H, J=7.1 Hz, OC $\left.\underline{H}_{2} \mathrm{CH}_{3}\right), 7.07(\mathrm{~m}, 2 \mathrm{H}$, H-7, H-8), 7.49 (t, 1H, J=7.6 Hz, H-6), 8.00/7.95 (d, $1 \mathrm{H}, J=7.6 \mathrm{~Hz}, \mathrm{H}-5), 9.39$ (s, 1H, 3-NH), 9.49 (s, $1 \mathrm{H}$, $=\mathrm{NN} \underline{H}), 10.71$ (s, 1H, 1-NH); LC-MS, $m / z=289[\mathrm{M}+1]$; Anal. calcd. for $\mathrm{C}_{14} \mathrm{H}_{16} \mathrm{~N}_{4} \mathrm{O}_{3}$ : C, 58.33; H, 5.59; N, 19.43 . Found: C, 58.36; H, 5.61; N, 19.46.

Ethyl 3-[(2-oxo-2,3-dihydroquinazolin-4(1H)-ylidene)hydrazono]-3-phenylpropanoate (6i). Yield - 57.0\%. M.p. - $216-218^{\circ} \mathrm{C}$; LC-MS, $m / z=351$ [M+1]; Anal. calcd. for $\mathrm{C}_{19} \mathrm{H}_{18} \mathrm{~N}_{4} \mathrm{O}_{3}: \mathrm{C}, 65.13 ; \mathrm{H}, 5.18 ; \mathrm{N}, 15.99$. Found: $\mathrm{C}$, 65.16; H, 5.21; N, 16.02 .

Ethyl 3-(2-furyl)-3-[(2-oxo-2,3-dihydroquinazolin4(1H)-ylidene)hydrazono]propanoate (6j). Yield - 52.9\%. 
M.p. $-230-232^{\circ} \mathrm{C} ;{ }^{1} \mathrm{H}-\mathrm{NMR}, \delta: 1.11(\mathrm{t}, 3 \mathrm{H}, J=7.1 \mathrm{~Hz}$, $\left.\mathrm{OCH}_{2} \mathrm{C}_{3}\right), 3.94\left(\mathrm{~s}, 2 \mathrm{H}, \mathrm{C}_{2}\right), 4.04(\mathrm{q}, 2 \mathrm{H}, J=7.1 \mathrm{~Hz}$, $\left.\mathrm{OC} \underline{H}_{2} \mathrm{CH}_{3}\right), 6.65(\mathrm{t}, 1 \mathrm{H}, J=1.5 \mathrm{~Hz}, \mathrm{H}-4 \mathrm{Fur}), 7.08(\mathrm{~d}, 1 \mathrm{H}$, $J=7.6 \mathrm{~Hz}, \mathrm{H}-8), 7.13$ (t, 1H, J=7.6 Hz, H-7), 7.42 (d, $1 \mathrm{H}$, $J=3.2 \mathrm{~Hz}, \mathrm{H}-3$ Fur), 7.50 (t, 1H, J=7.6 Hz, H-6), 7.85 (s, 1H, H-5 Fur), 8.00 (d, 1H, J=7.6 Hz, H-5), 9.77 (s, $1 \mathrm{H}, 3-\mathrm{NH}$ ), 10.84 (s, $1 \mathrm{H}, 1-\mathrm{NH}$ ); LC-MS, $m / z=341$ [M+1]; Anal. calcd. for $\mathrm{C}_{17} \mathrm{H}_{16} \mathrm{~N}_{4} \mathrm{O}_{3}: \mathrm{C}, 60.00 ; \mathrm{H}, 4.74$; $\mathrm{N}, 16.46$. Found: C, 60.06; H, 4.76; N, 16.51 .

Methyl 4-oxo-2-[(2-oxo-2,3-dihydroquinazolin-4(1H)ylidene) hydrazono]-4-phenylbutanoate (6k). Yield 65.9\%. M.p. $-228-230{ }^{\circ} \mathrm{C} ;{ }^{1} \mathrm{H}-\mathrm{NMR}, \delta: 3.80$ (s, 3H, $-\mathrm{OC}_{3}$ ), $4.57\left(\mathrm{~s}, 2 \mathrm{H},-\underline{\mathrm{H}}_{2} \mathrm{z}\right), 6.97(\mathrm{t}, 1 \mathrm{H}, J=7.6 \mathrm{~Hz}, \mathrm{H}-7), 7.08(\mathrm{~d}$, $1 \mathrm{H}, J=8.3 \mathrm{~Hz}, \mathrm{H}-8), 7.67$ (t, $1 \mathrm{H}, J=7.1 \mathrm{~Hz}, \mathrm{H}-6), 7.56-$ $7.50(\mathrm{~m}, 3 \mathrm{H}, \mathrm{H}-3, \mathrm{H}-4, \mathrm{H}-5 \mathrm{Ph}), 7.71(\mathrm{~d}, 1 \mathrm{H}, J=8.1 \mathrm{~Hz}$, H-5), 8.01 (d, 2H, J=8.1 Hz, H-2, H-6 Ph), 9.62 (s, 1H, 3-N $\underline{H}$ ), 11.07 (s, 1H, 1-N $\underline{H}$ ); LC-MS, $m / z=365[\mathrm{M}+1]$; Anal. calcd. for $\mathrm{C}_{19} \mathrm{H}_{16} \mathrm{~N}_{4} \mathrm{O}_{4}$ : C, 62.63; $\mathrm{H}, 4.43 ; \mathrm{N}, 15.38$. Found: C, 62.67; H, 4.47; N, 15.41.

Methyl 4-(4-methylphenyl)-4-oxo-2-[(2-oxo-2,3-dihydroquinazolin-4(1H)-ylidene)hydrazono]butanoate (61). Yield $-58.1 \%$. M.p. $-235-237^{\circ} \mathrm{C}$; ${ }^{1} \mathrm{H}-\mathrm{NMR}$, $\delta: 2.39\left(\mathrm{~s}, 3 \mathrm{H},-\mathrm{C}_{3}\right), 3.80\left(\mathrm{~s}, 3 \mathrm{H},-\mathrm{OC} \underline{H}_{3}\right), 4.53(\mathrm{~s}, 2 \mathrm{H}$, $\left.-\underline{H}_{2}=\right), 6.97(\mathrm{t}, 1 \mathrm{H}, J=7.6 \mathrm{~Hz}, \mathrm{H}-7), 7.09$ (d, $1 \mathrm{H}, J=8.3$ $\mathrm{Hz}, \mathrm{H}-8), 7.34$ (d, 2H, J=8.1 Hz, H-3, H-5 Ph), 7.51 (t, $1 \mathrm{H}, J=7.1 \mathrm{~Hz}, \mathrm{H}-6$ ), 7.72 (d, 1H, J=7.8 Hz, H-5), 7.90 (d, 2H, J=8.1 Hz, H-2, H-6 Ph), 9.53 (s, 1H, 3-N타), 11.05 (s, $1 \mathrm{H}, 1-\mathrm{N} \underline{H}$ ); LC-MS, $m / z=379$ [M+1]; Anal. calcd. for $\mathrm{C}_{20} \mathrm{H}_{18} \mathrm{~N}_{4} \mathrm{O}_{4}$ : C, 63.49; $\mathrm{H}, 4.79 ; \mathrm{N}, 14.81$. Found: $\mathrm{C}$, 63.52; H, 4.83; N, 14.84 .

Methyl 4-(4-methoxyphenyl)-4-oxo-2-[(2-oxo-2,3dihydroquinazolin-4(1H)-ylidene) hydrazono]butanoate (6m). Yield $-61.0 \%$. M.p. $-222-224^{\circ} \mathrm{C} ;{ }^{1} \mathrm{H}-\mathrm{NMR}$, $\delta: 3.79\left(\mathrm{~s}, 3 \mathrm{H},-\mathrm{OC} \underline{H}_{3}\right), 3.85\left(\mathrm{~s}, 3 \mathrm{H},-\mathrm{OC} \underline{H}_{3}\right), 4.52(\mathrm{~s}, 2 \mathrm{H}$, $\left.-\mathrm{CH}_{2} \mathrm{z}\right), 6.99(\mathrm{t}, 1 \mathrm{H}, J=7.6 \mathrm{~Hz}, \mathrm{H}-7), 7.05(\mathrm{~d}, 2 \mathrm{H}, J=8.6 \mathrm{~Hz}$, $\mathrm{H}-3, \mathrm{H}-5 \mathrm{Ph}$ ), 7.07 (d, 1H, J=8.6 Hz, H-8), 7.52 (t, 1H, $J=7.3 \mathrm{~Hz}, \mathrm{H}-6$ ) , 7.77 (d, 1H, J=7.8 Hz, H-5), 8.00 (d, $2 \mathrm{H}, J=8.8 \mathrm{~Hz}, \mathrm{H}-2, \mathrm{H}-6 \mathrm{Ph}), 9.60$ (s, $1 \mathrm{H}, 3-\mathrm{N} \underline{H}), 11.06$ (s, $1 \mathrm{H}, 1-\mathrm{N} \underline{H}$ ); LC-MS, $m / z=394$ [M+1]; Anal. calcd. for $\mathrm{C}_{20} \mathrm{H}_{18} \mathrm{~N}_{4} \mathrm{O}_{5}$ : C, 60.91; $\mathrm{H}, 4.60 ; \mathrm{N}, 14.21$. Found: $\mathrm{C}$, 60.89; H, 4.58; N, 14.18 .

Methyl 4-(4-chlorophenyl)-4-oxo-2-[(2-oxo-2,3-dihydroquinazolin-4(1H)-ylidene)hydrazono]butanoate (6n). Yield $-45.1 \%$. M.p. $-238-240{ }^{\circ} \mathrm{C} ;{ }^{1} \mathrm{H}-\mathrm{NMR}$, $\delta: 3.81\left(\mathrm{~s}, 3 \mathrm{H},-\mathrm{OC} \underline{H}_{3}\right), 4.55\left(\mathrm{~s}, 2 \mathrm{H},-\mathrm{C}_{2}-\right), 6.97(\mathrm{t}, 1 \mathrm{H}$, $\left.J=7.8 \mathrm{~Hz}, J^{2}=1.2 \mathrm{~Hz}, \mathrm{H}-7\right), 7.06$ (d, 2H, $J=8.6 \mathrm{~Hz}, \mathrm{H}-3, \mathrm{H}-5$ $\mathrm{Ph}$ ), 7.07 (d, 1H, J=8.3 Hz, H-8), 7.52 (t, $1 \mathrm{H}, J=7.3 \mathrm{~Hz}$, $\left.J^{2}=1.5 \mathrm{~Hz}, \mathrm{H}-6\right), 7.69$ (d, 1H, J=7.8 Hz, H-5), 8.01 (d, $2 \mathrm{H}, J=8.6 \mathrm{~Hz}, \mathrm{H}-2, \mathrm{H}-6 \mathrm{Ph}$ ), 9.59 (s, 1H, 3-N $\underline{H}$ ), 11.08 (s, $1 \mathrm{H}, 1-\mathrm{N} \underline{H}$ ); LC-MS, $m / z=399$ [M+1]; Anal. calcd. for $\mathrm{C}_{19} \mathrm{H}_{15} \mathrm{ClN}_{4} \mathrm{O}_{4}$ : C, 57.22; $\mathrm{H}, 3.79 ; \mathrm{Cl}, 8.89 ; \mathrm{N}, 14.05$. Found: C, 57.26; H, 3.81; Cl, 8.92; N, 14.08 .

Methyl4-(2-furyl)-4-oxo-2-[(2-oxo-2,3-dihydroquinazolin-4(1H)-ylidene)hydrazono]butanoate (6o). Yield - 56.5\%. M.p. - 224-226 ${ }^{\circ} \mathrm{C}$; ${ }^{1} \mathrm{H}-\mathrm{NMR}, \delta: 3.81$ (s, 3H, $-\mathrm{OC} \underline{H}_{3}$ ), 4.37 (s, $2 \mathrm{H},-\mathrm{C}_{2}-$ ), 6.76 (d, $1 \mathrm{H}, J=1.7 \mathrm{~Hz}, \mathrm{H}-3$ Fur), $7.01\left(\mathrm{t}, 1 \mathrm{H}, \mathrm{H}-6, J^{2}=0.7 \mathrm{~Hz}, J=7.3 \mathrm{~Hz}\right), 7.09(\mathrm{t}, 1 \mathrm{H}$,
$J=8.3 \mathrm{~Hz}, \mathrm{H}-7$ ), 7.56 (d, 1H, J=3.4 Hz, H-5 Fur), 7.67 (dd, $\left.1 \mathrm{H}, J=8.1 \mathrm{~Hz}, J^{2}=1.0 \mathrm{~Hz}, \mathrm{H}-5\right), 7.94$ (t, $1 \mathrm{H}, \mathrm{H}-6$, $J^{2}=1.5 \mathrm{~Hz}, J=7.3 \mathrm{~Hz}$ ), 8.02 (d, 1H, $J=1.0 \mathrm{~Hz}, \mathrm{H}-3 \mathrm{Fur}$ ), 9.65 (s, 1H, 3-N $\underline{H}$ ), 11.07 (s, 1H, 1-N $\underline{H}$ ); LC-MS, $m / z$ $=355$ [M+1]; Anal. calcd. for $\mathrm{C}_{17} \mathrm{H}_{14} \mathrm{~N}_{4} \mathrm{O}_{5}$ : C, 57.63; $\mathrm{H}$, 3.98; N, 15.81. Found: C, 57.66; H, 4.02; N, 15.83 .

Methyl 4-(2-thienyl)-4-oxo-2-[(2-oxo-2,3-dihydroquinazolin-4(1H)-ylidene)hydrazono]butanoate (6p). Yield - 48.6\%. M.p. $-240-241^{\circ} \mathrm{C}$; ${ }^{1} \mathrm{H}-\mathrm{NMR}, \delta: 3.81$ (s, $\left.3 \mathrm{H},-\mathrm{OC} \underline{H}_{3}\right), 4.52\left(\mathrm{~s}, 2 \mathrm{H},-\underline{\mathrm{H}}_{2}-\right), 6.98(\mathrm{~d}, 1 \mathrm{H}, J=7.6 \mathrm{~Hz}$, $\mathrm{H}-7), 7.09(\mathrm{~d}, 1 \mathrm{H}, J=7.8 \mathrm{~Hz}, \mathrm{H}-8), 7.28(\mathrm{t}, 1 \mathrm{H}, J=4.4 \mathrm{~Hz}$, $\left.J^{2}=1.0 \mathrm{~Hz}, \mathrm{H}-4 \mathrm{Th}.\right), 7.52\left(\mathrm{t}, 1 \mathrm{H}, J=7.6 \mathrm{~Hz}, J^{2}=1.2 \mathrm{~Hz}\right.$, $\mathrm{H}-6$ ), 7.67 (d, 1H, J=7.6 Hz, H-5), 8.03 (d, $1 \mathrm{H}, J=7.3 \mathrm{~Hz}$, $J^{2}=1.5 \mathrm{~Hz}, \mathrm{H}-5 \mathrm{Th}$.), 8.11 (d, 1H, H-3 Th), 9.63 (s, 1H, 3-N $\underline{H}$ ), 11.07 (s, 1H, 1-N $\underline{H}$ ); LC-MS, $m / z=371[\mathrm{M}+1]$; Anal. calcd. for $\mathrm{C}_{17} \mathrm{H}_{14} \mathrm{~N}_{4} \mathrm{O}_{4} \mathrm{~S}: \mathrm{C}, 55.13 ; \mathrm{H}, 3.81 ; \mathrm{N}, 15.13$; S, 8.66. Found: C, 55.16; H, 3.84; N, 15.19; S, 8/69.

The general method of synthesis of $3-\mathrm{R}-2 \mathrm{H}$ [1,2,4]triazino[2,3-c]quinazolin-2-ones (7a-7g).

Method A. Heat esters 3a-3g (0.005 Mol) in $10 \mathrm{ml}$ of glacial acetic acid for $6 \mathrm{~h}$. Remove the solvent under the vacuum, add $5 \mathrm{ml}$ of methanol to the residue, filter the precipitate, wash on the filter with diethyl ether and dry.

Method B. Add carbonyldiimidazole $(0.0055 \mathrm{Mol})$ to the suspension of the corresponding 2-aryl-2$\{(3 \mathrm{H}$-quinazolin-4-ylidene)hydrazono\}acetic acid (2c2f, 2i) $(0.005 \mathrm{Mol})$ in $10 \mathrm{ml}$ of anhydrous dioxane or DMF. Heat the mixture at $80^{\circ} \mathrm{C}$ for $1 \mathrm{~h}$, cool, filter the precipitate formed and dry.

3-Methyl-2H-[1,2,4]triazino[2,3-c]quinazolin-2one (7a). Yield - Method A, 62.9\%; method B, 82.6\%. M.p. $-242-244^{\circ} \mathrm{C} ;{ }^{1} \mathrm{H}-\mathrm{NMR}, \delta: 2.50$ (s, $3 \mathrm{H}, \mathrm{CH}_{3}$ ), 7.79 (t, $1 \mathrm{H}, J=7.6 \mathrm{~Hz}, \mathrm{H}-10), 7.90$ (d, 1H, J=8.0 Hz, H-8), 8.02 (t, 1H, J=7.8 Hz, H-9), 8.53 (d, 1H, J=7.8 Hz, H-11), 8.94 (s, $1 \mathrm{H}, \mathrm{H}-6) ;{ }^{13} \mathrm{C}-\mathrm{NMR}, \delta: 18.1 ; 120.2,125.8,128.2$, 129.5, 135.8, 144.3, 144.5, 152.1, 156.5, 161.3. LC-MS, $m / z=213$ [M+1]; Anal. calcd. for $\mathrm{C}_{11} \mathrm{H}_{8} \mathrm{~N}_{4} \mathrm{O}: \mathrm{C}, 62.26$; H, 3.80; N, 26.40. Found: C, 62.25; H, 3.79; N, 26.37.

3-Benzyl-2H-[1,2,4]triazino[2,3-c]quinazolin-2one (7b). Yield - Method A, 86.8\%; method B, 89.3\%. M.p. $-195-196{ }^{\circ} \mathrm{C} ;{ }^{1} \mathrm{H}-\mathrm{NMR}, \delta: 4.08$ (s, $2 \mathrm{H}, \mathrm{C}_{2}$ ), 7.377.24 (m, 5H, H-2, H-3, H-4, H-5, H-6, Ph), 7.76 (t, 1H, $J=7.4 \mathrm{~Hz}, \mathrm{H}-10), 7.90$ (d, 1H, J=7.2 Hz, H-8), 8.00 (t, $1 \mathrm{H}, J=7.4 \mathrm{~Hz}, \mathrm{H}-9$ ), 8.52 (d, 1H, J=7.2 Hz, H-11), 8.90 (s, 1H, H-6); LC-MS, $m / z=289$ [M+1]; Anal. calcd. for $\mathrm{C}_{17} \mathrm{H}_{12} \mathrm{~N}_{4} \mathrm{O}$ : C, 70.82; $\mathrm{H}, 4.20$; N, 19.43. Found: C, 70.85; $\mathrm{H}, 4.23 ; \mathrm{N}, 19.44$.

3-(4-Nitrobenzyl)-2H-[1,2,4]triazino[2,3-c]quinazolin-2-one (7c). Yield - Method A, 85.1\%; method B, 84.7\%. M.p. - 266-268 ${ }^{\circ} \mathrm{C} ;{ }^{1} \mathrm{H}-\mathrm{NMR}, \delta: 4.29$ (s, $2 \mathrm{H}, \mathrm{CH}_{2}$ ), 7.66 (d, 2H, J=7.8 Hz, H-2, H-6 Ph), 7.78 (t, $1 \mathrm{H}, J=7.2 \mathrm{~Hz}$, $\mathrm{H}=10), 7.91$ (d, $1 \mathrm{H}, J=7.6 \mathrm{~Hz}, \mathrm{H}-8), 8.01(\mathrm{t}, 1 \mathrm{H}, J=8.4 \mathrm{~Hz}$, $\mathrm{H}=9$ ), $8.15(\mathrm{~d}, 2 \mathrm{H}, J=8.4 \mathrm{~Hz}, \mathrm{H}-3, \mathrm{H}-5 \mathrm{Ph}), 8.55(\mathrm{~d}, 1 \mathrm{H}$, $J=8.4 \mathrm{~Hz}, \mathrm{H}-11), 8.80$ (s, 1H, H-6); LC-MS, $m / z=335$ [M+1]; Anal. calcd. for $\mathrm{C}_{17} \mathrm{H}_{11} \mathrm{~N}_{5} \mathrm{O}_{3}$ : C, 61.26; $\mathrm{H}, 3.33$; N, 21.01. Found: C, 61.25; H, 3.30; N, 20.99 . 
3-Phenyl-2H-[1,2,4]triazino[2,3-c]quinazolin-2-one (7d). Yield - Method A, 72.9\%; method B, 80.7\%. M.p. $-246-248^{\circ} \mathrm{C} ;{ }^{1} \mathrm{H}-\mathrm{NMR}, \delta: 7.58$ (m, 3H, H-3, H-4, H-5 Ph), $7.83\left(\mathrm{dt}, 1 \mathrm{H},{ }^{3} \mathrm{~J}=8.0 \mathrm{~Hz},{ }^{4} \mathrm{~J}=0.8 \mathrm{~Hz}, \mathrm{H}-10\right), 7.95$ (d, $1 \mathrm{H}, J=8.0 \mathrm{~Hz}, \mathrm{H}=8), 8.05\left(\mathrm{dt}, 1 \mathrm{H},{ }^{3} J=8.2 \mathrm{~Hz},{ }^{4} J=1.3\right.$ $\mathrm{Hz}, \mathrm{H}-9$ ), 8.21 (d, 2H, ${ }^{3} J=8.2 \mathrm{~Hz},{ }^{4} J=1.2 \mathrm{~Hz}, \mathrm{H}-2, \mathrm{H}-6$ $\mathrm{Ph}$ ), 8.59 (dd, 1H, ${ }^{3} \mathrm{~J}=8.1 \mathrm{~Hz},{ }^{4} J=0.8 \mathrm{~Hz}, \mathrm{H}-11$ ), 9.09 (s, $1 \mathrm{H}, \mathrm{H}-6) ;{ }^{13} \mathrm{C}$ NMR, $\delta$ : $119.8,125.9,128.2,128.7$, $129.7,129.8,131.7,132.2,135.9,144.2,144.7,151.3$, 151.7, 160.4; LC-MS, $m / z=275[\mathrm{M}+1]$; EI-MS, $m / z$ $\left(\mathrm{I}_{\text {rel }}, \%\right)=275$ (4.7), 274 (2.1), 248 (4.3), 205 (3.3), 172 (9.8), 171 (100.0), 143 (3.7), 129 (14.2), 103 (11.1), 102 (6.2), 77 (3.3), 76 (19.5), 75 (6.3), 74 (2.7), 64 (5.5), 63 (20.3), 62 (11.2), 61 (3.0), 52 (4.9), 51 (5.5), 50 (6.9); Anal. calcd. for $\mathrm{C}_{16} \mathrm{H}_{10} \mathrm{~N}_{4} \mathrm{O}$ : C, 70.07; H, 3.67; N, 20.43. Found: C, 70.05; H, 3.63; N, 20.45.

3-(4-Methylphenyl)-2H-[1,2,4]triazino[2,3-c]quinazolin-2-one (7e). Yield - Method A, 83.2\%; method B, 80.7\%; ${ }^{1} \mathrm{H}-\mathrm{NMR}, \delta: 2.46$ (s, 3H, $\underline{\mathrm{H}}_{3}$ ), 7.28 (d, $2 \mathrm{H}$, $J=8.2 \mathrm{~Hz}, \mathrm{H}-3, \mathrm{H}-5 \mathrm{Ph}), 7.77$ (t, 1H, J=7.8 Hz, H-10), 7.89 (d, $1 \mathrm{H}, J=7.9 \mathrm{~Hz}, \mathrm{H}-8), 7.97$ (t, $1 \mathrm{H}, J=8.0 \mathrm{~Hz}, \mathrm{H}-9$ ), 8.22 (d, 2H, J=8.2 Hz, H-2, H-6 Ph), 8.67 (d, 1H, J=8.1 Hz, H-11), 8.81 (s, 1H, H-6); LC-MS, $m / z=289$ [M+1]; EI-MS, $m / z\left(\mathrm{I}_{\mathrm{rel}}, \%\right)=172$ (8.4), 171 (100), 143 (5.5), 129 (50.2), 117 (33.4), 116 (45.7), 103 (5.9), 102 (27.1); Anal. calcd. for $\mathrm{C}_{17} \mathrm{H}_{12} \mathrm{~N}_{4} \mathrm{O}: \mathrm{C}, 70.82 ; \mathrm{H}, 4.20$; N, 19.43. Found: C, 70.83; H, 4.20; N, 19.43.

3-(4-Methoxyphenyl)-2 H-[1,2,4]triazino [2,3-c] quinazolin-2-one (7f). Yield - Method A, 49.3\%; method B, 86.4\%. M.p. $-247-248^{\circ} \mathrm{C} ;{ }^{1} \mathrm{H}-\mathrm{NMR}, \delta: 3.85$ (s, $3 \mathrm{H}, \mathrm{OC} \underline{H}_{3}$ ), 7.11 (d, $2 \mathrm{H}, J=8.2 \mathrm{~Hz}, \mathrm{H}-3, \mathrm{H}-5 \mathrm{Ph}$ ), 7.81 (t, $1 \mathrm{H}, J=7.8 \mathrm{~Hz}, \mathrm{H}-10), 7.94$ (d, $1 \mathrm{H}, J=7.9 \mathrm{~Hz}, \mathrm{H}-8$ ), 8.03 (t, 1H, J=7.8 Hz, H-9), 8.31 (d, 2H, J=8.2 Hz, H-2, H-6 Ph), 8.57 (d, H, J=7.8 Hz, H-11), 9.06 (s, 1H, H-6); LC-MS, $m / z=305[\mathrm{M}+1]$; EI-MS, $m / z\left(\mathrm{I}_{\text {rel, }} \%\right)=304$ (3.1), 276 (8.1), 190 (7.4), 187 (5), 172 (8.8), 171 (100), 169 (7.7), 134 (6.6), 133 (58.8), 132 (7.2), 129 (33.9), 111 (5.7), 102 (13.4); Anal. calcd. for $\mathrm{C}_{17} \mathrm{H}_{12} \mathrm{~N}_{4} \mathrm{O}_{2}$ : C, 67.10; H, 3.97; N, 18.41. Found: C, 67.13; H, 4.01; N, 18.43.

3-(2-Thienyl)-2H-[1,2,4]triazino[2,3-c]quinazolin-2-one (7g). Yield - Method A, 71.4\%; method B, 83.0\%. M.p. $-279-280^{\circ} \mathrm{C} ;{ }^{1} \mathrm{H}-\mathrm{NMR}, \delta: 7.31(\mathrm{t}, 1 \mathrm{H}, \mathrm{J}=$ $4.3 \mathrm{~Hz}, \mathrm{H}-4$ Th.), 7.98 (d, 1H, J=5.0 Hz, H-3 Th.), 7.82 (t, 1H, J=7.8 Hz, H-10), 7.94 (d, 1H, J=8.1 Hz, H-8), 8.04 (t, $1 \mathrm{H}, J=7.8 \mathrm{~Hz}, \mathrm{H}=9$ ), 8.40 (d, $1 \mathrm{H}, J=3.2 \mathrm{~Hz}, \mathrm{H}-5$ Th.), 8.58 (d, 1H, J=8.1 Hz, H-11), 9.04 (s, 1H, H-6); ${ }^{13} \mathrm{C}-\mathrm{NMR}, \delta$ : $120.0,125.9,128.3,128.6,129.7,133.0$, 133.6, 134.4, 135.8, 144.1, 144.4, 146.7, 151.1, 159.4; LC-MS, $m / z=281$ [M+1]; EI-MS, m/z (Irel, \%): 254 (7.0), 227 (13.6), 213 (12.7), 211 (16.6), 173 (7.6), 172 (88.5), 171 (93.9), 143 (27.7), 130 (13.5), 129 (100.0), 116 (6.1), 110 (5.1), 109 (58.1), 103 (6.2), 102 (35.7); Anal. calcd. for $\mathrm{C}_{14} \mathrm{H}_{8} \mathrm{~N}_{4} \mathrm{OS}$ : C, 59.99; $\mathrm{H}$, 2.88; N, 19.99; S, 11.44. Found: C, 60.01; H, 2.91; N, 20.03; S, 11.46.
The general method of synthesis of 3-[2-oxo-2ethyl]-2H-[1,2,4]triazino[2,3-c]quinazolin-2-ones (8a-8d).

Heat esters 6a-6d (0.005 Mol) for $6 \mathrm{~h}$ in $10 \mathrm{ml}$ of glacial acetic acid. Remove the solvent under the vacuum, add $5 \mathrm{ml}$ of methanol to the residue, filter the precipitate, wash on the filter with diethyl ether and dry.

3-(2-Phenyl-2-oxoethyl)-2H-[1,2,4]triazino[2,3-c] quinazolin-2-one (8a). Yield-74.4\%. M.p. $-286-288^{\circ} \mathrm{C}$. ${ }^{1} \mathrm{H}$ NMR, $\delta: 4.58\left(\mathrm{~s}, 2 \mathrm{H}, \mathrm{CH}_{2}\right), 7.54(\mathrm{t}, 2 \mathrm{H}, J=7.8 \mathrm{~Hz}$, $\left.\mathrm{H}-3^{\prime}, 5^{\prime}\right), 7.72\left(\mathrm{t}, 1 \mathrm{H}, J=7.8 \mathrm{~Hz}, \mathrm{H}-4^{\prime}\right), 7.82(\mathrm{t}, 1 \mathrm{H}, J=7.8 \mathrm{~Hz}$, $\mathrm{H}-10), 7.94(\mathrm{~d}, 1 \mathrm{H}, J=8.0 \mathrm{~Hz}, \mathrm{H}-8), 8.04(\mathrm{t}, 1 \mathrm{H}, J=7.8 \mathrm{~Hz}$, H-9), 8.09 (d, 2H, J=8.0 Hz, H-2',6'), 8.31 (d, $1 \mathrm{H}, J=8.0 \mathrm{~Hz}$, $\mathrm{H}-11), 8.99$ (s, $1 \mathrm{H}, \mathrm{H}-6) .{ }^{13} \mathrm{C}$ NMR (100 MHz) $\delta=41.70$, $120.11,125.91,128.30,128.89$ (2C), 129.34 (2C), 129.62, $134.29,136.04,136.49,144.29,144.37,152.32,155.40$, 160.60, 195.41. LC-MS, $m / z=317$ [M+1]. Anal. calcd for $\mathrm{C}_{18} \mathrm{H}_{12} \mathrm{~N}_{4} \mathrm{O}_{2}$ : C, 68.35; $\mathrm{H}, 3.82 ; \mathrm{N}, 17.71$. Found: $\mathrm{C}$, $68.41 ; \mathrm{H}, 3.75 ; \mathrm{N}, 17.79$.

3-[2-(4-Methylphenyl)-2-oxoethyl]-2H-[1,2,4]triazino[2,3-c]quinazolin-2-one (8c). Yield - 51.5\%. M.p. - 236-238 ${ }^{\circ} \mathrm{C} .{ }^{1} \mathrm{H}$ NMR, $\delta: 2.41\left(\mathrm{~s}, 3 \mathrm{H}, \mathrm{CH}_{3}\right.$ ), 4.54 (s, $\left.2 \mathrm{H}, \mathrm{CH}_{2}\right), 7.39,7.98\left(\mathrm{~d}, 2 \mathrm{H}, J=8.0 \mathrm{~Hz}, \mathrm{H}_{\text {Phenyl }}\right), 7.82(\mathrm{t}$, $1 \mathrm{H}, J=7.8 \mathrm{~Hz}, \mathrm{H}-10$ ), 7.94 (d, 1H, J=8.0 Hz, H-8), 8.05 (t, 1H, J=7.8 Hz, H-9), 8.57 (d, 1H, J=8.0 Hz, H-11), 8.99 (s, 1H, H-6). ${ }^{13} \mathrm{C}$ NMR (100 MHz) $\delta=21.72,41.59$, $120.15,125.93,128.32,129.01$ (2C), 129.63, 129.87 (2C), 134.06, 136.04, 144.33, 144.40, 144.79, 152.34, 155.47, 160.62, 194.87. LC-MS, $m / z=331\left(\mathrm{MH}^{+}\right)$. Anal. calcd for $\mathrm{C}_{19} \mathrm{H}_{14} \mathrm{~N}_{4} \mathrm{O}_{2}$ : C, 69.08; $\mathrm{H}, 4.27 ; \mathrm{N}, 16.96$. Found: C, 69.19; H, 4.21; N, 16.98 .

3-[2-(4-Methoxyphenyl)-2-oxoethyl]-2H-[1,2,4]triazino[2,3-c]quinazolin-2-one (8c). Yield - 71.5\%. M.p. - 276-278 ${ }^{\circ} \mathrm{C} .{ }^{1} \mathrm{H}$ NMR, $\delta: 3.88$ (s, $3 \mathrm{H}, \mathrm{OCH}_{3}$ ), 4.52 (s, $2 \mathrm{H}, \mathrm{CH}_{2}$ ) 7.10 (d, 2H, J=8.1 Hz, H-3',5'), $7.82(\mathrm{t}, 1 \mathrm{H}$, $J=7.8 \mathrm{~Hz}, \mathrm{H}-10), 7.94$ (d, 1H, J=8.0 Hz, H-8), 8.05 (m, $\left.3 \mathrm{H}, \mathrm{H}-9,2^{\prime}, 6^{\prime}\right), 8.58$ (d, 1H, J=8.0 Hz, H-11), 8.98 (s, 1H, H-6). ${ }^{13}$ C NMR, $\delta: 41.38,56.14,114.53,120.15,125.92$, $128.31,129.45,129.63,131.29,136.05,144.33,144.41$, $152.32,155.57,160.63,164.09,193.68$. LC-MS, $m / z$ $=348,347[\mathrm{M}+1]$. EI-MS, $m / z\left(\mathrm{I}_{\text {rel }} \%\right)=346\left(\mathrm{M}^{+}, 13.8\right)$, 175 (5.2), 172 (6.1), 171 (40.4), 136 (10.9), 135 (100.0), 129 (17.8), 102 (5.2), 92 (5.2). Anal. calcd for $\mathrm{C}_{19} \mathrm{H}_{14} \mathrm{~N}_{4} \mathrm{O}_{3}$ : C, 65.89; H, 4.07; N, 16.18. Found: C, 65.95; H, 3.92; $\mathrm{N}, 16.31$.

3-[2-Thiophen-2-yl-2-oxoethyl]-2H-[1,2,4]triazino[2,3-c]quinazolin-2-one (8d). Yield - 72.9\%. M.p. 256-258 ${ }^{\circ} \mathrm{C} .{ }^{1} \mathrm{H}$ NMR, $\delta: 4.52\left(\mathrm{~s}, 2 \mathrm{H}, \mathrm{CH}_{2}\right), 7.31(\mathrm{t}, 1 \mathrm{H}$, $\left.J=4.0 \mathrm{~Hz}, \mathrm{H}-4^{\prime}\right), 7.79(\mathrm{t}, 1 \mathrm{H}, J=7.8 \mathrm{~Hz}, \mathrm{H}-10), 7.91(\mathrm{~d}$, $1 \mathrm{H}, J=7.9 \mathrm{~Hz}, \mathrm{H}-8), 8.03(\mathrm{t}, 1 \mathrm{H}, J=8.0 \mathrm{~Hz}, \mathrm{H}-9), 8.09$ (d, $1 \mathrm{H}, J=4.9 \mathrm{~Hz}, \mathrm{H}-3^{\prime}$ ), 8.18 (d, 1H, J=3.2 Hz, H-5'), 8.55 (d, 1H, J=8.0 Hz, H-11), 8.97 (s, $1 \mathrm{H}, \mathrm{H}-6) .{ }^{13} \mathrm{C}$ NMR, $\delta: 42.02,120.10,125.93,128.29,129.41,129.62,135.23$, $136.05,136.24,143.36,144.29,144.38,152.33,154.73$, 160.57, 188.00. LC-MS, $m / z=323$ [M+1]. EI-MS, $m / z$ $\left(\mathrm{I}_{\mathrm{rel}}, \%\right)=325(5.2), 324\left([\mathrm{M}+2]^{+*}, 13.4\right), 322\left(\mathrm{M}^{+\bullet}\right.$, 
34.5), 321 (100.0), 170 (13.1), 168 (6.3). Anal. calcd for $\mathrm{C}_{16} \mathrm{H}_{10} \mathrm{~N}_{4} \mathrm{O}_{2} \mathrm{~S}$ : C, 59.62; $\mathrm{H}, 3.13 ; \mathrm{N}, 17.38$. Found: $\mathrm{C}$, $59.70 ; \mathrm{H}, 3.21 ; \mathrm{N}, 17.29$.

The general method of synthesis of $3-\mathrm{R}-2 \mathrm{H}$ [1,2,4]triazino[2,3-c]quinazoline-2,6(7H)-dione (9a-9d).

Add carbonyldiimidazole $(0.0055 \mathrm{Mol})$ to the suspension of the corresponding 2-R-[2-oxo-2,3-dihydroquinazolin-4 $(1 \mathrm{H})$-ylidene)hydrazono]acetic acid $(5.1,5.4-5.6,5.8)(0.005 \mathrm{Mol})$ in $10 \mathrm{ml}$ of anhydrous dioxane or $0.9 \mathrm{~g}$ of DMF. Heat the mixture at $80^{\circ} \mathrm{C}$ for $1 \mathrm{~h}$, cool, filter the precipitate formed and dry.

3-Methyl-2H-[1,2,4]triazino[2,3-c]quinazoline-2,6 (7H)-dione (9a). Yield - 78.9\%. M.p. $>320{ }^{\circ} \mathrm{C} ;{ }^{1} \mathrm{H}-\mathrm{NMR}$, $\delta: 2.33$ (s, 3H, $\left.\mathrm{CH}_{3}\right), 7.50(\mathrm{~m}, 2 \mathrm{H}, \mathrm{H}-9, \mathrm{H}-8), 7.74(\mathrm{t}, 1 \mathrm{H}$, $J=7.6 \mathrm{~Hz}, \mathrm{H}-10$ ), 8.29 (d, $1 \mathrm{H}, J=8.1 \mathrm{~Hz}, \mathrm{H}-11$ ), 11.97 (s, $1 \mathrm{H}, 7-\mathrm{N} \underline{H}$ ); LC-MS, $m / z=229$ [M+1]; Anal. calcd. for $\mathrm{C}_{11} \mathrm{H}_{8} \mathrm{~N}_{4} \mathrm{O}_{2}$ : C, 57.89; $\mathrm{H}, 3.53 ; \mathrm{N}, 24.55$. Found: $\mathrm{C}$, 57.90; H, 3.54; N, 24.57.

3-Phenyl-2H-[1,2,4]triazino[2,3-c]quinazoline-2,6 (7H)-dione (9b). Yield -91.9\%. M.p. $>320^{\circ} \mathrm{C} ;{ }^{1} \mathrm{H}-\mathrm{NMR}$, $\delta: 7.29$ (d, 1H, J=8.0 Hz, H-8), 7.35 (t, $1 \mathrm{H}, J=7.8 \mathrm{~Hz}$, $\mathrm{H}-9), 7.55\left(\mathrm{~m}, 3 \mathrm{H}, \mathrm{H}^{3}, \mathrm{H}^{4}, \mathrm{H}^{5} \mathrm{Ph}\right), 7.75(\mathrm{t}, 1 \mathrm{H}, J=7.4 \mathrm{~Hz}$, H-10), 8.19 (d, 2H, H-2, H-6 Ph, J=7.4 Hz), 8.29 (d, $1 \mathrm{H}, J=8.0 \mathrm{~Hz}, \mathrm{H}-11$ ), 12.37 (s, $1 \mathrm{H}, 7-\mathrm{N} \underline{H}$ ); ${ }^{13} \mathrm{C}-\mathrm{NMR}, \delta$ : 160.4, 154.4, 149.6, 145.3, 138.8, 136.1, 132.7, 131.4, 129.6, 128.7, 126.9, 124.0, 116.0, 113.5; LC-MS, $m / z$ $=291[\mathrm{M}+1]$; EI-MS, $m / z\left(\mathrm{I}_{\text {rel }} \%\right)=290$ (7.7), 263 (6.3), 188 (12.6), 187 (100), 171 (6.3), 159 (30.6), 145 (20.8), 144 (8.8), 117 (9.9), 103 (23.4); Anal. calcd. for $\mathrm{C}_{16} \mathrm{H}_{10} \mathrm{~N}_{4} \mathrm{O}_{2}$ : C, 66.20; H, 3.47; N, 19.30. Found: C, 66.23; H, 3.51; $\mathrm{N}, 19.35$.

3-(4-Methylphenyl)-2H-[1,2,4]triazino[2,3-c]quinazoline-2,6(7H)-dione (9c). Yield -99.5\%. M.p. $>320^{\circ} \mathrm{C}$; ${ }^{1} \mathrm{H}-\mathrm{NMR}, \delta: 2.39$ (s, $3 \mathrm{H}, \mathrm{C}_{3}$ ), 7.30 (d, $1 \mathrm{H}, J=8.0 \mathrm{~Hz}$, H-8), 7.35 (t, 1H, H-9), 7.39 (d, 2H, J=8.0 Hz, H-3, H-5 $\mathrm{Ph}$ ), $7.76(\mathrm{t}, 1 \mathrm{H}, J=7.8 \mathrm{~Hz}, \mathrm{H}-10), 8.13$ (d, 2H, J=8.2 Hz, H-2, H-6 Ph), 8.28 (d, 1H, J=7.8 Hz, H-11), 12.36 (s, $1 \mathrm{H}, 7-\mathrm{N} \underline{H}$ ); LC-MS, $m / z=305$ [M+1]; Anal. calcd. for $\mathrm{C}_{17} \mathrm{H}_{12} \mathrm{~N}_{4} \mathrm{O}_{2}$ : $\mathrm{C}, 67.10 ; \mathrm{H}, 3.97 ; \mathrm{N}, 18.41$. Found: $\mathrm{C}, 67.08$; $\mathrm{H}, 3.95 ; \mathrm{N}, 18.39$.

3-(4-Methoxyphenyl)-2H-[1,2,4]triazino[2,3-c]quinazoline-2,6(7H)-dione (9d). Yield - 99.5\%. M.p. $>320^{\circ} \mathrm{C}$; ${ }^{1} \mathrm{H}-\mathrm{NMR}, \delta: 3.84$ (s, $3 \mathrm{H}, \mathrm{OC} \underline{H}_{3}$ ), 7.07 (d, $2 \mathrm{H}, J=8.9 \mathrm{~Hz}$, $\mathrm{H}-3, \mathrm{H}-5 \mathrm{Ph}$ ), 7.30 (d, 1H, J=8.2 Hz, H-8), 7.35 (t, 1H, $J=7.4 \mathrm{~Hz}, \mathrm{H}-9), 7.75$ (t, 1H, J=7.4 Hz, H-10), 8.27 (m, 3H, H-11 Quin, H-2, H-6 Ph), 12.35 (s, 1H, 7-N $\underline{H}$ ); LCMS, $m / z=321[\mathrm{M}+1]$; Anal. calcd. for $\mathrm{C}_{17} \mathrm{H}_{12} \mathrm{~N}_{4} \mathrm{O}_{3}$ : C, 63.75; H, 3.78; N, 17.49. Found: C, 63.78; H, 3.81; N, 17.41.

3-(2-Thienyl)-2H-[1,2,4]triazino[2,3-c]quinazoline-2,6(7H)-dione (9e). Yield $-91.2 \%$. M.p. $>320^{\circ} \mathrm{C}$; ${ }^{1} \mathrm{H}-\mathrm{NMR}, \delta: 7.27$ (t, 1H, J=4.9 Hz, H-4 Th.); 7.32 (d, $1 \mathrm{H}, J=8.0 \mathrm{~Hz}, \mathrm{H}-8), 7.37$ (t, 1H, J=7.8 Hz, H-9), 7.78 (t, $1 \mathrm{H}, J=7.4 \mathrm{~Hz}, \mathrm{H}-10$ ), 7.93 (d, 1H, J=4.5 Hz, H-5 Th.), 8.29 (d, 1H, J=8.1 Hz, H-11), 8.32 (s, 1H, H-3 Th.), 12.43 (s, 1H, 7-N $\underline{H}$ ); LC-MS, $m / z=297$ [M+1]; Anal. calcd. for
$\mathrm{C}_{14} \mathrm{H}_{8} \mathrm{~N}_{4} \mathrm{O}_{2} \mathrm{~S}: \mathrm{C}, 56.75 ; \mathrm{H}, 2.72 ; \mathrm{N}, 18.91 ; \mathrm{S}, 10.82$. Found:

C, 56.79; H, 2.74; N, 18.94; S, 10.84 .

The general method of synthesis of 3-(2-aminophenyl)-6-R-1,2,4-triazin-5(2H)-ones (10a-10g).

Add hydrazine hydrate $(0.025 \mathrm{Mol})$ to the suspension of the corresponding substituted 3-R-2H-[1,2,4] triazino[2,3-c]quinazolin-2-one (7.1-7.7) $(0.005 \mathrm{Mol})$ in $15 \mathrm{ml}$ of propan-2-ol and reflux for $1 \mathrm{~h}$. Cool the reaction mixture, acidify with hydrochloric acid to $\mathrm{pH}=4-5$. Filter the precipitate formed, wash with water and dry.

3-(2-Aminophenyl)-6-methyl-1,2,4-triazin-5(2H)-one (10a). Yield - 46.5\%. M.p. $-240-241^{\circ} \mathrm{C} ;{ }^{1} \mathrm{H}-\mathrm{NMR}, \delta$ : $2.19\left(\mathrm{~s}, 3 \mathrm{H}, \mathrm{CH}_{3}\right), 6.60(\mathrm{t}, 1 \mathrm{H}, J=7.9 \mathrm{~Hz}, \mathrm{H}-5), 6.80(\mathrm{~d}$, $1 \mathrm{H}, J=8.1 \mathrm{~Hz}, \mathrm{H}-3), 7.25(\mathrm{t}, 1 \mathrm{H}, J=8.3 \mathrm{~Hz}, \mathrm{H}-4), 7.71(\mathrm{~d}$, $1 \mathrm{H}, J=8.0 \mathrm{~Hz}, \mathrm{H}-6$ ), 8.44 (br.s., $2 \mathrm{H},-\mathrm{NH}_{2}$ ); ${ }^{13} \mathrm{C}-\mathrm{NMR}, \delta$ : 17.6, 110.2, 115.7, 115.7, 117.5, 117.5, 128.7, 133.4, 133.4, 150.2; LC-MS, $m / z=203$ [M+1], Anal. calcd. for $\mathrm{C}_{10} \mathrm{H}_{10} \mathrm{~N}_{4} \mathrm{O}: \mathrm{C}, 59.40 ; \mathrm{H}, 4.98 ; \mathrm{N}, 27.71$. Found: $\mathrm{C}, 59.42$; $\mathrm{H}, 4.99 ; \mathrm{N}, 27.74$.

3-(2-Aminophenyl)-6-benzyl-1,2,4-triazin-5(2H)one (10b). Yield - 92.4\%. M.p. - 282-284 ${ }^{\circ} \mathrm{C} ;{ }^{1} \mathrm{H}-\mathrm{NMR}$, $\delta: 3.93\left(\mathrm{~d}, 1 \mathrm{H}, J=6.2 \mathrm{~Hz}, \mathrm{CH}_{2}\right), 6.59(\mathrm{t}, 1 \mathrm{H}, J=7.8 \mathrm{~Hz}$, $\mathrm{H}-5), 6.80(\mathrm{~d}, 1 \mathrm{H}, J=8.0 \mathrm{~Hz}, \mathrm{H}-3), 7.22(\mathrm{t}, 1 \mathrm{H}, J=6.6 \mathrm{~Hz}$, H-4), 7.30 (m, 5H, H-2', H-3', H-4' ,H-5', H-6' Ph), 7.60 (d, $1 \mathrm{H}, J=8.2 \mathrm{~Hz}, \mathrm{H}-6$ ), 9.12 (br.s., $2 \mathrm{H},-\mathrm{NH}_{2}$ ); ${ }^{13} \mathrm{C}-\mathrm{NMR}$, $\delta: 36.7,109.9,115.7,117.5,126.9,128.6,128.7,128.7$, 128.7, 129.8, 129.8, 129.8, 129.8, 133.5, 137.1, 150.4; LC-MS, $m / z=279[\mathrm{M}+1]$, Anal. calcd for $\mathrm{C}_{16} \mathrm{H}_{14} \mathrm{~N}_{4} \mathrm{O}: \mathrm{C}$, 69.05; H, 5.07; N, 20.13. Found: C, 69.08; H, 5.09; N, 20.15 .

3-(2-Aminophenyl)-6-(4-nitrobenzyl)-1,2,4-triazin$5(2 \mathrm{H})$-one (10c). Yield - 82.5\%. M.p. $-264-266^{\circ} \mathrm{C}$; ${ }^{1} \mathrm{H}-\mathrm{NMR}, \delta: 4.10\left(\mathrm{~s}, 1 \mathrm{H}, \mathrm{CH}_{2}\right.$ ), 6.59 (t, 1H, J=7.4 Hz, H-5 $\mathrm{Ph}), 6.80(\mathrm{~d}, 1 \mathrm{H}, J=8.4 \mathrm{~Hz}, \mathrm{H}-3 \mathrm{Ph}), 7.23(\mathrm{t}, 1 \mathrm{H}, J=7.2$ Hz, H-4 Ph), 7.60 (m, 3H, H-6 Ph, H-2', H-6' Ph), 8.18 (d, $2 \mathrm{H}, \mathrm{J}=8.0 \mathrm{~Hz}, \mathrm{H}-3$ ', $\mathrm{H}-5^{\prime} \mathrm{Ph}$ ), 9.18 (br.s., $2 \mathrm{H},-\mathrm{NH}_{2}$ ); ${ }^{13} \mathrm{C}$-NMR, $\delta: 36.03,109.17,115.12,116.97,123.23,128.06$, $130.63,132.97,145.05,146.18,149.84 ;$ LC-MS, $m / z=$ $324[\mathrm{M}+1]$, Anal. calcd. for $\mathrm{C}_{16} \mathrm{H}_{13} \mathrm{~N}_{5} \mathrm{O}_{3}: \mathrm{C}, 59.44 ; \mathrm{H}$, 4.05; N, 21.66.17. Found: C, 59.45; H, 4.06; N, 21.69.

3-(2-Aminophenyl)-6-phenyl-1,2,4-triazin-5(2H)-one (10d). Yield - 58.7\%. M.p. - 290-292 ${ }^{\circ} \mathrm{C} ;{ }^{1} \mathrm{H}-\mathrm{NMR}, \delta$ : $6.64(\mathrm{t}, J=7.4 \mathrm{~Hz}, 1 \mathrm{H}, \mathrm{H}-5 \mathrm{Ph}), 6.84(\mathrm{~d}, 1 \mathrm{H}, J=8.5 \mathrm{~Hz}$, $\mathrm{H}-3 \mathrm{Ph}), 7.26(\mathrm{t}, 1 \mathrm{H}, J=7.4 \mathrm{~Hz}, \mathrm{H}-4 \mathrm{Ph}), 7.50(\mathrm{~m}, 3 \mathrm{H}$, H-3', H-4', H-5' Ph), 7.72 (d, 1H, J=7.8 Hz, H-6 Ph), 8.14 (d, 2H, J=4.1 Hz, H-2',H-6' Ph,), 9.5 (br.s., $2 \mathrm{H},-\mathrm{NH}_{2}$ ); ${ }^{13} \mathrm{C}$-NMR, $\delta: 109.7,115.7,117.5,128.6,128.6,128.6$, $128.8,128.8,128.9,128.9,128.9,130.4,133.5,133.6$, 150.6; LC-MS, $m / z=265$ [M+1], Anal. calcd. for $\mathrm{C}_{15} \mathrm{H}_{12} \mathrm{~N}_{4} \mathrm{O}$ : C, 68.17; H, 4.58; N, 21.20. Found: C, 68.20; H, 4.59; $\mathrm{N}, 21.24$.

3-(2-Aminophenyl)-6-(4-methylphenyl)-1,2,4-triazin-5(2H)-one (10e). Yield - 52.2\%. M.p. $-258-260^{\circ} \mathrm{C}$; ${ }^{1} \mathrm{H}-\mathrm{NMR}, \delta: 2.36\left(\mathrm{~s}, 3 \mathrm{H}, \mathrm{CH}_{3}\right), 6.63(\mathrm{t}, 1 \mathrm{H}, J=7.4 \mathrm{~Hz}, \mathrm{H}-5)$, $6.83(\mathrm{~d}, 1 \mathrm{H}, J=8.2 \mathrm{~Hz}, \mathrm{H}-3), 7.26$ (t, 1H, J=7.4 Hz, H-4), 7.28 (d, 2H, J=8.2 Hz, H-3', H-5`), 7.69 (d, 1H, J=8.4 Hz, 
H-6), 8.06 (d, 2H, J=8.2 Hz, H-2',H-6' Ph), 9.17 (br.s., $\left.2 \mathrm{H},-\mathrm{NH}_{2}\right) ;{ }^{13} \mathrm{C}-\mathrm{NMR}, \delta: 21.01,109.16,115.12,116.95$, $128.19,128.60,130.12,132.96,139.64,149.92$; LCMS, $m / z=279[\mathrm{M}+1]$, Anal. calcd. for $\mathrm{C}_{16} \mathrm{H}_{14} \mathrm{~N}_{4} \mathrm{O}: \mathrm{C}, 69.05$; H, 5.07; N, 20.13. Found: C, 69.09; H, 5.11; N, 20.18.

3-(2-Aminophenyl)-6-(4-methoxyphenyl)-1,2,4-triazin-5(2H)-one (10f) Yield - 74.8\%. M.p. $-265-266^{\circ} \mathrm{C}$; ${ }^{1} \mathrm{H}-\mathrm{NMR}, \delta$ : $3.82\left(\mathrm{~s}, 3 \mathrm{H}, \mathrm{OCH}_{3}\right), 6.63(\mathrm{t}, J=7.8 \mathrm{~Hz}, 1 \mathrm{H}, \mathrm{H}-5$ Ph), 6.83 (d, J=8.4 Hz, 1H, H-3 Ph,), 7.06 (d, J=8.9 Hz, 2H, H-3', H-5' Ph), 7.25 (t, J=8.0 Hz, 1H, H-4 Ph), 7.70 (d, J=8.2 Hz, 1H, H-6 Ph), 8.18 (d, J=8.8 Hz, 2H, H-2', H-6' Ph), 9.20 (br.s., $2 \mathrm{H},-\mathrm{NH}_{2}$ ); ${ }^{13} \mathrm{C}-\mathrm{NMR}, \delta: 55.22,109.23$, 113.47, 115.11, 116.93, 125.23, 128.16, 129.88, 132.89, 149.87, 160.61; Anal. calcd. for $\mathrm{C}_{16} \mathrm{H}_{14} \mathrm{~N}_{4} \mathrm{O}_{2}$ : C, 65.30; H, 4.79; N, 19.04. Found: C, 65.33; H, 4.81; N, 19.11.

3-(2-Aminophenyl)-6-(thienyl-2)-1,2,4-triazin5(2H)-one (10g). Yield - 25.8\%. M.p. - 296-297 ${ }^{\circ} \mathrm{C}$; ${ }^{1} \mathrm{H}-\mathrm{NMR}, \delta: 6.62(\mathrm{t}, J=7.8 \mathrm{~Hz}, 1 \mathrm{H}, \mathrm{H}-4 \mathrm{Ph}), 6.82(\mathrm{~d}$, $J=8.1 \mathrm{~Hz}, 1 \mathrm{H}, \mathrm{H}-6 \mathrm{Ph}), 7.25$ (t, J=7.8 Hz, 1H, H-5 Ph), 7.31 (t, J=4.2 Hz, 1H, H-4 Th.), 7.67 (d, J=7.8 Hz, 1H, H-3 Ph), 7.78 (d, J=4.9 Hz, 1H, H-5 Th.), 8.21 (d, J=3.4 Hz, 1H, H-3 Th.), 9.26 (br.s., $2 \mathrm{H},-\mathrm{NH}_{2}$ ); ${ }^{13} \mathrm{C}-\mathrm{NMR}, \delta: 150.4$, 135.7, 133.5, 131.2, 130.6, 130.6, 128.8, 128.8, 128.3, 117.5, 115.8, 109.9; LC-MS, $m / z=269$ [M+1], Anal. calcd. $\mathrm{C}_{13} \mathrm{H}_{10} \mathrm{~N}_{4}$ OS: C, 57.76; H, 73; N, 20.73. Found: C, 57.76; H, 3.73; N, 20.73.

The general method of synthesis 3'-(2-aminophenyl)-3-R-spiro[pyrazoline-5,6'(1'H)-1,2,4-triazin]-5'(4'H)-one (11.1-11.4).

Add hydrazine hydrate $(0.40 \mathrm{Mol})$ to the appropriate 3-[2-oxo-2-R-ethyl]-2H-[1,2,4] triazino[2,3-c] quinazolin-2-ones (8a-8d) $(0.10 \mathrm{Mol})$ in $15 \mathrm{ml}$ of propan-2-ol, reflux the resulting mixture for 6-8 h. After cooling filter the precipitate and wash with propan-2-ol.

3'-(2-Aminophenyl)-3-phenyl-spiro[pyrazoline5,6'(1'H)-1,2,4-triazin]-5'(4'H)-one (11a). Yield - 87.5\%. M.p. $-236-238^{\circ} \mathrm{C} .{ }^{1} \mathrm{H}$ NMR, $\delta: 2.95,3.84(\mathrm{~d}, 1 \mathrm{H}, J=17.6 \mathrm{~Hz}$, $\mathrm{CH}_{2}$ ), 6.32 (br. s, 2H, NH${ }_{2}$ ), 6.55 (t, 1H, J=7.6 Hz, H-5'), $6.71\left(\mathrm{~d}, 1 \mathrm{H}, J=7.8 \mathrm{~Hz}, \mathrm{H}-3^{\prime}\right), 7.05\left(\mathrm{t}, 1 \mathrm{H}, J=7.8 \mathrm{~Hz}, \mathrm{H}-4^{\prime}\right)$, 7.35 (d, 1H, J=7.6 Hz, H-6'), 7.40 (t, 3H, J=7.6 Hz, $\mathrm{H}-3,4,5), 7.65$ (d, 2H, J=7.4 Hz, H-2,6), 8.22, 8.14 (s, $1 \mathrm{H}, \mathrm{NH}), 10.84$ (s, $1 \mathrm{H}, \mathrm{NH}) .{ }^{13} \mathrm{C}$ NMR, $\delta: 39.01,77.72$, 113.16, 115.29, 116.04, 125.64, 125.86, 127.86, 128.77, 129.01, 129.42, 129.87, 133.31, 140.31, 147.59, 148.10, 163.97. LC-MS, $m / z=322,321[\mathrm{M}+1]$. Anal. calcd for $\mathrm{C}_{17} \mathrm{H}_{16} \mathrm{~N}_{6} \mathrm{O}$ : C, 63.74; H, 5.03; N, 26.23. Found: C, 63.88; H, 5.12; N, 26.11.

3'-(2-Aminophenyl)-3-(4-methylphenyl)-spiro [pyrazoline-5,6'(1'H)-1,2,4-triazin]-5'(4'H)-one (11b). Yield - 68.8\%. M.p. $-206-208^{\circ} \mathrm{C} .{ }^{1} \mathrm{H}$ NMR, $\delta: 2.92,3.80$ (d, $1 \mathrm{H}, J=17.6 \mathrm{~Hz}, \mathrm{CH}_{2}$ ), 6.32 (br. s, $2 \mathrm{H}, \mathrm{NH}_{2}$ ), 6.54 (t, $\left.1 \mathrm{H}, J=7.6 \mathrm{~Hz}, \mathrm{H}-5^{\prime}\right), 6.70$ (d, 1H, J=8.1 Hz, H-3'), 7.04 (t, $1 \mathrm{H}, J=7.8 \mathrm{~Hz}, \mathrm{H}-4^{\prime}$ ), 7.20 (d, 2H, J=8.1 Hz, H-3,5), 7.41 (d, 1H, J=7.8 Hz, H-6'), 7.54 (d, 2H, J=8.1 Hz, H-2,6), 8.13, 8.10 (s, 1H, NH), 10.82 (s, $1 \mathrm{H}, \mathrm{NH}) .{ }^{13} \mathrm{C}$ NMR, $\delta$ : $21.43,39.10,77.58,113.13,115.25,116.00,125.85$
(2C), 127.83, 129.59 (2C), 129.83, 130.59, 138.24, 140.25, 147.58, 148.23, 164.02. LC-MS, $m / z=335$ [M+1]. Anal. calcd for $\mathrm{C}_{18} \mathrm{H}_{18} \mathrm{~N}_{6} \mathrm{O}$ : C, 64.66; H, 5.43; N, 25.13. Found: C, 64.77; H, 5.51; N, 25.05.

3'-(2-Aminophenyl)-3-(4-methoxyphenyl)-spiro [pyrazoline-5,6'(1'H)-1,2,4-triazin]-5'(4'H)-one (11c). Yield - 91.3\%. M.p. - 214-216 ${ }^{\circ} \mathrm{C} .{ }^{1} \mathrm{H}$ NMR, $\delta: 2.91,3.80$ (d, 1H, J=17.6 Hz, $\mathrm{CH}_{2}$ ), 6.32 (br. s, $2 \mathrm{H}, \mathrm{NH}_{2}$ ) 6.54 (t, $\left.1 \mathrm{H}, J=7.6 \mathrm{~Hz}, \mathrm{H}-5^{\prime}\right), 6.70$ (d, 1H, J=8.1 Hz, H-3'), 6.95 (d, $2 \mathrm{H}, J=8.5 \mathrm{~Hz}, \mathrm{H}-3,5), 7.04$ (t, 1H, J=7.8 Hz, H-4'), 7.41 (d, 1H, J=7.8 Hz, H-6'), 7.59 (d, 2H, J=8.5 Hz, H-2,6), 7.97, 8.11 (s, 1H, NH), 10.81 (s, $1 \mathrm{H}, \mathrm{NH}) .{ }^{13} \mathrm{C} \mathrm{NMR}$, $\delta: 39.28,55.68,77.58,113.16,114.46$ (2C), 115.26, 116.01, 126.00, 127.38 (2C), 127.82, 129.83, 140.25, 147.58, 148.26, 159.96, 164.08. LC-MS, $m / z=351$ [M+1]; EI-MS, $m / z\left(\mathrm{I}_{\text {rel }}, \%\right)=351\left([\mathrm{M}+1]^{+\bullet}, 13.7\right), 350\left(\mathrm{M}^{+\bullet}\right.$, 100.0), 344 (9.8), 334 (16.4), 333 (26.8), 332 ([M $\left.\left.\mathrm{H}_{2} \mathrm{O}\right]^{+\bullet}, 71.1\right), 331$ (27.6), 321 (10.7), 319 (34.8), 200 (22.9), 198 (24.9), 197 (5.9), 159 (16.3). Anal. calcd for $\mathrm{C}_{18} \mathrm{H}_{18} \mathrm{~N}_{6} \mathrm{O}_{2}$ : C, 61.70; $\mathrm{H}, 5.18 ; \mathrm{N}, 23.99$. Found: $\mathrm{C}$, 61.79; H, 5.25; N, 23.85.

3'-(2-Aminophenyl)-3-(thienyl-2)-spiro[pyrazoline-5,6'(1'H)-1,2,4-triazin]-5'(4'H)-one (11d). Yield 68.6\%. M.p. $-256-258^{\circ} \mathrm{C} .{ }^{1} \mathrm{H}$ NMR, $\delta: 2.95,3.83$ (d, $1 \mathrm{H}, J=17.6 \mathrm{~Hz}, \mathrm{CH}_{2}$ ), 6.31 (br. s, $2 \mathrm{H}, \mathrm{NH}_{2}$ ), 6.53 (t, $1 \mathrm{H}$, $J=7.6 \mathrm{~Hz}, \mathrm{H}-5^{\prime}$ ), 6.69 (d, 1H, J=8.1 Hz, H-3'), 7.04 (t, $\left.1 \mathrm{H}, J=7.8 \mathrm{~Hz}, \mathrm{H}-4^{\prime}\right), 7.08\left(\mathrm{dd}, 1 \mathrm{H}, J_{\mathrm{H} 4-\mathrm{H} 5}=5.1 \mathrm{~Hz}, J_{\mathrm{H} 4-\mathrm{H} 3}\right.$ $=3.6 \mathrm{~Hz}, \mathrm{H}-4), 7.24\left(\mathrm{~d}, 1 \mathrm{H}, J_{\mathrm{H} 3-\mathrm{H} 4}=3.6 \mathrm{~Hz}, \mathrm{H}-3\right), 7.40$ (d, 1H, J=7.8 Hz, H-6'), $7.50\left(\mathrm{~d}, 1 \mathrm{H}, J_{\mathrm{H} 5-\mathrm{H} 4}=5.1 \mathrm{~Hz}, \mathrm{H}-5\right)$, 8.13, 8.16 (s, 1H, NH), $10.84(\mathrm{~s}, 1 \mathrm{H}, \mathrm{NH}) .{ }^{13} \mathrm{C} \mathrm{NMR}, \delta$ : 39.53, 77.84, 113.08, 115.26, 116.02, 126.94, 126.97, 127.83, 128.04, 129.87, 136.94, 140.30, 144.55, 147.58, 163.78. LC-MS, $m / z=327[\mathrm{M}+1]$. Anal. calcd for $\mathrm{C}_{15} \mathrm{H}_{14} \mathrm{~N}_{6} \mathrm{OS}$ : C, 55.20; H, 4.32; N, 25.75. Found: C, 55.32; H, 4.44; N, 25.70.

Cytotoxic activity against malignant human tumor cells

The primary anticancer assay was performed at human tumour cell lines panel derived from nine neoplastic diseases in accordance with the protocol of the Drug Evaluation Branch, National Cancer Institute, Bethesda. The compounds tested were added to the culture at a single concentration $\left(10^{-5} \mathrm{M}\right)$, and the cultures were incubated for $48 \mathrm{~h}$. End point determinations were made with a protein binding dye, sulforhodamine B (SRB). Results for each compound tested were reported as the percent of growth of the treated cells when compared to the untreated control cells. The percentage growth was evaluated spectrophotometrically versus controls not treated with test agents. The cytotoxic and/or growth inhibitory effects of the most active compounds selected were tested in vitro against the full panel of about 60 human tumour cell lines at 10 -fold dilutions of five concentrations ranging from $10^{-4}$ to $10^{-8} \mathrm{M}$. A 48 -h continuous drug exposure protocol was followed and the SRB protein assay was used to estimate cell viability 
or growth. Using seven absorbance measurements [time zero, $\left(\mathrm{T}_{\mathrm{z}}\right)$, control growth in the absence of a drug (C), and test growth in the presence of a drug at the five concentration levels $\left.\left(\mathrm{T}_{\mathrm{i}}\right)\right]$, the percentage growth was calculated at each of the drug concentrations levels. The percentage growth inhibition was calculated as:

$\left[\left(T_{i}-T_{z}\right) /\left(C-T_{z}\right)\right] \times 100$ for concentrations for which $\mathrm{T}_{\mathrm{i}} \geq \mathrm{T}_{\mathrm{z}}$,

$\left.\left[\left(\mathrm{T}_{\mathrm{i}}-\mathrm{T}_{\mathrm{z}}\right)\right] / \mathrm{T}_{\mathrm{z}}\right] \times 100$ for concentrations for which $\mathrm{T}_{\mathrm{i}}<\mathrm{T}_{\mathrm{z}}$.

Three dose response parameters were calculated for each compound. The growth inhibition of $50 \%$ $\left(\mathrm{GI}_{50}\right)$ was calculated from $\left[\left(\mathrm{T}_{\mathrm{i}}-\mathrm{T}^{\mathrm{z}}\right) /\left(\mathrm{C}-\mathrm{T}_{\mathrm{z}}\right)\right] \times 100=$ $=50$, which was the drug concentration resulting in $50 \%$ lower net protein increase in the treated cells (measured by SRB staining) compared to the net protein increase seen in the control cells. The drug concentration resulting in the total growth inhibition (TGI) was calculated from $\mathrm{T}_{\mathrm{i}}=\mathrm{T}_{\mathrm{z}}$. The $\mathrm{LC}_{50}$ (the concentration of the drug resulting in $50 \%$ reduction in the protein measured at the end of the drug treatment compared to that at the beginning) indicating a net loss of cells following treatment was calculated from $\left[\left(\mathrm{T}_{\mathrm{i}}-\mathrm{T}_{\mathrm{z}}\right) / \mathrm{T}_{\mathrm{z}}\right] \times 100=-50$. Values were calculated for each of these three parameters if the level of activity was reached; however, if the effect was not reached or was exceeded, the value for that parameter was expressed as greater or less than the maximum or minimum concentration tested. The $\log \mathrm{GI}_{50}, \log \mathrm{TGI}$, $\log \mathrm{LC}_{50}$ were then determined, defined as the mean of the log's of the individual $\mathrm{GI}_{50}$, TGI, $\mathrm{LC}_{50}$ values. The lowest values were obtained with the most sensitive cell lines.

\section{Conclusions}

In the present paper the structural optimization of [(2-R-quinazolin-4-ylidene)hydrazono]carboxylic acids and esters has been conducted, and the series of new heterocycles have been synthesized. Forty of the compounds synthesized have been tested and most of them have exhibited the antitumour activity against leukemia, melanoma, lung, colon, CNS, ovarian, renal, prostate and breast cancers cell lines. Screening of the anticancer activity in vitro has yielded the most active compounds $\mathbf{2 c}, \mathbf{3 b}$ and $\mathbf{3 c}$ in the micromolar concentrations at the $\mathrm{GI}_{50}$ level $\left(\log \mathrm{GI}_{50}\right.$ is -6.43 up to -5.64 for different cell lines). Compound $\mathbf{2 c}$ has a distinctive selectivity against leukemia, $\mathbf{3 b}$ - against leukemia, non-small cell lung cancer, colon and breast cancer, 3c - against breast cancer. Compounds 2c, $\mathbf{3 b}$ and $\mathbf{3 c}$ have shown the highest sensitivity against leukemia cell lines CCRF-CEM $\left(\log \mathrm{GI}_{50}=-6.10\right.$; 6.05; 5.81, respectively), compounds $\mathbf{3 b}$ and $\mathbf{3} \mathbf{c}-$ against breast cancer cell lines HS 578T $\left(\log \mathrm{GI}_{50}=-5.83 ;-6.43\right.$, respectively). All the facts mentioned characterise the class of the compounds under study as a promising object for chemical modification aimed at searching new anticancer agents.

\section{References}

1. Abou-Seri S. M., Abouzid K., Abou El Ella D. A. Eur. J. Med. Chem., 2011, 46, pp.647-658. doi: 10.1016/j.ejmech.2010.11.045.

2. Aniszewski T. Alkaloids-secrets of life, Elsavier, 2007, 316 .

3. Boyd M. R. Can. Drug Discov. Dev., 1997, 2, pp.23-43.

4. Boyd M. R., Paull K. D. Drug Dev Res, 1995, 34, pp.91-109. doi: 10.1002/ddr.430340203

5. Denny W. A. IL Farmako, 2001, 56, pp.51-56. doi: 10.1016/S0014-827X(01)01026-6.

6. Gibson K. H., Grundy W., Godfrey A. A., Woodburn J. R., Ashton Curry B. J., Scarlett L., Barker A. J., Brown D. S. Bioorg. Med. Chem. Lett., 1997, 10, pp.2723-2728. doi: 10.1016/S0960-894X(97)10059-2.

7. Karpenko A. V., Kovalenko S. I., Shishkin O. V. Tetrahedron, 2009, 65(31), pp.5964-597. doi:10.1016/j.tet.2009.05.091.

8. Karpenko O. V., Kovalenko S. I., Chekotylo O. O., Shyshkyna S. V. Heterocycles, 2007, 71(3), pp.619-626. doi: 10.3987/COM-06-10971.

9. Kovalenko S. I., Voskoboynik A. Yu., Karpenko A. V. Chemistry and chemical technology (Ukraine), 2008, 2, pp.22-24.

10. Kovalenko S. I., Voskoboynik A. Yu., Karpenko A. V. Journal of Organic and Pharmaceutical chemistry (Ukraine), 2007, 5, 4(20), pp.54-62.

11. Kovalenko S. I., Voskoboynik A. Yu., Karpenko A. V., Omelchenko I. V. Journal of Organic and Pharmaceutical Chemistry (Ukraine), 2008, 1, 4(20), pp.54-62.

12. Marzaro G., Guiotto A., Adriana Chilin A. Expert Opin. Ther. Patents, 2012, 22(3), pp.223-252. doi: 10.1517/13543776.2012.665876.

13. Michael J. P. Nat. Prod. Rep., 2005, 22, pp. 627-646. doi: 10.1039/B413750G.

14. Monks A., Scudiero D., Skehan P., Shoemaker R., Paull K., Vistica D., Hose C., Langley J., Cronise P., Vaigro-Wolff A. J. Natl. Cancer Inst., 1991, 83, pp.757766. doi: 10.1093/jnci/83.11.757.

15. Pawar V. G., Sos M. L., Rode H. B., Rabiller M., Heynck S., Otterlo W. A. L.,Thomas R. K., Rauh D. J. Med. Chem., 2010, 53, pp.2892-2901. doi: 10.1021/ jm901877j.

16. Voskoboynik A. Y., Berest G. G., Kovalenko S. I., Omelchenko I. V., Shishkin O. V. Chemistry and chemical technology (Ukraine), 2010,4, pp.16-20.

17. Voskoboynik A. Yu., Berest G. G., Skorina D. Yu., Karpenko A. V., Kovalenko S. I. Chemistry \& Chemical Technology. - Lviv Polytechnic National University, 2011, 5(2), pp.129-132.

18. Wang Y. D., Miller K., Boschelli D. H., Fei Ye, Biqi Wu, Floyd M. B., Powell D. W., Wissner A., Weber J., Boschelli M. F. Bioorg. Med. Chem. Lett. 2000, 10, pp.2477-2480. doi: 10.1016/S0960-894X(00)00493-5.

Надійшла до редакції 25.06.2014 р.

\section{Acknowledgement}

The authors are grateful to "Enamine Ltd." (Kiev, Ukraine) for financial support of this work, and the team of the Drug Synthesis and Chemistry Branch, National Cancer Institute, Bethesda, MD, USA, for in vitro evaluation of the anticancer activity. The authors have declared no conflict of interest. 